\title{
QUANTITATIVE STUDIES ON THE
}

\section{RATE OF RESPIRATORY METABOLISM}

IN PLANARIA

A THESIS SUBMITTED TO THE

\section{FACULTY OF THE GRADUATE SCHOOL OF THE}

UNIVERSITY OF MINNESOTA

BY

GEORGE DELWIN NLILN

IN PARTIAL FULFILLMENT OF THE REQUIREMENTS

EOR THE DEGREE OF

DOCTOR OF PHILOSOPHY

IUNE

1919 
QUANTITATIVE STUDIES ON THE RATE OF RESPIRATORY METABOLISM IN PLANARIA

I. Thi Efrect of Potassium Cyanide on the Rate of Oxygen CONSUMPTION

BY

GEORGE DELWIN ALLEN

From the Department of Animal Biology, University of Minnesota

REPRINTED From THE AMERICAN JodpNAL of PHYstology

Vol. XLVIII, No. 1, Febritary, 1919 
Reprinted from Thy Amrrican Journal of Physioloay, Vol. 48, No. 1, February, 1919

\title{
QUANTITATIVE STUDIES ON THE RATE OF RESPIRATORY METABOLISM IN PLANARIA
}

\section{The Effect of Potassium Cyanide on the Rate of Oxygen ConsUMPTION}

\author{
GEORGE DELWIN ALLEN
}

From the Department of Animal Biology, University of Minnesota

Received for publication December 21, 1918

\section{INTRODUCTION}

For the study of energy relations in organisms, the lower animals offer certain advantages over the higher vertebrates. Such regulatory mechanisms as those controlling the ventilation of the lungs, the rate of flow of the blood, the oxygen-carrying power of the blood and the maintenance of constant body temperature, which impose limitations upon experimentation with higher vertebrates, can be avoided by the selection of proper material from among invertebrates. Planaria possess none of these mechanisms and they are well fitted for such studies because they can withstand prolonged starvation or can ingest a large meal, and they have remarkable powers of regeneration and agamic reproduction. Experiments upon Planaria have played a prominent rôle in the formulation of theories by Child (1) regarding the so-called "rate of metabolism" in relation to senescence, rejuvenescence and dominance in organisms. Child used the susceptibility of animals and parts of animals to the toxic action of $\mathrm{KCN}$ as a measure of the "rate of metabolism." This use of cyanide was based upon the belief of many physiologists that it inhibits oxidations in organisms and upon certain qualitative tests in which, it is reported, the carbon dioxide production by worms in Tashiro's "biometer" agreed with what was expected from their susceptíbility to cyanide. No quantitative studies of the metabolism of Planaria by direct methods of measurement have been published heretofore. The author has undertaken a series of such studies for the purpose of determining whether $\mathrm{KCN}$ can be used to measure the rate of oxidation in these animals and to determine the 
important facts regarding the rate of oxidation in Planaria in relation to nutrition, age and morphogenesis. These studies were suggested by Prof. E. J. Lund, under whose direction they have been carried out and to whom I wish to express my most sincere appreciation for assistance and encouragement.

The present paper deals with methods of measuring the oxygen consumption by Planaria and the effect of KCN upon the oxygen consumption by these animals.

The belief that cyanides inhibit intracellular oxidations finds support in a number of studies of the respiratory exchange of organisms, beginning with the classical studies of Geppert (2). Schroeder (3) reported a marked decrease in the oxygen consumption by the mold, Aspergillus niger, in KCN solutions. Warburg (4) and Loeb and Wasteneys (5) agree that the oxygen consumption by sea urchin eggs is decreased very strongly in cyanide solutions; and Loeb and Wasteneys (6) have shown a similar effect of cyanide on the oxygen consumption by Fundulus embryos and by the jellyfish, Gonionemus. Experiments of Hyman (7) also tend to show a decrease in the oxygen consumption by marine sponges in $\mathrm{KCN}$, although there may be question regarding the rate of flow of water through the sponge in cyanide solutions in these experiments. On the other hand Lund (8) has found that the oxygen consumption by Paramecium is independent of the action of KCN.

In non-living systems various authors since Schonbein (9) have found that cyanides inhibit the activity of oxidizing enzymes, but in some cases the cyanide has an opposite effect. Thus Kastle and Loevenhart (10) report that $\mathrm{HCN}$ inhibits the oxidations of guaiacum by potato oxidase and many inorganic oxides and peroxides, but that it accelerates the oxidation of guaiacum by silver oxide. Loevenhart (11) found that $\mathrm{HCN}$ retards catalysis of hydrogen peroxide by platinum black, silver and extract of tissues, but that it accelerates catalysis of hydrogen peroxide when copper or iron and its salts are used. And the same author (12) finds that $\mathrm{HCN}$ accelerates the eatalyzing action of copper sulphate upon the oxidation of formic acid by hydrogen peroxide. Matthews and Walker (13) find that HCN prevents the oxidation of cystein to cystin but (14) that it accelerates the oxidation of impure cystin or cystin solutions containing ferric chloride, and that it has no effect on the oxidation of pure cystin.

These results lead to caution about predicting that KCN inhibits oxidations in every system. Are the oxidation systems in all organisms 
alike in respect to $\mathrm{KCN}$ or are there some oxidation systems like the oxidation of cystein and other systems like the oxidation of cystin? May there be other animals than Paramecium whose respiratory exchange is not affected by cyanides? In determining the value of $\mathrm{KCN}$ as a measure of the rate of oxidations in any form it is necessary, first of all, to determine its effect upon the oxidations in that form. It has not been shown, heretofore, that $\mathrm{KCN}$ affects the oxidations in Planaria.

\section{METHODS}

The materials used in this investigation were Planaria maculata, collected from the Mississippi River, and Planaria agilis, purchased and reared in the laboratory. The latter species has been found more convenient for experimentation and most of the experiments reported in this paper were performed with this species. Worms of the former species cling to the substratum so tenaciously that it is often necessary to loosen them with a probe. Not only is this inconvenient but it introduces the danger of injuring the animals.

In each experiment the animals selected were as nearly uniform in size as possible, and had not recently regenerated the head. All animals used in a single experiment were taken from the same stock, having the same history for some days previous to the experiment. The nutritive history and the relative size of worms used in each experiment are stated in the heading of the table reporting the results of the experiment.

The general method employed for determining the oxygen consumption was to place worms in tap water of known content of dissolved oxygen, and at the end of a stated period of time to remove the worms and analyze the water for dissolved oxygen, and so to determine by difference the amount of oxygen consumed. The general procedure was similar to that described by Lund (15) for determining the oxygen consumption by Paramecium, except that the worms were removed from the bottles at the end of the experiment, before the reagents were added, thus eliminating any errors due to absorption of iodine by the organisms during the analysis.

Reagents for Winkler's method of analysis were made up as given by Sutton $(16$, p. 285$)$ except that 2 cc. of concentrated hydrochloric acid were used as given by Birge and Juday $(17$, p. 13$)$. The thiosulphate solution was standardized at intervals against known weights of freshly resublimed iodine. 
A large carboy was filled with the tap water to be used in an experiment. When the tap water was much warmer or cooler than the room temperature it was allowed to stand in the carboy for twenty-four hours or longer to reach the room temperature. The water was thoroughly stirred and brought into approximate equilibrium with room air as to its dissolved oxygen by drawing a stream of air through it for about two hours. The bottles used in the experiment were then all filled in rapid succession by siphoning water from the carboy to the bottom of the bottles, allowing them to overflow about three times their volume of water. All bottles had fitted ground glass stoppers and were of the same capacity. Bottles which had originally 1 or $2 \mathrm{cc}$. more than $132 \mathrm{cc}$. capacity contained pieces of glass rod to

TABLE 1

Showing the degree of uniformity of filling and analysis of 28 bottles filled in order with aerated tap water and analyzed at once

\begin{tabular}{|c|c|c|c|}
\hline CC. OF THOSULPATE & C. OF THIOSCLPHATE & CC. OF THTOSULPHATE & cC. OF THLOSOLPHATE \\
\hline 4.55 & 4.56 & 4.53 & 4.58 \\
\hline 4.59 & 4.55 & 4.57 & 4.52 \\
\hline 4.56 & 4.56 & 4.60 & 4.55 \\
\hline 4.52 & 4.54 & 4.58 & 4.59 \\
\hline 4.57 & 4.55 & 4.58 & 4.56 \\
\hline 4.58 & 4.56 & 4.52 & 4.57 \\
\hline 4.57 & 4,55 & 4.56 & 4.53 \\
\hline
\end{tabular}

Maximum.................................. 4.60 ce. thiosulphate Minimum ................................. 4.52 cc. thiosulphate Average ................................ 4.56 ce. thiosulphate

make them uniform with the others. The degree of uniformity of filling and analysis is illustrated by table 1, which shows the result of filling the whole series of 28 bottles with aerated tap water and analyzing them at once. The analyses ranged from $4.52 \mathrm{cc}$. to $4.60 \mathrm{cc}$. thiosulphate. The average of all analyses was $4.56 \mathrm{cc}$. thiosulphate. The maximum error in an individual analysis, therefore, was about 1 per cent of the total oxygen content of a bottle, and since duplicate determinations were made in all experiments, the error in filling and analysis was reduced even below this figure.

The bottles needed in an experiment were filled in order, as explained above. Then three or four bottles, selected from different parts of the series, were set aside as "blanks." For example, in the experiment reported in table 2 the 1st, 6 th and 11th bottles filled were chosen as 
blanks. The average of the analyses of the blanks was taken to represent the amount of oxygen in each of the other bottles at the beginning of the experiment. Uniformity among blanks, chosen in this way, was taken to show uniformity of filling of the whole series of experimental bottles.

Worms were introduced into experimental bottles by means of a glass pipette of suitable size. With care, a worm can be introduced into a bottle by touching the pipette to the surface of the water in the bottle without introdueing more than a drop of water. In removing worms at the end of an experiment, the Planaria agilis were loosened by gently rotating the bottle, and were then picked out individually by means of the pipette. In this operation, care was taken not to introduce any bubbles of air in the bottle and not to draw into the pipette any water from the vessel into which the worms were transferred. Planaria maculata cling to the substratum very tenaciously. Frequently it was necessary to loosen them by means of a wire probe, flattened at the end to form a spatula. The following tests show that the error from introducing probes and pipettes into bottles to remove worms was negligible. Seven bottles were filled with aerated tap water. Four of these were analyzed as controls, giving an average oxygen content of 4.03 cc. thiosulphate. Each of the other three bottles was opened and the pipette was introduced twenty-five times, drawing in and expelling water thrice each time. The average oxygen content of these bottles was then found to be $4.04 \mathrm{cc}$. thiosulphate, showing no difference from the controls. The water in the bottles in this case was approximately in equilibrium with air as to its dissolved oxygen. Under such circumstances it was not to be expected that the manipulations described would affect the oxygen content appreciably.

At the end of an experiment, however, after part of the oxygen has been consumed, the water is no longer in equilibrium with air and these manipulations might alter the oxygen content. The following test meets these conditions. Six bottles were filled with boiled tap water of low oxygen content. Three alternate bottles were analyzed as controls, giving an average oxygen content of $1.74 \mathrm{cc}$. thiosulphate. Into each of the other three bottles ten worms were introduced and then immediately removed. These experimental bottles gave an average oxygen content of $1.80 \mathrm{cc}$. thiosulphate, showing a difference of $0.06 \mathrm{cc}$. thiosulphate from the controls. In the experiments to be reported, the oxygen content of the bottles at the end of the experimental periods was rarely reduced below $2.50 \mathrm{cc}$. thiosulphate. More- 
over, any error from this source would tend to diminish differences in oxygen consumption rather than to produce them to any degree.

In some eases, removing worms removed so much water that there was danger of enclosing a bubble of air in closing the bottle after introdueing the reagents. To prevent this possibility, the uniform procedure. was followed of displacing $2 \mathrm{cc}$. of water with a glass rod before introducing the reagents. The rods used for this purpose were of the same volume and were marked so that they could not be confused with other rods present in certain bottles for the purpose of standardizing the volume. This procedure was adopted in experiments with Planaria maculata, which are difficult to handle with a pipette, and was continued in a routine manner in all experiments. In all cases blanks were handled in the same manner as experimental bottles in this respect. In calculating the oxygen consumption in cubic centimeters of oxygen gas, ef. table 10 , columns 3 and 6 , correction was made for the $4 \mathrm{cc}$. displaced by the glass rods as well as for the $2 \mathrm{cc}$. displaced by the added reagents. These corrections were not made in the tables giving the oxygen consumption in eubic centimeters of thiosulphate since they do not alter relative values.

It required from two to four minutes to remove worms from a bottle and introduce the reagents. When an experiment contained several parts and there were two or three duplicate bottles in each part, it often required half an hour or even an hour to carry out these manipulations. Under such circumstances, to avoid serious error from the fact that the length of the experimental period was greater for certain bottles than for others, bottles were handled in the same order at the end of the period as at the beginning. In all experiments a record was made of the exact time of handling each bottle, and these times were so arranged as to insure that there was no variation from bottle to bottle in the length of the experimental period.

The following test shows that the iodine error from mucous secretions of the worms was also negligible. In eaeh of four bottles, six worms were left for four and a half days, after which time they were removed and the bottles were filled slowly with aerated tap water so as to avoid violent currents that might remove accumulations of mucus. The average of the four analyses was $4.63 \mathrm{cc}$. thiosulphate, while four clean bottles filled at the same time from the same aerated tap water gave an average analysis of $4.65 \mathrm{cc}$. thiosulphate.

In the experiments reported in the present paper, each contains its own temperature control since all comparisons that have been made 
are between worms that were tested simultaneously and under the same eonditions of temperature. However, except in the first two preliminary experiments, all bottles were placed in a water bath within a constant temperature oven at $20^{\circ} \mathrm{C}$, so that different experiments are comparable so far as temperature is concerned.

For each experiment the potassium cyanide was freshly weighed out, and a relatively strong solution, e.g., 0.01 molecular, was made with the aerated tap water used in the experiment. The bottles were filled in the usual manner. Those bottles that were not to contain cyanide were closed at once. A measured amount of the stronger cyanide solution was run in from a pipette or burette at the bottom of the other bottles, which were then closed and shaken well before introducing worms. The concentration of the solution was regulated so that the amount of solution added never exceeded $5 \mathrm{cc}$. and was usually about $2 \mathrm{cc}$. Upon opening the bottles, before introducing worms, a $2 \mathrm{cc}$. rod was inserted into each, displacing enough water to make it certain that it could be closed again without leaving any bubbles of air. All bottles in the experiment, including the blanks, were handled alike in this respect.

Potassium cyanide in the concentrations used does not cause any appreciable error in the Winkler oxygen analysis. This was shown by a preliminary test in which three bottles of aerated tap water containing $\mathrm{KCN}$ in 0.0004 molecular concentration gave an average oxygen analysis of $4.00 \mathrm{ec}$. thiosulphate, while three bottles of aerated tap water without cyanide gave an average of $3.99 \mathrm{ce}$. thiosulphate. In some experiments eyanide solution was introduced into part of the blanks but no appreciable difference in the analyses was found between them and the other blanks not containing $\mathrm{KCN}$, so that this procedure was not always followed.

The experimental method has been explained in considerable detail because several sources of error might readily occur if care is not taken in the details of manipulation. However, when careful methods are followed, their accuracy may be judged by their results. When duplicate determinations in the same experiment show uniformity of result and when a series of determinations with graduated differences in a certain experimental factor such as concentration of KCN shows a consistently graduated series of differences in result, the experiment carries conviction of reliability even when the actual figures are not large. All experiments have been earried out in duplicate of two or three simultaneous but independent determinations as a control upon 
the accuracy of the methods. The tables show all the individual determinations, even at the expense of making the tables more involved, in order that the uniformity among duplicate determinations may be clearly seen.

\section{OXYGEN CONSUMPTION BY PLANARIA IN KCN SOLUTIONS OF DIFFERENT CONCENTRATIONS}

To determine, first of all, whether KCN decreases the oxidations in Planaria, a preliminary experiment was performed with Planaria maculata, in which the oxygen consumption was tested first in aerated tap water and next in aerated tap water containing $\mathrm{KCN}$. Table 2 states the conditions and gives the results. The headings of the columns are self explanatory. Part A gives the analyses of the blanks, which tell the amount of oxygen in the experimental bottles of part B at the beginning of the experiment, and which serve also as a control for the uniformity of filling of the experimental bottles. The first test in aerated tap water is a control to show the degree of uniformity of oxygen consumption by the animals used in the different bottles of the experiment. In the second test, the bottles of set I contained no $\mathrm{KCN}$, and serve, therefore, as a control for those sets in which cyanide was used. Bottles of set II contained the strongest KCN solution, set III a weaker solution and set IV the most dilute solution. Column 4 shows that in every case worms in cyanide solutions used much less oxygen than those in pure water. In the previous test, column 2, they all used approximately the same amounts of oxygen. Column 4 indicates also that worms in the weakest solutions, i.e., set IV, used more oxygen than those in stronger solutions, but the worms in the stronger solutions suffered injury, as is shown in column 6 , so that this experiment is inconclusive so far as concerns the relative effects of KCN solutions of different concentrations. Worms of set IV, however, all of which remained alive and uninjured in 0.000076 molecular KCN, showed a reduction of over half in their oxygen consumption.

A second preliminary experiment was then performed with Planaria agilis, using weaker solutions of $\mathrm{KCN}$. The conditions and results are shown in table 3 . The general organization of the experiment and the controls was the same as in the former experiment. Column 2 shows again that worms in cyanide solutions invariably consumed less oxygen than those in pure water, while column 1 shows that in the preliminary test in pure water they all consumed approximately the 
TABLE 2

Preliminary experiment showing decrease in the oxygen consumption by Planaria maculata in KCN solutions. Worms, medium size, in laboratory six days without food, 10 individuals in each bottle. Room temperature $20^{\circ}$ to $24^{\circ} \mathrm{C}$. $1 \mathrm{cc}$. thiosulphate $=0.1751 \mathrm{cc}$. oxygen at $N . T$. P.

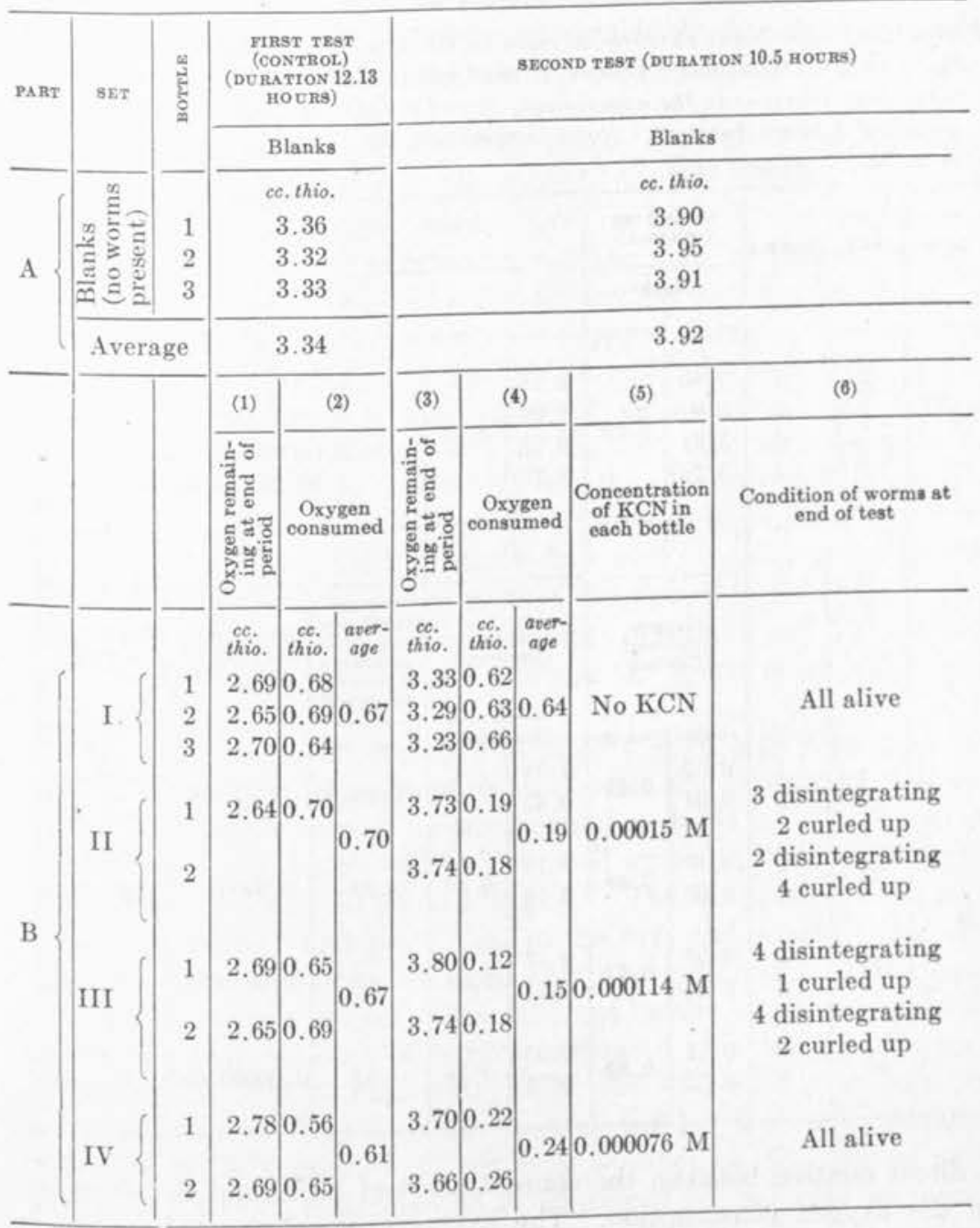


same amounts. In this experiment all worms remained alive and uninjured. A comparison of the averages in columns 2 and 4 shows that there is an inverse relation between the concentration of the cyanide and the oxygen consumption or, in other words, that there is

TABLE 3

Preliminary experiment showing decrease in the oxygen consumption by Planaria agilis in KCN solutions. Worms, 11 to $13 \mathrm{~mm}$. in length; fed beefliver daily till three days previous to the experiment; 10 individuals in each bottle. Each test period of 8 hours duration. Room temperature, $22^{\circ}$ to $24^{\circ} \mathrm{C}$. $1 \mathrm{cc}$. thiosulphate $=0.1751 \mathrm{cc}$. oxygen at $N . T . P$.

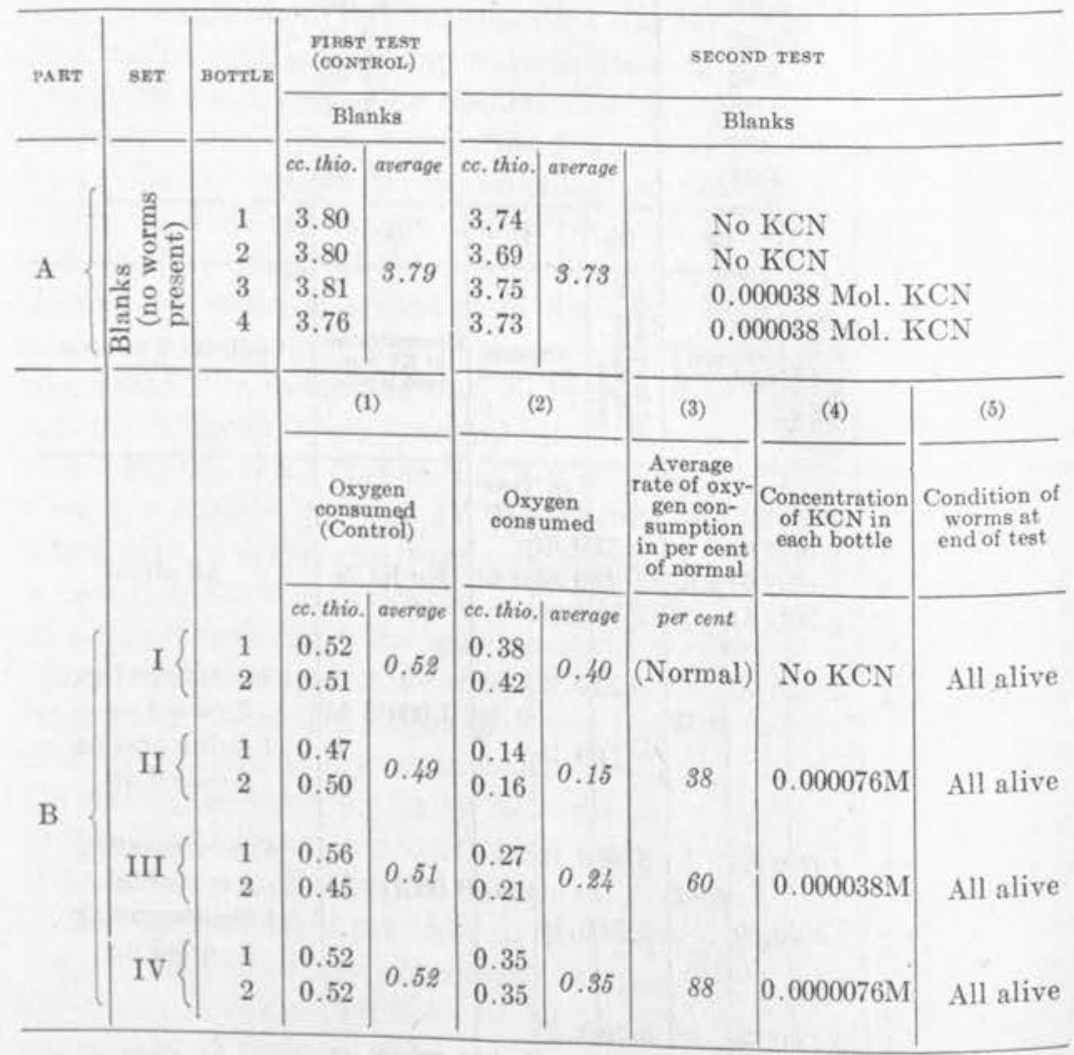

a direct relation between the concentration of $\mathrm{KCN}$ and the decrease in the oxygen consumption. The averages of column 2 have been converted into percentages in column 3 , where it is seen that the oxygen consumption in 0.000076 molecular $\mathrm{KCN}$ was only 38 per cent of 
normal. In the previous experiment, table 2, the oxygen consumption in this same concentration of cyanide was 36 per cent of normal.

It might be noted that at the end of this experiment, when the worms in cyanide were disturbed, they all became active but there was a very marked gradation in the rate of locomotion in the different concentrations of $\mathrm{KCN}$. In the strongest cyanide the rate was least while in the weakest cyanide the rate was only slightly less than that of the worms in pure water.

In order to determine the general character of the proportionality between the concentration of the cyanide and the amount of oxygen consumed, the experiment summarized in table 4 was performed. The general plan of the experiment was the same as that of the previous experiments except that a greater number and a wider range of concentrations of KCN were used. Seven different concentrations were employed, ranging from 0.00000076 molecular to 0.00038 molecular. Column 1 shows a high degree of uniformity in the oxygen consumption of the different sets in the first test without cyanide. Column 2 shows that in the second test the oxygen consumption decreased very regularly as the concentration of KCN increased. In the strongest solution, set VIII, the worms were all disintegrated at the end of the experimental period so that the figures in this part of the table may, perhaps, be neglected. Worms in sets VI and VII seemed to be near the limit of their resistance and the figures of set VII might be questioned.

While the experiment recorded in table 4 gave very consistent results, the absolute values were so small that the experiment was repeated with larger worms, as summarized in table 5. The "second part" of this experiment will be discussed under the topic "Reversibility of the action of KCN on Planaria." For the present, attention is confined to the "first part," i.e., to the first and second tests. In this experiment all worms remained alive and uninjured. In the control test, the worms in each of the different bottles consumed approximately the same amount of oxygen, column 1 . In the cyanide test the worms in 0.00023 molecular KCN, set VII, consumed only 28 per cent as much oxygen as the control, set I. Worms in 0.00015 molecular $\mathrm{KCN}$ consumed 35 per cent as much as the control and worms in 0.000076 molecular KCN consumed 53 per cent as much oxygen as the control. In the still weaker concentrations the oxygen consumption was practically the same as the control. These concentrations were very dilute and were chosen to see whether minimal 


\section{TABLE 4}

Showing the relation of decrease in the oxygen consumption by Planaria agilis in $K C N$ solutions to the concentration of the KCN. Worms, 10 to $13 \mathrm{~mm}$. in length; fed beef liver almost daily till 12 days previous to experiment; 10 individuals in each bottle. Temperature $19.7^{\circ}$ to $19,8^{\circ} \mathrm{C} . \quad 1 \mathrm{cc}$. thiosulphate $=0.1751 \mathrm{cc}$. oxygen at N.T.P.

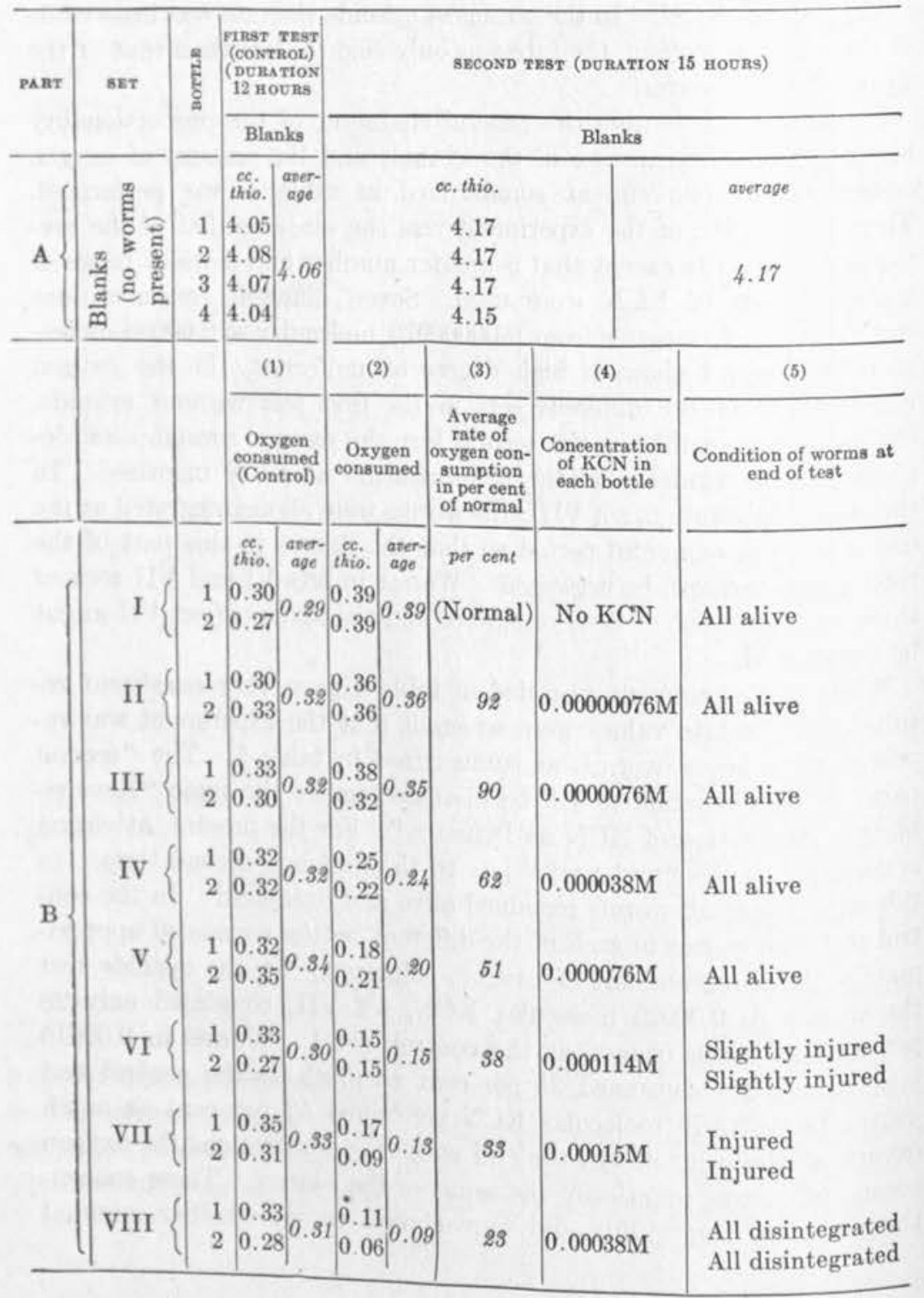


TABLE 5

First part (first and second tests) showing the relation of the decrease in the oxygen consumption by Planaria agilis in KCN solutions to the concentration of KCN. Worms, 15 to $16 \mathrm{~mm}$. in length and very broad, without food for 28 days previous to experiments, 10 individuals in each bottle. Each test period of 12 hours duration, with 12 hours interval between tests. Temperature $19.5^{\circ}$ to $20.0^{\circ} \mathrm{C} .1 \mathrm{cc}$, thiosulphate $=0.1729 \mathrm{cc}$. oxygen at $N . T . P$.

Second part (third test) showing reversibility of the effect of $K C N$ in reducing the oxygen consumption. Third test follows second test after interval of 12 hours.

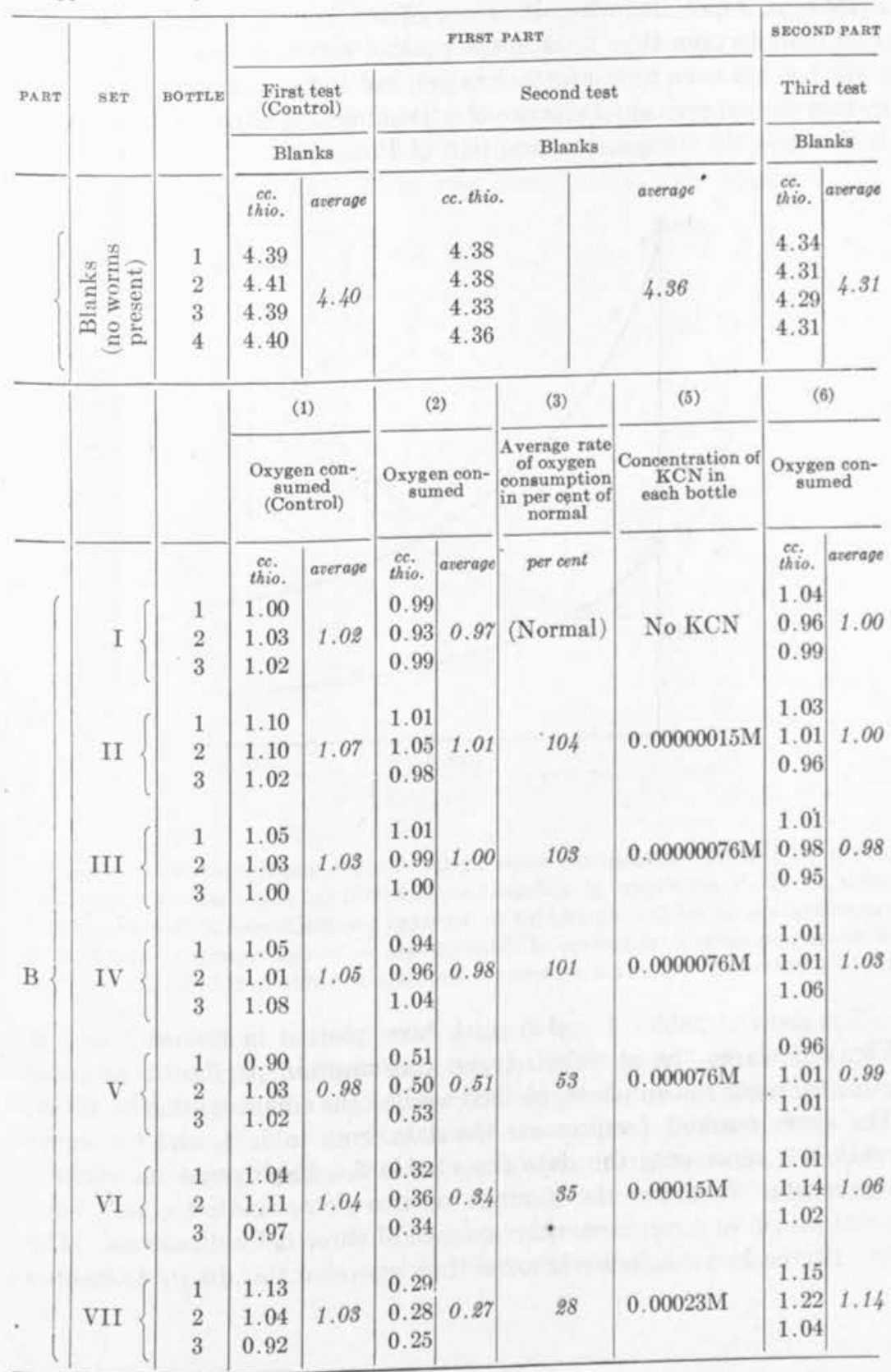


quantities of cyanide cause marked decrease or increase in the oxygen consumption. The results showed neither effect. The percentages in column 3.run slightly above the control but the difference is not significant, especially when it is considered that sets II, III and IV used more oxygen than set I in the control test also, column 1 . This point has not been tested further as yet, but so far as these experiments go they do not give any evidence of a "stimulating effect" of very weak $\mathrm{KCN}$ upon the oxygen consumption of Planaria.

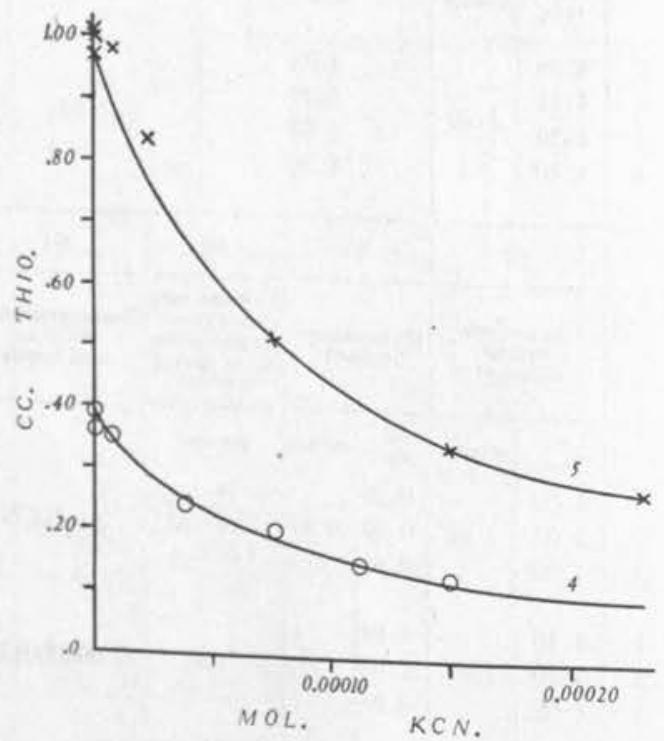

Fig. 1. Curves showing decrease in the oxygen consumption by Planaria agilis in KCN solutions of different concentration. Abscissas = molecular of worms, in cubic centimeters of = average oxygen consumption per bottle table 4, column 2. Curve 5 thiosulphate. Curve 4 represents the data of The data of table 5 , column 2 .

The data of tables 4 and 5 have been plotted in figures 1 and 2 . Figure 1 shows the average oxygen consumption per bottle in cubic The curve of thiosulphate, plotted against the concentration of KCN. marked 5 represents the data from table 4 , and the curve represents, therefore, the arom table 5. Each point on curve 4 point on curve 5 represents therage of two determinations, and each two curves do not coincide the average of three determinations. The 
of oxygen consumed by worms of different sizes, but it ean be seen at. a glance that they have the same general form. Figure 2 shows the average oxygen consumption in different $\mathrm{KCN}$ solutions, expressed in per cent of the control. As in figure 1, the curve marked 4 represents the data of table 4 and the curve marked 5 represents the data of table 5. Four things may be noted in figure 2: first, that the two curves almost coincide, showing that the two experiments, tables 4 and 5 , give identical results; second, that the curves fall sharply; third, that they are not straight lines; and fourth, that they approach the

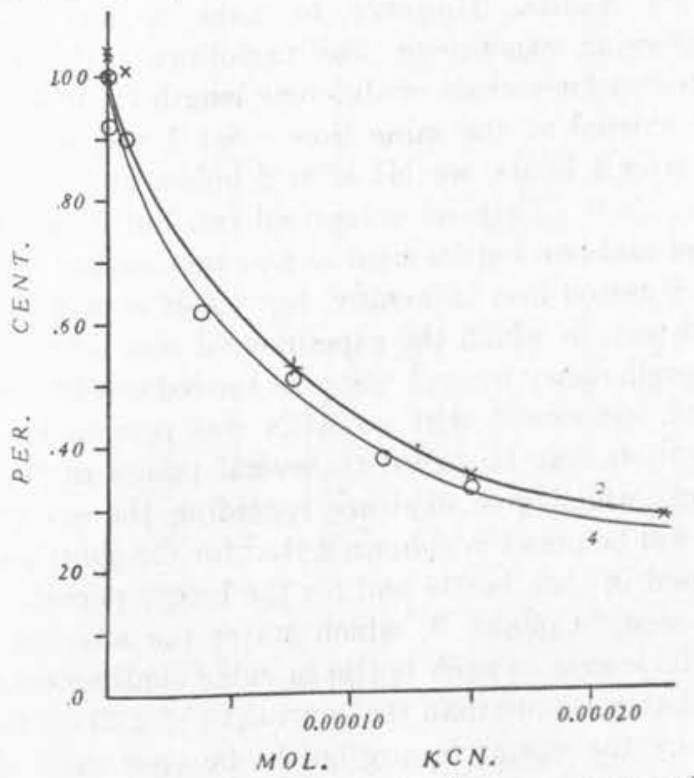

Fig. 2. Curves showing decrease in the rate of oxygen consumption by Planaria agilis in $\mathrm{KCN}$ solutions of different concentration. Abscissas = molecular concentration of $\mathrm{KCN}$. Ordinates $=$ rate of oxygen consumption in per cent of normal. Curve 4 represents the data of table 4 , column 3 . Curve 5 represents the data of table 5 , column 3 .

horizontal at about 20 per cent of the normal. We may conclude, therefore, that lower concentrations of $\mathrm{KCN}$ have proportionately greater effect upon the oxidations than more concentrated solutions; and second, that the oxidations cannot be reduced by cyanide below about 20 per cent of the normal. In other words, these results indicate that a residual oxidation amounting to about 20 per cent of the normal cannot be inhibited by KCN. No clear evidence is obtained from experiments 4 and 5 for a stimulation of oxidations in weak solutions of $\mathrm{KCN}$. 
It is possible that the rate at which Planaria use oxygen in $\mathrm{KCN}$ solutions ehanges with time. Miss Hyman (7) reports finding such changes in the oxygen consumption by sponges for the first two or three half-hour periods. But when longer experimental periods are employed, as in the experiments reported in this paper, it seems improbable that the precise length of the period should alter the general character of the results. However, to make certain regarding this point, the following experiment was performed. Different sets of worms were tested for periods of different length from 2 to 36 hours. All sets were started at the same time. Set I was stopped after 2 hours, set II after 4 hours, set III after 8 hours, etc., as can be seen in column 1, table 6 . Each set comprised two bottles of worms used as a control set and two bottles used as an experimental set.

All sets were tested first in aerated tap water as a general control for the second test, in which the experimental sets were treated with KCN. This preliminary control test was carried out in every respect like the second test except that no KCN was present in any of the bottles. Attention may be called to several points in the results of the control test which give evidence regarding the accuracy of the methods. It will be noted in column 2 that for the short periods more worms were used in each bottle and for the longer periods fewer individuals were used. Column 3 , which states the amount of oxygen absorbed by the worms in each bottle in cubic centimeters of thiosulphate, shows that not more than the equivalent of $2.20 \mathrm{cc}$. thiosulphate was absorbed by the worms in any bottle, i.e., not more than about half of the amount of oxygen available in each bottle at the beginning of the period, $4.21 \mathrm{cc}$. thiosulphate. The worms of the longer experimental periods were not subjected, therefore, to oxygen starvation. In the next place, the degree of uniformity among the individual determinations is shown in column 4. In this column the oxygen consumption has been reduced to the common basis of the number of cubic centimeters of oxygen gas at normal temperature and pressure absorbed per 10 worms per 24 hours. The individual determinations ranged from 4.02 to $4.50 \mathrm{ce}$. of oxygen, with the exception of one determination, set $\mathrm{Vb}$, bottle 1 , which was as low as 3.38 ec. oxygen. An examination of further records of this particular lot of worms is instructive. Table 8 gives the oxygen consumption by the worms in each 
TABLE 6

Showing that Planaria agilis in a KCN solution maintains approximately the same rate of oxygen consumption during time periods of very different length. Worms 15 to $16 \mathrm{~mm}$. in length and very broad; without food for 18 days previous to the experiment except feedings on the 5 th and 6 th days before the experiment. Concentration of $K C N=0.00003$ molecular. All bottles started at the same time and analyzed after periods of different length, as noted. Temperature $1.94^{\circ}$ to $20.0^{\circ} \mathrm{C}$. All worms alive at the end of the experiment. $1 \mathrm{cc}$. thiosulphate $=0,1747 \mathrm{cc}$. oxygen at N.T.P.

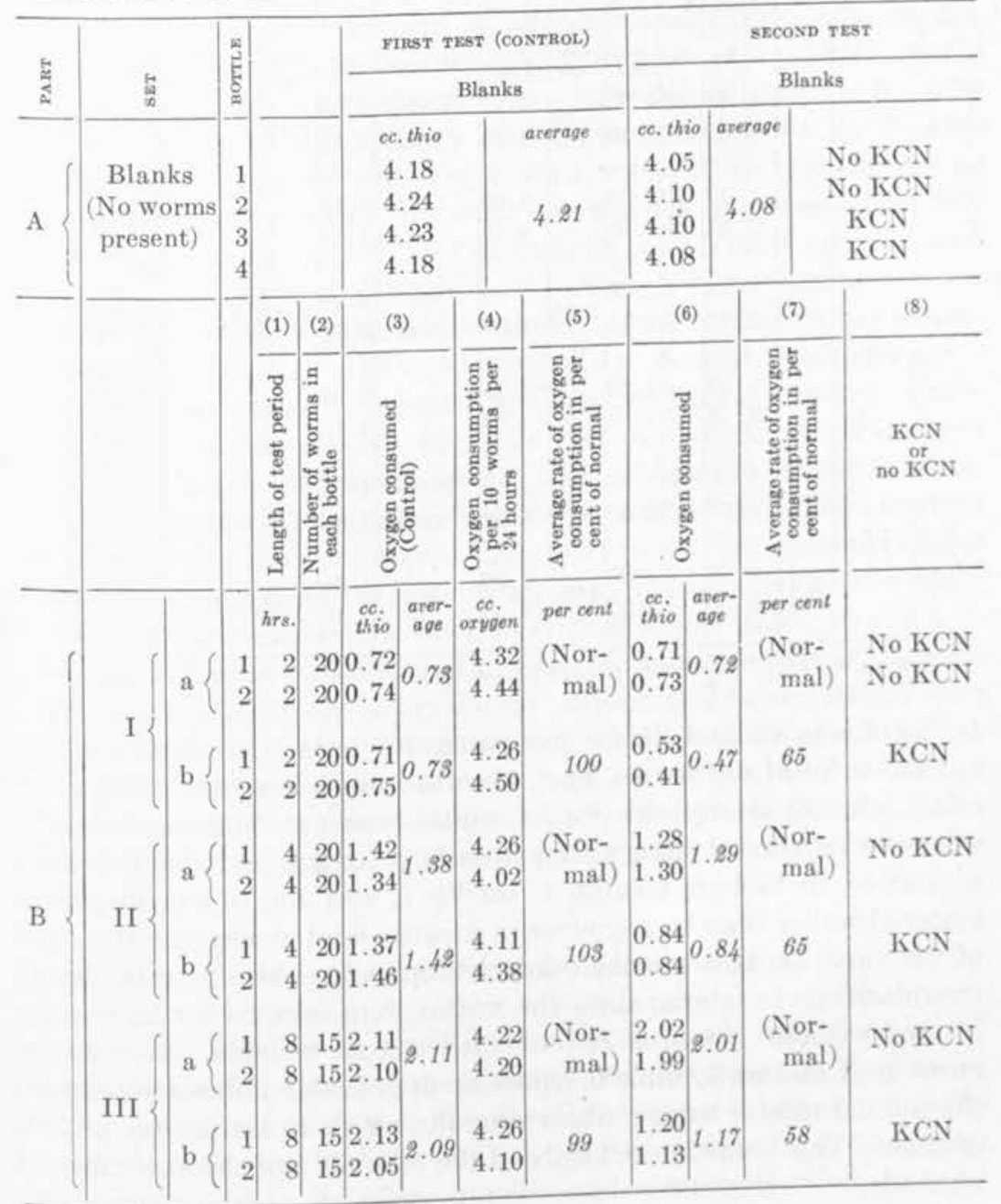


TABLE 6-Continued

\begin{tabular}{|c|c|c|c|c|c|c|c|c|c|c|c|}
\hline & \multirow{2}{*}{\multicolumn{2}{|c|}{ 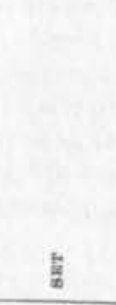 }} & & (1) & (2) & 3) & (4) & (5) & (6) & (7) & (8) \\
\hline 5 & & & है & 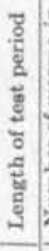 & 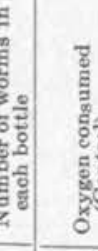 & ชิ & 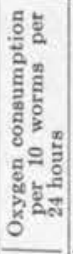 & 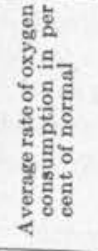 & 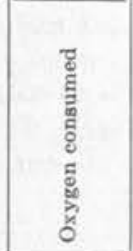 & 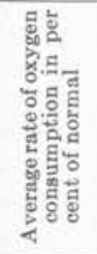 & $\begin{array}{c}\mathrm{KCN} \\
\text { or } \\
\text { no } \mathrm{KCN}\end{array}$ \\
\hline & \multirow{3}{*}{ IV } & & & hre. & $\mid \begin{array}{c}\text { ce. } \\
\text { thio }\end{array}$ & \begin{tabular}{|c|} 
aver- \\
age
\end{tabular} & $\begin{array}{c}c c . \\
\text { oxygen }\end{array}$ & per cent & \begin{tabular}{c|c}
$c c$. & aver- \\
thio & age
\end{tabular} & per cent & \\
\hline & & a & $\begin{array}{l}1 \\
2\end{array}$ & $\begin{array}{l}12 \\
12\end{array}$ & \begin{tabular}{l|l|l|}
10 & 2.06 \\
10 & 2.10
\end{tabular} & 2.08 & $\begin{array}{l}4.12 \\
4.20\end{array}$ & $\begin{array}{l}\text { (Nor- } \\
\text { mal) }\end{array}$ & $\begin{array}{l}1.98 \\
2.11\end{array} \mid 2.05$ & $\begin{array}{c}\text { (Nor- } \\
\text { mal) }\end{array}$ & No KCN \\
\hline & & b & $\begin{array}{l}1 \\
2\end{array}$ & $\begin{array}{l}12 \\
12\end{array}$ & \begin{tabular}{l|l|}
10 & 2.03 \\
10 & 2.08
\end{tabular} & 2.06 & $\begin{array}{l}4.06 \\
4.16\end{array}$ & 99 & \begin{tabular}{|l|l|}
1.10 & 1.12 \\
1.13 & 1.12 \\
\end{tabular} & 55 & $\mathrm{KCN}$ \\
\hline & \multirow[t]{2}{*}{ V } & a & $\begin{array}{l}1 \\
2\end{array}$ & $\begin{array}{l}24 \\
24\end{array}$ & \begin{tabular}{l|l|}
5 & 2.20 \\
5 & 2.15
\end{tabular} & 2.18 & $\begin{array}{l}4.40 \\
4.30\end{array}$ & $\begin{array}{r}\text { (Nor- } \\
\text { mal) }\end{array}$ & \begin{tabular}{|l|l|}
2.08 & \\
2.05 & 2.07 \\
\end{tabular} & $\begin{array}{l}\text { (Nor- } \\
\text { mal) }\end{array}$ & No $\mathrm{KCN}$ \\
\hline & & b & $\begin{array}{l}1 \\
2\end{array}$ & $\begin{array}{l}24 \\
24\end{array}$ & \begin{tabular}{ll|}
5 & 1.69 \\
5 & 2.04
\end{tabular} & 1.87 & $\begin{array}{l}3.38 \\
4.08\end{array}$ & 86 & $\mid$\begin{tabular}{l|l}
0.92 & 1.02 \\
1.12 & 1.02
\end{tabular} & $49^{*}$ & $\mathrm{KCN}$ \\
\hline & \multirow[t]{2}{*}{ VI } & a & $\begin{array}{l}1 \\
2\end{array}$ & $\begin{array}{l}36 \\
36\end{array}$ & \begin{tabular}{l|l|}
3 & 1.88 \\
3 & 2.02
\end{tabular} & 1.95 & $\begin{array}{l}4.16 \\
4.49\end{array}$ & $\begin{array}{l}\text { (Nor- } \\
\text { mal) }\end{array}$ & \begin{tabular}{l|l}
1.73 \\
1.88
\end{tabular} \mid 1.81 & $\begin{array}{r}\text { (Nor- } \\
\text { mal) }\end{array}$ & No KCN \\
\hline & & b & \begin{tabular}{|l}
1 \\
2
\end{tabular} & $\begin{array}{l}36 \\
36\end{array}$ & \begin{tabular}{l|l|}
3 & 1.97 \\
3 & 2.02 \\
\end{tabular} & 2.00 & $\begin{array}{l}4.38 \\
4.49\end{array}$ & 103 & $\left|\begin{array}{l}1.08 \\
1.10\end{array}\right| 1.09$ & 60 & $\mathrm{KCN}$ \\
\hline
\end{tabular}

Corrected to 57 per cent, ef. text page 111.

bottle of sets $\mathrm{Va}$ and $\mathrm{Vb}$ for five successive tests. In every test this particular lot of worms, set $\mathrm{Vb} 1$, absorbed much less oxygen than any other lot. Evidently this lot of worms was not equivalent to the of $3.38 \mathrm{ec}$, in normal capacity for absorbing oxygen and the low value material rather than , column 4 , set $\mathrm{Vb} 1$, was due to irregularity of of the variation between the orror in experimental measurement. Part irregularities of material the other determinations also may be due to of size without measuremce the worms were selected for uniformity noted that column 4 , table 0 , their actual weights. It may be the normal rate of oxygen 6 , shows no appreciable difference between of time. This is further absorption during short and longer periods methods. 
The amount of oxygen absorbed by the worms in each bottle during the second test is given in cubic centimeters of thiosulphate in column 6. In this test the experimental worms were treated with 0.00003 molecular KCN. This concentration was chosen because it has been found to cause a reduction in oxygen consumption which is intermediate between the maximum and minimum effects of cyanide. The oxygen consumption by worms in this solution during each of the different periods of time, from two to thirty-six hours, was compared with that of the corresponding untreated worms. For example, the average oxygen consumption by the control set, Ia, which were in pure water for 2 hours, was 0.72 cc. thiosulphate, column 6 . The average oxygen consumption by the experimental set, Ib, which were in cyanide for the same period of 2 hours, was $0.47 \mathrm{cc}$. thiosulphate or 65 per cent of the normal. Similarly the average oxygen consumption of the other control sets: IIa, IIIa, IVa, Va, and VIa, column 6 , were each taken as normal or 100 per cent, column 7 , with which were compared the average oxygen consumption of the corresponding experimental sets: IIb, IIIb, IVb, Vb, and VIb. Similar calculations for the first test, column 5 , showed that the experimental sets were equivalent to the control sets in every case excepting set $\mathrm{V}$, which has been discussed above. Column 7 shows, then, that the cyanide-treated worms in the second test used about 60 per cent of the normal amount of oxygen. As explained above, the worms in set $\mathrm{Vb} 1$ were not equivalent to those in other bottles. When this fact is taken into account, the 49 per cent in column 7 , set $\mathrm{Vb}$, becomes 57 per cent.

In this experiment the rate of oxygen consumption in cyanide solution was practically the same during periods of different length from two to thirty-six hours. The inhibitory action of $\mathrm{KCN}$ on oxidations in Planaria was immediate or very rapid, therefore, and it did not change with time, at least within the limits of the experiment. There was no evidence of an initial stimulating effect of cyanide on the oxidations.

\section{REVERSIBILITY OF THE ACTION OF KCN ON PLANARIA}

Potassium cyanide is sometimes classed among the anesthetics. One of the characteristics of the action of the anestheties is their reversibility, i.e., the fact that if the anesthetic has not been given in too strong concentration and has not acted for too long a time, the organism recovers from its effect rapidly and completely after removal 
from its action. Several experiments demonstrated that the action of $\mathrm{KCN}$ on the oxygen absorption by Planaria is reversible.

Table 5, column 5, shows the complete recovery of the original rate of oxidation by Planaria after their removal from solutions of cyanide in which their oxidations were only 28 to 53 per cent of the normal.

\section{TABLE 7}

Showing reversibility of the effect of KCN on the oxygen consumption by Planaria agilis. Worms 15 to $16 \mathrm{~mm}$. in length and very broad; without food for 18 days preceding the experiment except feedings on the 5th and 6th days previous to experiment; 20 individuals in each bottle. Each test period of 4 hours duration. Concentration of $K C N$ solution $=0.00003$ molecular. After worms were removed from the KCN of the 2nd test they were washed repeatedly in tap water and set for the 3rd test within 30 minutes. Data of the $18 t$ and 2 nd tests included also in table 6. Temperature $19.4^{\circ}$ to $20.0^{\circ} \mathrm{C}$. $1 \mathrm{cc}$. thiosulphate $=0.1747 \mathrm{cc}$. oxygen at N.T.P.

\begin{tabular}{|c|c|c|c|c|c|c|c|c|c|c|c|}
\hline \multirow[t]{2}{*}{ PART } & \multirow[t]{2}{*}{ SET } & \multirow[t]{2}{*}{ BotrLE } & \multicolumn{2}{|c|}{$\begin{array}{l}\text { FIRst TEST } \\
\text { (CONTROL) }\end{array}$} & \multicolumn{3}{|c|}{ 8ECOND TEST } & \multicolumn{2}{|c|}{ THIRD TEST } & \multicolumn{2}{|c|}{ FOURTH TEBT } \\
\hline & & & \multicolumn{2}{|c|}{ Blanks } & \multicolumn{3}{|c|}{ Blanka } & \multicolumn{2}{|c|}{ Blanks } & \multicolumn{2}{|c|}{ Blanks } \\
\hline \multirow{5}{*}{ A } & \multirow{5}{*}{ 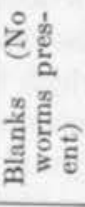 } & & $\begin{array}{l}\text { ce. } \\
\text { thio }\end{array}$ & $\begin{array}{c}\text { aver- } \\
\text { age }\end{array}$ & $\begin{array}{c}c e . \\
\text { thio }\end{array}$ & $\begin{array}{c}\text { arer- } \\
\text { age }\end{array}$ & & $\begin{array}{l}\text { cc. } \\
\text { thio }\end{array}$ & $\begin{array}{c}\text { aver- } \\
\text { age }\end{array}$ & $\begin{array}{l}\text { cc. } \\
\text { thio }\end{array}$ & $\begin{array}{c}\text { aver- } \\
\text { age }\end{array}$ \\
\hline & & 1 & 4.18 & & 4.05 & & No KCN & 4.31 & & 4.36 & \\
\hline & & 2 & 4.24 & 4.81 & 4.10 & 408 & No KCN & 4.34 & 101 & 4.39 & 187 \\
\hline & & 4 & 4.23 & & 4.10 & & $\mathrm{KCN}$ & 4.38 & 4.34 & 4.40 & 4.01 \\
\hline & & & & & 4.08 & & $\mathrm{KCN}$ & 4.32 & & 4.34 & \\
\hline & & & \multicolumn{2}{|c|}{ (1) } & \multicolumn{2}{|c|}{ (2) } & (3) & \multicolumn{2}{|c|}{ (4) } & \multicolumn{2}{|c|}{ (5) } \\
\hline & & & \multicolumn{2}{|c|}{$\begin{array}{l}\text { Oxygen } \\
\text { consumed }\end{array}$} & \multicolumn{2}{|c|}{$\begin{array}{c}\text { Oxygen } \\
\text { consumed }\end{array}$} & $\begin{array}{l}\mathrm{KCN} \text { or } \\
\text { no KCN }\end{array}$ & \multicolumn{2}{|c|}{$\begin{array}{l}\text { Oxygen } \\
\text { consumed }\end{array}$} & \multicolumn{2}{|c|}{$\begin{array}{l}\text { Oxygen } \\
\text { consumed }\end{array}$} \\
\hline \multirow{5}{*}{ B } & \multirow{3}{*}{$\mathrm{IIa}$} & \multirow{3}{*}{$\begin{array}{l}1 \\
2\end{array}$} & \multirow{3}{*}{\begin{tabular}{l|} 
ce. \\
thio \\
1.42 \\
1.34
\end{tabular}} & \multirow{3}{*}{$\begin{array}{l}\text { aver- } \\
\text { age } \\
1.38\end{array}$} & \multirow{3}{*}{\multicolumn{2}{|c|}{\begin{tabular}{|c|c|} 
ce. & aver- \\
thio & age \\
1.28 & \\
1.30 & 1.29 \\
\end{tabular}}} & \multirow{3}{*}{ No KCN } & \multirow{3}{*}{$\begin{array}{l}\begin{array}{l}c c . \\
\text { thio } \\
1.30 \\
1.38\end{array}\end{array}$} & \multirow{3}{*}{$\begin{array}{c}\begin{array}{c}\text { axer- } \\
\text { age }\end{array} \\
1.34\end{array}$} & \multirow{3}{*}{$\begin{array}{l}c c . \\
\text { thio } \\
1.40 \\
1.45\end{array}$} & \multirow{3}{*}{$\begin{array}{l}\begin{array}{c}\text { aver- } \\
\text { age }\end{array} \\
1.43\end{array}$} \\
\hline & & & & & & & & & & & \\
\hline & & & & & & & & & & & \\
\hline & \multirow[t]{2}{*}{ IIb } & 1 & 1,37 & |a & 0.84 & & & \multirow{2}{*}{$\begin{array}{l}1.41 \\
1.44\end{array}$} & \multirow[b]{2}{*}{1.43} & & \\
\hline & & 2 & 1.46 & 1,42 & 0.84 & 0.84 & $\mathrm{KCN}$ & & & $\begin{array}{l}1.40 \\
1.46\end{array}$ & 1.47 \\
\hline \multicolumn{3}{|c|}{ Per cent of normal } & & 103 & & 65 & & & 107 & & 103 \\
\hline
\end{tabular}

Twelve hours intervened between the second and third tests in this recovery of the that the experiment gives no idea of the rapidity of the

Table 7 shows that rate, but it does show completeness of recovery. cyanide in reducing the recovery is as rapid as is the action of the control test. The second test, cons. The first test, column 1, was the control test. The second test, column 2, showed a decrease in the 
oxygen consumption to 65 per cent of the normal in 0.00003 molecular $\mathrm{KCN}$. The third and fourth tests show complete recovery of the normal consumption in tap water. The third test followed the second with only thirty minutes interval. In this experiment the test periods were each of four hours' duration. The first and second tests of this

TABLE 8

Showing reversibility of the effect of $K C N$ on the oxygen consumption by Planaria agilis. Worms 15 to $16 \mathrm{~mm}$, in length and very broad; without food for 18 days preceding experiment except for feedings on the 5th and 6th days previous to the experiment; 5 individuals in each bottle. Concentration of KCN, 0.00003 molecular. After worms were removed from KCN of the 2nd test they were washed repeatedly in tap water and put into bottles for the 3rd test within 17 minutes. Temperature 19.4 to $20.0^{\circ} \mathrm{C}$. $1 \mathrm{cc}$. thiosulphate $=0.1747 \mathrm{cc}$. oxygen at $N, T, P$. Data of 1 st and 2nd lests included in table 6.

\begin{tabular}{|c|c|c|c|c|c|c|c|c|c|c|c|c|c|}
\hline \multirow[t]{2}{*}{ PART } & \multirow[t]{2}{*}{ SET } & \multirow[t]{2}{*}{ BOTTLE } & \multicolumn{2}{|c|}{$\begin{array}{l}\text { FIRST } \\
\text { TEST }\end{array}$} & \multicolumn{3}{|c|}{ SECOND TEST } & \multicolumn{2}{|c|}{$\begin{array}{l}\text { THIBD } \\
\text { TEST }\end{array}$} & \multicolumn{2}{|c|}{$\begin{array}{l}\text { FODRTH } \\
\text { TEST }\end{array}$} & \multicolumn{2}{|c|}{$\begin{array}{l}\text { FIFTH } \\
\text { TEST }\end{array}$} \\
\hline & & & \multicolumn{2}{|c|}{ Blanks } & \multicolumn{3}{|c|}{ Blanks } & \multicolumn{2}{|c|}{ Blanks } & \multicolumn{2}{|c|}{ Blanks } & \multicolumn{2}{|c|}{ Blanks } \\
\hline A & 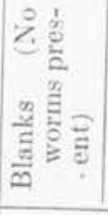 & $\begin{array}{l}1 \\
2 \\
3 \\
4\end{array}$ & $\left|\begin{array}{c}\text { cc. } \\
\text { thio } \\
4.18 \\
4.24 \\
4.23 \\
4.18\end{array}\right|$ & $\begin{array}{c}\text { aver- } \\
\text { age } \\
4.21\end{array}$ & $\mid \begin{array}{c}\text { cc. } \\
\text { thio } \\
4.05 \\
4.10 \\
4.10 \\
4.08\end{array}$ & $\left|\begin{array}{c}\text { aver- } \\
\text { age } \\
4.08\end{array}\right|$ & $\begin{array}{c}K C N \text { or } \\
\text { no } K C N \\
\text { No KCN } \\
\text { No KCN } \\
K C N \\
K C N\end{array}$ & $\mid \begin{array}{c}\text { ce. } \\
\text { thio } \\
4.23 \\
4.30 \\
4.31 \\
4.24\end{array}$ & $\begin{array}{c}\text { aver- } \\
\text { age } \\
4.37 \\
\end{array}$ & $\mid \begin{array}{c}\text { ce. } \\
\text { thio } \\
4.35 \\
4.38 \\
4.39 \\
4.32\end{array}$ & 4. 36 & $\left|\begin{array}{l}\text { cc. } \\
\text { thio } \\
4.17 \\
4.18 \\
4.20 \\
4.16\end{array}\right|^{4}$ & $\begin{array}{l}\text { aver- } \\
\text { age } \\
4.18\end{array}$ \\
\hline & & & \multicolumn{2}{|c|}{ (1) } & \multicolumn{2}{|c|}{ (2) } & (3) & \multicolumn{2}{|c|}{ (4) } & \multicolumn{2}{|c|}{ (5) } & \multicolumn{2}{|c|}{ (6) } \\
\hline & & & \multicolumn{2}{|c|}{$\begin{array}{c}\text { Oxygen } \\
\text { consumed } \\
\text { in } \\
24 \text { hours }\end{array}$} & \multicolumn{2}{|c|}{$\begin{array}{c}\text { Oxygen } \\
\text { consumed } \\
\text { in } \\
24 \text { hours }\end{array}$} & $\underset{\mathrm{KCN}}{\mathrm{KCN} \text { no }}$ & \multicolumn{2}{|c|}{$\begin{array}{c}\text { Oxygen } \\
\text { consumed } \\
\text { in } \\
6 \text { hours }\end{array}$} & \multicolumn{2}{|c|}{$\begin{array}{c}\text { Oxygen } \\
\text { consumed } \\
\text { in } \\
6 \text { hours }\end{array}$} & \multicolumn{2}{|c|}{$\begin{array}{c}\text { Oxygen } \\
\text { consumed } \\
\text { in } \\
24.6 \text { hours }\end{array}$} \\
\hline \multirow{3}{*}{ B } & & & $\begin{array}{l}c c . \\
\text { thio }\end{array}$ & $\begin{array}{c}\text { arer- } \\
\text { age }\end{array}$ & $\left|\begin{array}{c}c_{i} \\
\text { thio }\end{array}\right|$ & $\begin{array}{l}\text { aver- } \\
\text { age }\end{array}$ & & $\begin{array}{l}\text { cc. } \\
\text { thio }\end{array}$ & $\begin{array}{l}\text { arer- } \\
\text { age }\end{array}$ & thio & $\begin{array}{l}\text { arer- } \\
\text { age }\end{array}$ & thio & $\begin{array}{l}\text { azer- } \\
\text { age }\end{array}$ \\
\hline & $\mathrm{V}_{\mathrm{a}}$ & $\begin{array}{l}1 \\
2\end{array}$ & $\begin{array}{l}2.20 \\
2.15\end{array}$ & 2.18 & $\left|\begin{array}{l}2.08 \\
2.05\end{array}\right|$ & 2.07 & No $\mathrm{KCN}$ & $\left|\begin{array}{l}0.63 \\
0.65\end{array}\right| \mathrm{C}$ & 0.64 & $\mid \begin{array}{l}0.59 \\
0.58\end{array}$ & 0.59 & $\left|\begin{array}{l}2.00 \\
1.95\end{array}\right|$ & 1.98 \\
\hline & $\mathrm{Vb}$ & $\begin{array}{l}1 \\
2\end{array}$ & $\begin{array}{l}1.69 \\
2.04\end{array}$ & 1.87 & $\begin{array}{l}0.92 \\
1.12\end{array}$ & 1.02 & $\mathrm{KCN}$ & $\begin{array}{l}0.52 \\
0.67\end{array}$ & 0.60 & $\begin{array}{l}0.49 \\
0.56\end{array} \mid$ & 0.53 & $\left|\begin{array}{l}1.52 \\
1.89\end{array}\right|$ & 1.71 \\
\hline \multicolumn{3}{|c|}{ Per cent of control } & & 86 & & 49 & & & 94 & & 90 & & 86 \\
\hline
\end{tabular}

table are included also in table 6. After a short exposure, therefore, to cyanide which reduced the oxygen consumption 40 per cent, the consumption rose again to normal after removal from the cyanide solution, as rapidly as it fell in the cyanide.

Table 8 shows a similar rapid recovery of the normal oxygen consumption by worms after long exposure to eyanide solutions of the 
same concentration. In the control test, test 1 , set $\mathrm{Vb}$, the experimental worms used 86 per cent as much oxygen as the control worms, test 1 , set $\mathrm{Va}$, so that this is the normal consumption of these worms. In the second test the worms in 0.00003 molecular KCN, column 2, set $\mathrm{Vb}$, used 49 per cent as much oxygen as the control, column 2, set Va, i.e., they used 57 per cent as much as was normal for the experimental worms. In the third, fourth and fifth tests, the experimental worms recovered their normal consumption of oxygen. The first and second tests were each twenty-four hours in duration and the third and fourth were each six hours in duration. The interval between the second and third tests was only seventeen minutes. After exposure to the action of cyanide for twenty-four hours, therefore, the worms recovered so rapidly after removal from the cyanide solution that the normal rate was maintained for the first six hours. The first and second tests of this experiment are included also in table 6 .

RELATION BETWEEN THE OXYGEN CONSUMPTION BY PLANARIA IN KCN AND LOCOMOTOR ACTHITY

Since it has been demonstrated by numerous experiments that the oxygen consumption by Planaria falls very markedly in KCN solutions, the question arises whether this decrease can be accounted for by decreased locomotion in the cyanide solutions. The locomotion of Planaria can be stopped, as has been stated by Child (1, p. 161), by cutting off the head and this operation does not involve serious injury to the worm. To get a picture of how effective this measure is in stopping locomotion, the experiment recorded in table 9 was performed. Four bottles containing five worms each were placed in a darkened room where they could be observed very carefully without disturbing the worms. The first bottle contained normal worms; the second bottle, worms with the heads removed close behind the auricles; the third bottle, worms with the heads removed a short distance in front of the pharynx; and the fourth bottle contained worms in a 0.000076 molecular solution of $\mathrm{KCN}$. All bottles were observed at frequent intervals during eight hours. At each observation the number of worms found in movement in each bottle was recorded. After the first few observations the positions of the different individuals were the last observation and any worm which had changed position since the last observation was counted as in motion. This was very convenient in the case of the worms in the cyanide since they moved very 
slowly. The table shows that the removal of the head stops movement immediately and almost completely. After the original disturbance the normal worms required some time before coming to rest, but once at rest they remained so for hours, if not disturbed. The

TABLE 9

Showing that removal of the head of Planaria agilis is more effective than 0.000076 molecular KCN in stopping locomotion. Worms 12 to $14 \mathrm{~mm}$. in length; 5 individuals in each bottle. Worms of bottle I were normal. Bottle II, heads of worms removed a short distance posterior to auricles at 9:00 a.m. Bottle III, heads removed a short distance anterior to pharynx. Bottles I, II and III placed in dim light at 9:05 a.m. and not again disturbed. Bottle IV, worms placed in 0.000076 molecular KCN at 9:40 a.m.

\begin{tabular}{|c|c|c|c|c|c|c|c|c|c|c|c|c|c|c|}
\hline \multicolumn{5}{|c|}{$\begin{array}{l}\text { A } \\
\text { NUMBER OF 1NDIVIDEALA IN } \\
\text { MOTION OR MOVED } \\
\text { SINCE LABT OBSERVATION }\end{array}$} & \multicolumn{5}{|c|}{ A-continued } & \multicolumn{5}{|c|}{ A-continued } \\
\hline & I & II & III & IV & & I & II & III & IV & & 1 & II & III & IV \\
\hline & $\begin{array}{c}\text { Ë } \\
\text { है } \\
z\end{array}$ & हू है & 륧 & $\begin{array}{l}z \\
0 \\
\text { Z }\end{array}$ & & 랠 & 密 & 总 & $\begin{array}{l}Z \\
0 \\
\mathscr{Z}\end{array}$ & & 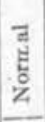 & 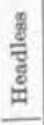 & 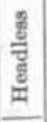 & Z \\
\hline $9: 10$ a.m. & 5 & 0 & 1 & & $10: 38$ a.m. & 2 & 0 & 0 & 4 & $1: 30$ p.m. & 0 & 0 & 0 & 3 \\
\hline $9: 15$ a.m. & 5 & 0 & 0 & & $10: 45$ a.m. & 1 & 0 & 0 & 2 & 1:45 p.m. & 0 & 0 & 0 & 3 \\
\hline $9: 20$ a.m. & 5 & 0 & 0 & & $10: 50$ a.m. & 1 & 0 & 0 & 2 & 2:05 p.m. & 0 & 0 & 0 & 1 \\
\hline $9: 25$ a.m. & 4 & 0 & 0 & & $10: 55$ a.m. & 1 & 0 & 0 & 2 & 2:15 p.m. & 0 & 0 & 0 & 1 \\
\hline $9: 30$ a.m. & 4 & 0 & 0 & & $11: 00 \mathrm{a} . \mathrm{m}$ & 2 & 0 & 0 & 3 & $2: 30$ p.m. & 0 & 0 & 0 & 0 \\
\hline $9: 35$ a.m. & 3 & 0 & 0 & & $11: 05$ a.m. & 1 & 0 & 0 & 2 & $2: 45$ p.m. & 0 & 0 & 0 & 1 \\
\hline $9: 40$ a.m. & 3 & 0 & 1 & & 11:10 a.m. & 1 & 0 & 0 & 2 & $3: 00$ p.m. & 0 & 0 & 0 & 1 \\
\hline $9: 45$ a.m. & 3 & 0 & 0 & 5 & $11: 15$ a.m. & 1 & 0 & 0 & 1 & $3: 20$ p.m. & 0 & 0 & 0 & 1 \\
\hline $9: 50$ a.m. & 3 & 0 & 1 & 5 & $11: 20$ a.m. & 1 & 0 & 0 & 2 & $3: 45$ p.m. & 0 & 0 & 0 & 0 \\
\hline $9: 55$ a.m. & 4 & 0 & 1 & 5 & $11: 25$ a.m. & 1 & 0 & 0 & 3 & 4:00 p.m. & 0 & 0 & 0 & 0 \\
\hline $10: 00$ a.m. & 3 & 0 & 1 & 5 & $11: 35$ a.m. & 1 & 0 & 0 & 2 & $4: 15$ p.m. & 0 & 0 & 0 & 0. \\
\hline $10 ; 05$ a.m. & 1 & 0 & 1 & 5 & $11: 45$ a.m. & 1 & 0 & 0 & 3 & $4: 30$ p.m. & 0 & 0 & 0 & 2 \\
\hline $10: 10$ a.m. & 1 & 0 & 1 & 5 & $11: 55$ a.m. & 0 & 0 & 0 & 3 & 4:50 p.m. & 0 & 0 & 0 & 2 \\
\hline $10: 15$ a.m. & 1 & 0 & 0 & 5 & $12: 05$ p.m. & 0 & 0 & 0 & 2 & 5:05 p.m. & 0 & 0 & 0 & 2 \\
\hline $10: 20$ a.m. & 1 & 0 & 1 & 5 & $12: 25$ p.m. & 0 & 0 & 0 & 4 & $5: 25$ p.m. & 0 & 0 & 0 & 0 \\
\hline $10: 25$ a.m. & 1 & 0 & 0 & 5 & 1:00 p.m. & 0 & 0 & 0 & 0 & & & & & \\
\hline 10:30 a.m. & 1 & 0 & 0 & 5 & 1:15 p.m. & 0 & 0 & 0 & 3 & & & & & \\
\hline
\end{tabular}

bottle of cyanide-treated worms was started thirty-five minutes later than the other bottles, but if the table is read with this is mind it will be seen that the worms in cyanide were in motion for even more of the time than the normal worms not in cyanide, although the rate of motion in cyanide was very slow. This experiment shows, there- 
TABLE 10

Showing that KCN reduces the rate of oxygen consumption by Planaria agilis far more than does removal of the head. Worms 12 to $14 \mathrm{~mm}$. in length; fed almost daily till the day before the experiment; 10 individuals in each bottle. Removal of heads performed within the half hour preceding the second test period. Each test period of 10 hours duration. Concentration of $K C N, 0.000076$ molecular. Temperature $19.6^{\circ}$ to $19.7^{\circ} \mathrm{C}$. Correction for $6 \mathrm{cc}$. of water displaced by rods and reagents: multiply by 1.048 . 1 cc. thiosulphate $=0.1751 \mathrm{cc}$, oxygen at N.T.P.

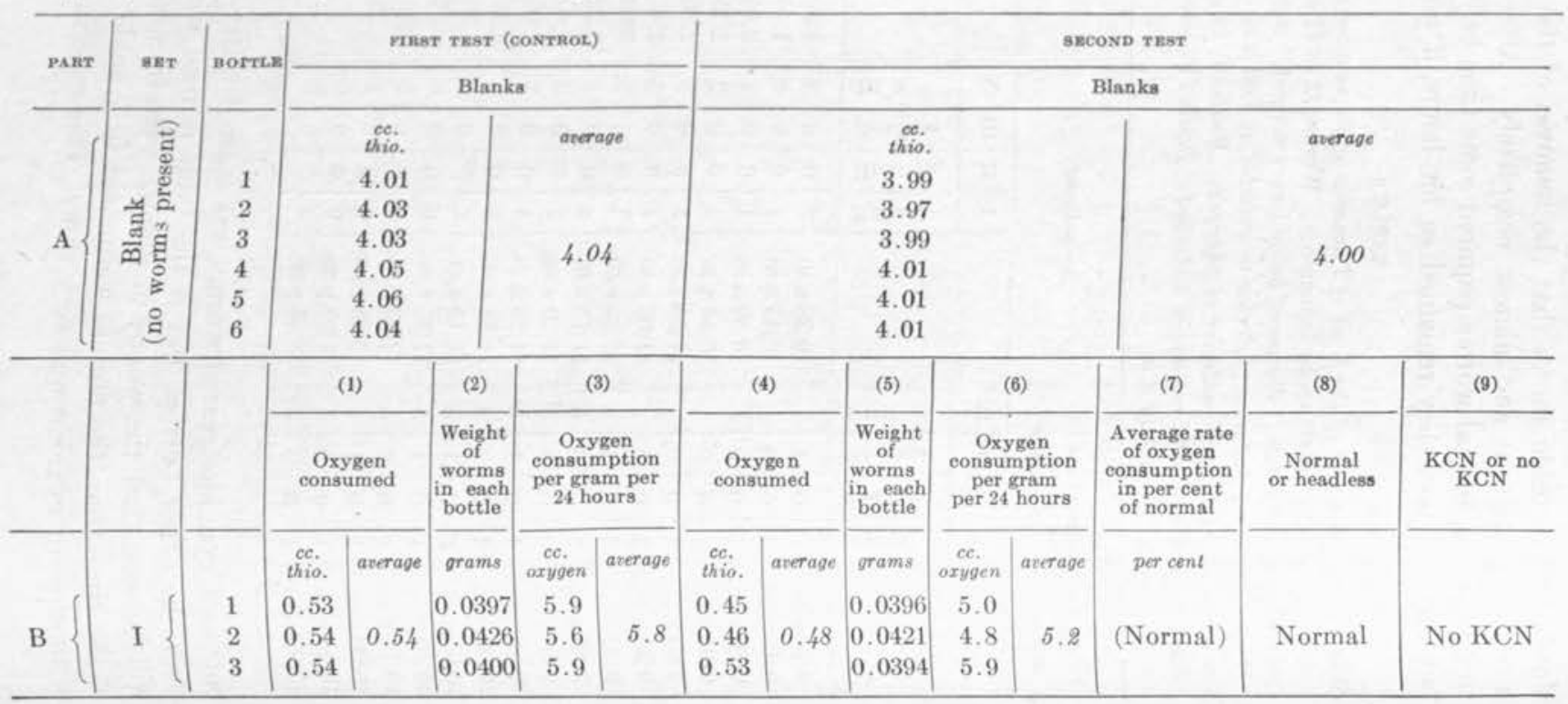




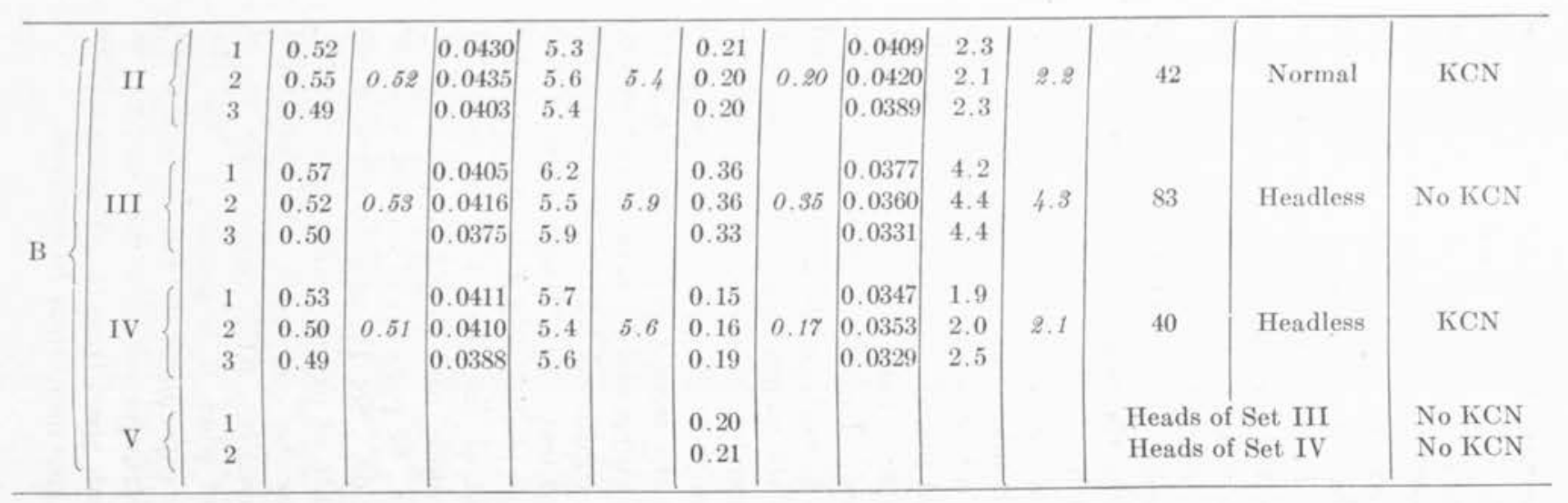


fore, that the locomotion is stopped more completely by cutting off the head than by immersion in cyanide.

It remains, then, to determine the relative effects of cutting off the head and of immersion in cyanide solutions upon the oxygen consumption by Planaria. The experiment summarized in table 10 shows that 0.000076 molecular $\mathrm{KCN}$ reduced the oxygen consumption three times as much as cutting off the head. In other words, the cyanide had three times as much effect in inhibiting the oxidations in Planaria as could be attributed to loss of movement. Furthermore, there was still some movement in the cyanide solution..

This experiment involves an element not included in other experments reported in this paper. When the head of a worm is cut off a considerable amount of tissue is removed, so that the amount of oxygen consumed after such removal cannot be compared with that before the removal, unless account is taken of the loss of body weight. In this experiment, therefore, the set of worms used in each bottle was weighed after each experimental period. The methods of weighing will be described in a later paper. Table 10, part A, gives the analyses of the blanks as heretofore. Part B, column 1, gives the oxygen consumption by the worms in each bottle during the control test. Column 2 gives the weight of the worms in each bottle and colmeters of oxygen gas at consumption by these worms in cubic centiweight of worms per 24 normal temperature and pressure per gram 6 give the corresponding hours. For the second test, columns 4, 5 and uneut and not in ding data. The worms of set I were control worms, gram per 24 hours during the They consumed $5.2 \mathrm{cc}$. of oxygen per in 0.000076 molecular $\mathrm{KCN}$ second test. Set II were uncut worms gram per 24 hours, i.e., 42 and they consumed 2.2 ce. of oxygen per III were headless worms, not in cent of the control or normal. Set of oxygen per gram per 24 hou in cyanide, and they consumed $4.3 \mathrm{cc}$. much as the normal worms in in cyanide. These had the in cyanide. Set IV were headless worms normal worms in cyanide. It rate of oxygen consumption as the after eliminating its effect upon movement, It may be concluded, therefore, that oxidations at least 50 per cent, and whent, $\mathrm{KCN}$ reduces the rate of concentration of cyanide used in this when it is considered that the a decrease of the oxidations as this experiment did not cause as great experiments, it may be concluded stronger solutions used in previous motion, KCN ean inhibit the that, apart from its effect upon loco- 
One further factor remains undetermined in these experiments. That is the relation of the loss of muscle tone in cyanide solutions to the reduction of the rate of oxidations. Headless worms contract strongly and it may be that they as well as the normal worms consume oxygen in maintaining a muscle tone which is lost in cyanide solutions.

\section{SUMMARY}

1. It has been proved that Winkler's method as carried out in these experiments is sufficiently reliable for the quantitative measurement of the oxygen consumption by Planaria.

2. The oxygen consumption by Planaria can be reduced to 30 per cent of the normal rate by $\mathrm{KCN}$ in a concentration as low as 0.0002 molecular.

3. The amount of the reduction varies with the concentration of the cyanide, not directly but as a power function, lower concentrations eausing proportionately greater reduction than higher concentrations.

4. The relation between the concentration of $\mathrm{KCN}$ and its inhibitory effect upon the rate of oxidation in Planaria agilis indicates that a residual oxidation amounting to about 20 per cent of the normal cannot be inhibited by $\mathrm{KCN}$.

5. No evidence was obtained of a stimulation of oxidations in low concentrations of $\mathrm{KCN}$.

6. The rate at which Planaria absorbed oxygen in a cyanide solution was found to be practically the same during periods of different length from two to thirty-six hours. The effect of cyanide is therefore almost immediate and does not change materially with time.

7. The action of KCN upon oxidations in Planaria agilis is reversible, worms recovering their normal level of oxidations rapidly and completely after removal from cyanide solutions.

8. The inhibition of oxidations in Planaria by $\mathrm{KCN}$ could be attributed in only small part to the cessation of movement which results from the anesthetic action of cyanide.

9. These experimental results are considered important in themselves. Questions of their theoretical interpretation in relation to the toxic action of $\mathrm{KCN}$ and to the use of cyanide as a measure of the rate of oxidations are left for later consideration. 


\section{BIBLIOGRAPHY}

(1) ChrL: : Senescence and rejuvenescence, Chicago, 1915.

(2) Geppert: Zeitschr. f. klin. Med., 1859, xv, 208, 307.

(3) SCHroeder: Jahrbucher f. wiss. Bot., 1907, xl, 409.

(4) Waravra: Zeitschr. f. physiol. Chem., 1910, lxvi, 305.

(5) LoEB AND WAstenzys: Biochem. Zeitschr., 1911, xxxvi, 345 ,

(6) LOEB AND W Asteneys: Biochem. Zeitsehr., 1913, lvi, 295.

(7) Hruss: This Journal, 1916, xl, 238.

(8) Lund: This Journal, 1918, xlv, 365.

(9) Sсно̆мвег: Z Zeitschr. f. Biol., 1867, iii, 140.

(10) Kastue and Loevenhart: Amer. Chem. Journ., 1901, xxvi, 539.

(11) Losvexhant: Amer. Chem. Journ., 1903 xxix, 397, 663, 411.

(12) Loevesuart: Ber. deutsch. ehem. Gesellsch., 1906, xxxix, 130.

(13) Matriews and Watker: Journ. Biol. Chem., 1909, vi, 29.

(14) MAtrhews aNd W WLKeR; Journ. Biol. Chem., 1909, vi, 289.
(15) LuND: This Journal, 1918, xlv, 351.

(16) SUTTEx: Volumetric anslysis, 1904, 287.

(17) Brrge and Jeday: Wisconsin Geol. and Nat. Hist. Survey, 1911, 16. 
QUANTITATIVE STUDIES ON THE RATE OF RESPIRATORY METABOLISM IN PLANARIA

II. The Rate of Oxygen Consumption purino Staryation, Feeding, Growth aNd Regeneration in Relation to the Method of Susobptibmity to Potassium Cyanide as a Measure of Rate of Metabolism

BY

GEORGE DELWIN AHLEN

From the Department of Animal Biology, Bniversity of Minuesota

Reprinted prom The American Journal op Phystolom Vol. XLIX, No. 3, August, 1919 
Reprinted from Thz American Journat of Puysiology, Vol. 49, No. 3

August, 1919

\section{QUANTITATIVE STUDIES ON THE RATE OF RESPIRATORY METABOLISM IN PLANARIA}

II. The Rate of Oxygen Consumption during Starvation, Feeding, Growth and Regeneration in Relation to the Method of Susceptibiutity to Potassium Cyanide as a Measure of Rate of Metabolism

\section{GEORGE DELWIN ALLEN}

From the Department of Animal Biology, University of Minnesota

Received for publication June 9, 1919

\section{INTRODUCTION}

A review of the literature concerning the rôle of what has been designated "rate of metabolism" in senescence, rejuvenescence and gradients along the body axes in lower animals ((1) to (9) and other references there cited), will show that little or nothing is known which is based on direct quantitative measurements of metabolism in the animals concerned. It has been assumed that relative susceptibility of an organism to the toxic action of potassium cyanide and other substances is a measure of rate of metabolism or rate of oxidation. This assumption has been uséd extensively as the basis for inferences regarding the metabolism in Planaria and other animals. The only attempts to measure the metabolism in these forms by methods which do not involve assumptions are certain tests reported by Child, (3, pp. 422, 434;4, pp. $73,161,202)$ of carbon dioxide production by Planaria in Tashiro's "biometer." These estimations were few in number, comparative not strictly quantitative, and we cannot judge from the account how carefully they were controlled. The purpose of the present paper is to present quantitative information regarding the oxidations in Planaria in relation to starvation and feeding, increase in size of the body, and regeneration; and secondly, to compare these results with the reported differences in the susceptibility of Planaria to potassium cyanide.

The term metabolism is commonly used in animal calorimetry to refer to the decomposition of organic compounds (total katabolism) 
yielding energy. It may be considered either from the standpoint of the quantities of the different foodstuffs decomposed and the completeness of this decomposition or from the standpoint of the quantities of energy yielded. The latter basis is used for expressing metabolism in a single quantitative term. Lusk, for example, says with regard to the "exact measurement of the metabolism":

Thus heat may become a measure of the total aetivity of the body. It is derived from the total metabolism and must be dependent on it and be a measure of it $(10$, p. 32$)$.

From this standpoint the oxidations are considered important as a source of energy and as a measure of the energy production. The term "rate of metabolism" seems to be used in this sense in some of the references on senescence and axial gradient, especially where studies of the metabolism of man and mammals are quoted (e.g., (4, pp. 63, 65, 271-273, 297-298)). The following statements seem to imply this meaning of the term.

There can be no doubt that the rate of metabolism or, more specifically, of oxidations inthe: e animals increases during the course of starvation ( 3, p. 435 ).

It has been shown that a relation exists between susceptibility and metabolic activity, more specifically the oxidations or energy-freeing reactions $(6$, p. 50$)$.

It is not certain, however, that the term is always used in the literature concerning "rate of metabolism" as equivalent to the rate of oxidations or of energy production. A distinction seems to be drawn between them in accordance with the following statement:

While oxidations are fundamental metabolic reactions, and serve in a general way as a measure of metabolic activity, a considerable range of variation in the different reactions which go to make up the metabolic complex may undoubtedly exist (4, p. 72).

A fact which must be kept in mind in using the term metabolism is that while energy transformation in the cell may be large, the corresponding quantity of material transformed may be small. This is true of respiratory metabolism, while on the other hand in a large number of metabolic processes the quantity of material being transformed is relatively very large while the energy change is hardly measurable. As pointed out by Lund (11, p. 168): 
It is very doubtful if the rate of oxidations as measured by carbon dioxide produetion or oxygen consumption ean even approximately ${ }^{1}$ be used as a measure of the rate of total metabolism (either of matter or energy ${ }^{1}$ ) in a cell, for it has never been shown that the speed of such processes as hydrolyses and changes in colloidal constitution are correlated to the speed of oxygen consumption or carbon dioxide production.

Furthermore, these processes are of a reversible character and matter and energy may pass through them repeatedly before appearing in the external exchanges of the animal. It is evident from these considerations that the terms metabolism and rate of metabolism may be and are used in different senses. On the one hand they may refer strictly to the rate of oxidations or more generally to the rate of energy production as measured by oxygen consumption, carbon dioxide production or heat liberation. On the other hand they may refer in a loose way to the rate of all metabolic processes, involving the complications just mentioned. These two usages are by no means equivalent. It is of vital importance to any profitable discussion of the rate of metabolism in organisms that it shall be clearly understood precisely what is under discussion. This matter cannot be over-emphasized. It is not a question of quibbling over the propriety of one definition as contrasted with another, which is a very unessential matter. But it is extremely important that there shall not be ambiguity as to meaning at any given point, and that an unconscious and unwarranted translation of fact into inference shall not be made. Statements regarding the rate of metabolism may be true when the term means one thing while the same statements may be untrue when the term means something else. If an established fact regarding the rate of metabolism in one sense is used as the basis for an inference regarding the rate of metabolism in a different sense, then great care must be exercised that the inference does not become confused with the fact. The present paper is concerned with the rate of metabolism in the sense of rate of energy production, with the usual qualifications concerning errors in the different methods of direct and indirect calorimetry, and of the possibility of other sources of energy than that represented by the respiratory exchange (see Krogh, (12), chap. i). This statement is made for the purpose of avoiding any ambiguity, and of guarding against the reading into the discussions of more than is intended.

${ }^{1}$ Italics and parenthesis mine. 


\section{METHODS}

Two species of Planaria, P. maculata and P. agilis, ${ }^{2}$ were used in the experiments reported in this paper. The general method for determining the amount of oxygen consumed was to place worms in a bottle of tap water of known content of dissolved oxygen for a stated period of time, and then to remove the worms and analyze the water by the Winkler method for the amount of oxygen remaining. A large carboy was filled with tap water and stirred to make sure that the amount of dissolved oxygen was uniform throughout. The bottles used in an experiment were filled in rapid succession, and the average of the analyses of three or four blanks containing no worms during the experiment was taken to represent the amount of oxygen in each of the experimental bottles at the beginning of the experiment. All bottles were of the same capacity, $132 \mathrm{cc}$. During analysis the amount of water displaced by the 2 cc. of reagents added is lost. As explained in a previous paper $(13$, p. 98$)$ removing worms at the end of a test may remove enough water to make it difficult to close bottles after adding the reagents without leaving air bubbles. This can be prevented by adding more reagents or by inserting a glass rod of known volume. In the experiments summarized in tables $3,4,5,6,8,12$ and 13 the reagents were diluted with an equal volume of distilled water and $2 \mathrm{cc}$. instead of $1 \mathrm{cc}$. of each were used. In the other experiments, glass rods of $2 \mathrm{cc}$. volume were used. The latter method appears preferable although it is unnecessary, if the worms in a single bottle are not too numerous and do not cling too firmly to the glass. The experimental methods are described in more detail in the previous paper. It was shown in that paper (13, table 1$)$ that when 28 bottles were filled with aerated tap water and analyzed at once, the maximum difference between individual analyses did not exceed $0.08 \mathrm{cc}$. thiosulphate. In the experiments reported previously 15 sets of three or four blanks were analyzed. In no case was the maximum difference between duplicate analyses greater than $0.06 \mathrm{cc}$. thiosulphate. For the experiments reported in the present paper 37 sets of blanks were analyzed. In one case a difference of 0.12 cc. thiosulphate was noted between duplicate analyses, but this was apparently an error in the reading. In only one other instance did the maximum difference amount to so much as 0.09 ce. thiosulphate. For all the experiments of both papers the average

${ }^{2}$ I am indebted to Dr. Ruth Higley for verifying the identification of these species. 
difference beteen the maximum and the minimum analyses in a series of blanks was $0.046 \mathrm{cc}$. thiosulphate. One drop of thiosulphate from the burette used averages $0.06 \mathrm{cc}$. in volume. (Titrations were made in a porcelain dish.) These figures therefore indicate the limits of experimental error in the method used and enable one to form a judgment of the accuracy of the data presented in the tables and curves.

The methods of weighing worms have not been described. In the earlier experiments reported in this paper, worms were removed individually to a glass plate in a drop of water, the excess water was absorbed with filter paper and the worm was transferred by means of a probe to a moistened filter paper in a weighing dish. All of the worms which were together in the same bottle in a respiration test were weighed at once, not individually. The error from evaporation was found to average 0.0005 gram. In later experiments a better method was followed. All the individuals from one bottle were transferred in a drop of water to a glass cover slip, the excess water was absorbed with filter paper, and the cover slip was dropped quickly into a weighing bottle half filled with water. When a weighing bottle with a well-ground stopper was used, the error from evaporation was only 0.0002 gram and was much less variable than in the earlier method. These average errors were added to the observed weight in each case.

In order to test the limits of error in the method just described, a single set of worms was weighed repeatedly, as shown in table 1 . The worms were weighed three times in rapid succession, and then were allowed to rest undisturbed for a few hours before the next series of weighings. It appeared at once that the first determination in a series was always highest and that the later ones were successively lower. The difference between the first and the third weight was sometimes over 6 per cent. This apparent loss was not permanent, however. After each period of rest the first weight was considerably higher than the last, and almost as high as the first weight of the preceding series. Figure 1 shows these relations graphically. These peculiar results are due, probably, to differences in the amount and character of the mucus. At the moment when excess water is removed from the group of worms on the cover slip, thicker mucus will retain more water; and since care must be exercised not to injure worms by excessive drying, they cannot safely be freed entirely from mucus. Figure 1 shows that the first weights of the different sets make a very regular series decreasing with time and starvation, in which individual variation did not reach 2 per cent. In order to weigh worms under uniform conditions in experi- 
ments, all sets were left undisturbed under dark cloth for some time, each set in a separate dish of water, and each set was taken for weighing with as little disturbance to the others as possible.

In experiments extending over a considerable period of time, the worms were weighed at intervals and the weights were plotted on a graph as in figure 2. The weight of each lot of worms at the middle of

TABLE 1

Shoving variation among successive weights of a set of Planaria agilis. Five large worms were weighed three times in rapid succession, then were left undisturbed for several hours under dark cloth and were weighed again as before, etc.

\begin{tabular}{|c|c|c|}
\hline DATE & TIME & พЕIGHT \\
\hline July $2 \ldots \ldots$ & $\begin{array}{l}10.50 \text { a.m. } \\
11.06 \text { a.m. } \\
11.24 \text { a.m. }\end{array}$ & $\begin{array}{l}0.0294 \\
0.0283 \\
0.0281\end{array}$ \\
\hline July $2 \ldots \ldots$. & $\begin{array}{l}1.30 \text { p.m. } \\
1.46 \text { p.m. } \\
2.02 \text { p.m. }\end{array}$ & $\begin{array}{l}0.0292 \\
0.0284 \\
0.0275\end{array}$ \\
\hline July $2 \ldots \ldots$ & $\begin{array}{l}4.44 \text { p.m. } \\
4.58 \text { p.m. } \\
5.12 \text { p.m. }\end{array}$ & $\begin{array}{l}0.0285 \\
0.0278 \\
0.0271\end{array}$ \\
\hline July $3 .$. & $\begin{array}{l}8.41 \text { a.m. } \\
9.04 \text { a.m. } \\
9.17 \text { a.m. }\end{array}$ & $\begin{array}{l}0.0276 \\
0.0271 \\
0.0265\end{array}$ \\
\hline July $3 \ldots$ & $\begin{array}{l}4.28 \text { p.m. } \\
4.40 \text { p.m. } \\
4.52 \text { p.m. }\end{array}$ & $\begin{array}{l}0.0272 \\
0.0267 \\
0.0259\end{array}$ \\
\hline July 4 .. & $\begin{array}{l}9.19 \text { a.m. } \\
9.34 \text { a.m. } \\
9.48 \text { a.m. }\end{array}$ & $\begin{array}{l}0.0258 \\
0.0256 \\
0.0251\end{array}$ \\
\hline
\end{tabular}

the test period was read off from the graph and taken as the average weight during the test. Figure 2 shows the weight curves for the worms of table.7. These worms were undergoing starvation and progressive decrease in size during the experiment. Inspection of the curves shows that the maximum error in individual weights was not over 3 per cent. Inspection of all the weight curves of the experiments in this paper shows that individual variations rarely exceeded 6 per cent. 
In the case of figure 2 and table 7 , none of the worms had to be discarded because of fission or accidental injury. In some other cases, worms underwent fission during the experiment. Such a worm was removed at once and a new weight was obtained. In later experiments, substitutes were kept ready for replacing such individuals. The substitutes were treated like the worms in the experiment except that their oxygen consumption was not measured unless they took the place of worms in experimental bottles.

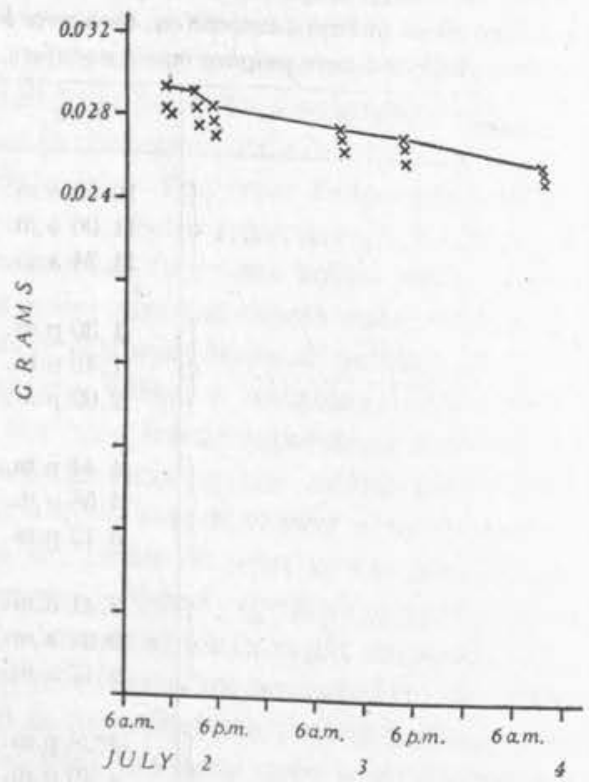

Fig. 1. Showing variation in successive weights of the same set of Planaris agilis. Abscissas, time in 6-hour periods. Ordinates, weight in grams. Solid line connects the first weights of successive series. See table 1.

During the experiments summarized in tables 7,9 and 14, the respiration bottles were immersed in a water bath within a constant temperature oven at $20^{\circ} \mathrm{C}$. Other experiments were carried out at the same temperature in a constant temperature bath.

The test periods were relatively long and the number of worms in each bottle was small. The worms of tables 7, 9 and 14; spent most of the time for six weeks in the respiration bottles. The results represent, therefore, almost continuous measurement of their metabolism through that period, and may be taken as the "normal metabolism" as the term is 
used by Krogh (12, p. 116). They do not represent rigidly "standard metabolism" (Krogh, (12), chap. iv) or "basal metabolism" of other authors, because locomotion was not absolutely eliminated, but when Planaria are left undisturbed for several hours they remain at rest for most of the time so that experimental periods of long duration approach nearly to the conditions for "standard metabolism" (see (13), table9).

In all experiments at least three parallel determinations upon different worms of the same history have been made. Along with the average result, the individual determinations are also given to show the range of variation among them.

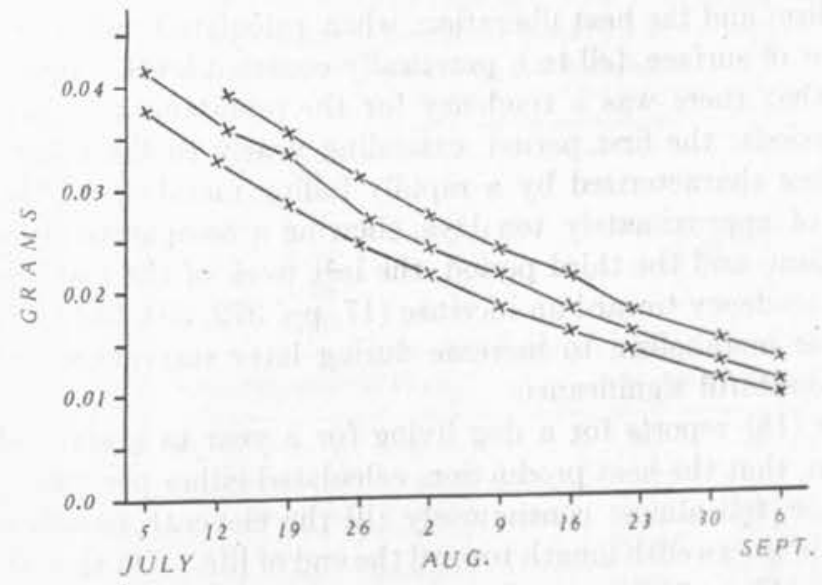

Fig. 2. Curves show decrease in weight of three sets of Planaria agilis of 5 worms each, during 9 weeks of starvation. Abseissas, time in weeks indicated by dates. Ordinates, total weight of 5 worms in grams. See table 7.

\section{OXIDATIONS DURING STARVATION}

The rate of metabolism of man and other higher vertebrates falls during the early stages of starvation. Johansson, Landergren, Sonden and Tigerstedt (14) found a decline from 33.15 to 31.20 calories per kilo during the first three days of starvation in man. The heat production during the third to fifth days inclusive remained constant. Among the numerous experiments of Benedict upon The influence of inanition on metabolism (15), are three of four days' duration, a fourth of five days' and a fifth of seven days' duration. In general they show a fall in the heat production during these periods, whether it is calculated per unit 
of weight or of surface, although in most cases the determinations for the first day were lower than those for the two or even three days following. This fall in heat production during the first few days of starvation is probably due to disappearance of food reserves.

The best observations on man show that metabolism remains fairly constant during prolonged starvation, when calculated per unit of weight or of surface. Lehman, Mueller, Munk, Senator and Zuntz (16) found the respiratory metabolism of Cetti, the professional faster, to remain practically uniform during a fast of 11 days, when calculated per unit of body weight. In Benedict's very complete study of the metabolism in a man starving for 31 days (17), both the respiratory metabolism and the heat liberation, when calculated either per unit of weight or of surface, fell to a practically constant level. Benedict concluded that there was a tendency for the metabolism to divide into three periods: the first period, extending nearly to the middle of the fast, being characterized by a rapidly falling metabolism; the second period, of approximately ten days, showing a comparatively constant metabolism, and the third period, the last week of the fast, showing a general tendency toward an increase $(17, \mathrm{pp} .372,384,391)$. The tendency for metabolism to increase during later starvation was slight and of doubtful significance.

Zuntz (18) reports for a dog living for a year in a state of undernutrition, that the heat production, calculated either per unit of weight or surface, fell almost continuously till the eleventh month and rose sharply in the twelfth month toward the end of life. On the other hand Benedict (17, p. 355$)$ quotes experiments by Awrorow on the metabolism of dogs starving for 44 days and 61 days respectively which show a sharp fall in the rate of heat production per unit weight during the first few days, i.e., from about 60 to 48 calories, followed by a gradual rise to a level somewhat above the original, i.e., to 60 to 72 calories, just before a premortal fall.

Warm-blooded animals, however, with their regulatory mechanisms may present special conditions as regards metabolism during starvation. Turning to the cold-blooded animals, the heat liberated by starving frogs per cubic centimeter of frog was found by Hill (19) to decrease during the first two weeks to a practically constant level during the next two weeks. Brunow (20) found a fall in respiratory metabolism in the crayfish during prolonged starvation. A knowledge of the rate of oxidations in Planaria during inanition would add materially to our limited information upon this subject in the cold-blooded animals. 
During the first few days of starvation in Planaria, as in other animals, there is a decrease in the rate of oxidations probably due to the diminishing effects of the residual food reserves from the last of the feedings. Table 2 gives a comparison of the rates of oxygen consumption by two lots of worms measured simultaneously, one lot fed daily

TABLE 2

Showing that Planaria agilis after three weeks starvation have a lower rate of oxygen consumption than unstarved worms of the same size. Worms of medium size with short tail because of recent fission; 9 individuals in each bottle. "Well-fed worms" were fed beef liver daily, missing an occasional day, up to the day before the test. "Starved worms" were well fed up to $2 \mathrm{z}$ days before the experiment. Temperature $20.4^{\circ} \mathrm{C}$. One cubic centimeter thiosulphate equals $0.1711 \mathrm{cc}$. oxygen at N.T. P. Test period 12 hours. Weighed once within 8 hours after the test

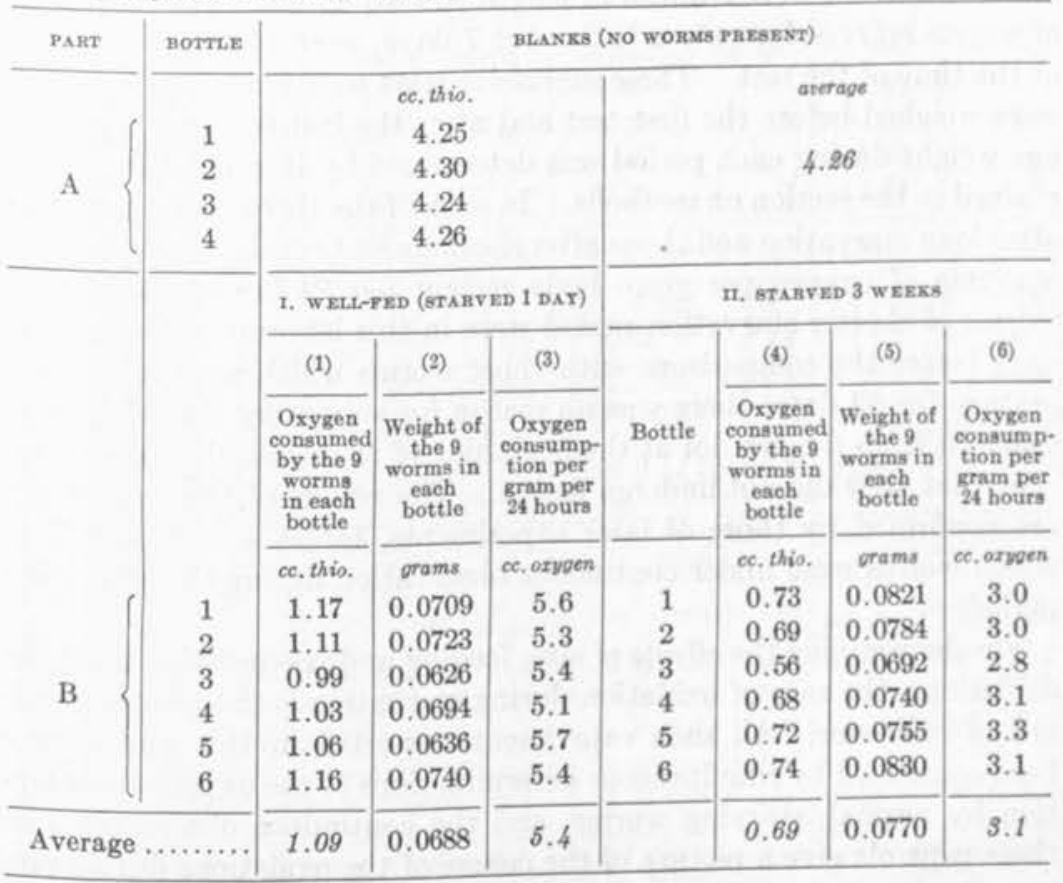

up to the day before the experiment and the other lot starving for three weeks previous to the test. The worms were of approximately the same weight. The well-fed worms absorbed 1.09 cc. thiosulphate equivalent of oxygen in 12 hours while the worms starved for three weeks absorbed only $0.69 \mathrm{cc}$. thiosulphate equivalent of oxygen. Cal- 
culated per gram of body weight, the well-fed worms consumed 5.4 tce. of oxygen per 24 hours and the worms starved for three weeks only $3.1 \mathrm{cc}$.

After the first few days of starvation of Planaria, during which the food reserves from the last feedings are effective in increasing the oxidations, the oxygen consumption per unit of weight remains practically constant for a long period of time. Table 3 shows a comparison between Planaria starved for 63 days and others starved for 7 days. The former worms, during the first four days in the laboratory, underwent natural fission, because of their large size and the sudden deprival of food. Only the anterior pieces were used in the experiment. They measured 10 to $13 \mathrm{~mm}$. in length. At the time of the respiration determinations, these were reduced in length to 7 to $8 \mathrm{~mm}$. The second lot of worms starved for only a little over 7 days, were 14 to $19 \mathrm{~mm}$. long at the time of the test. Three successive tests were made. The worms were weighed before the first test and after the last test and the average weight during each period was determined by interpolation, as explained in the section on methods. In each of the three tests the worms after long starvation and those after short starvation absorbed the same amounts of oxygen per gram body weight per 24 hours. While the worms of shorter starvation period were in this laboratory for only six days before the comparisons with those worms which were in the laboratory for 62 days, there was no reason for supposing that they were different from the first lot at the beginning of the starvation period, except that they did not undergo fission. The results of this experiment are confirmed by those of later experiments, tables $4,5,6$ and 7 , in which worms were under continuous observation during the starvation period.

For determining the effects of size, feeding and regeneration upon the oxidations, the rate of oxidation during starvation is the proper standard of reference. All such experiments reported in this paper have been controlled by simultaneous determinations of the oxygen consumption by normal, starving worms, and the continuous observations on these controls give a picture of the course of the oxidations during prolonged starvation. These observations are given in tables $4,5,6$ and 7. Since the effects of previous feeding were to be avoided in the experiments for which these worms were controls, the worms were starved for several days before beginning observations.

In the experiment recorded in table 4 , Planaria maculata that had been starving for several weeks were observed for 34 days during which 
TABLE 3

Showing that Planaria agilis after 63 days of starvation have the same rate of oxygen consumption as worms starved for only 7 days. The former worms underwent natural fission 62 to 59 days previous to the first test, because of their large size and sudden removal of food. The anterior pieces from this fission, measuring 10 to 13 mm. in length 59 days before the first test were reduced in length to 7 or $8 \mathrm{~mm}$. at the time of the first test; 10 worms in each bottle. The worms of short starvation period measured 14 to $19 \mathrm{~mm}$. in length; 5 worms in each bottle. The lengths of the three successive tests were, in order, 49,49 and 46.25 hours. Temperature $20^{\circ}$ C. plus or minus $0.15^{\circ} \mathrm{C}$., except a temporary fall to $16^{\circ} \mathrm{C}$., during the third test, which accounts for the low values in column 10. One cubic centimeter thiosulphate equals $0.1710 \mathrm{cc}$. oxygen at N.T.P. Worms weighed before the first test and after the third, and the average weight during each period determined by interpolation.

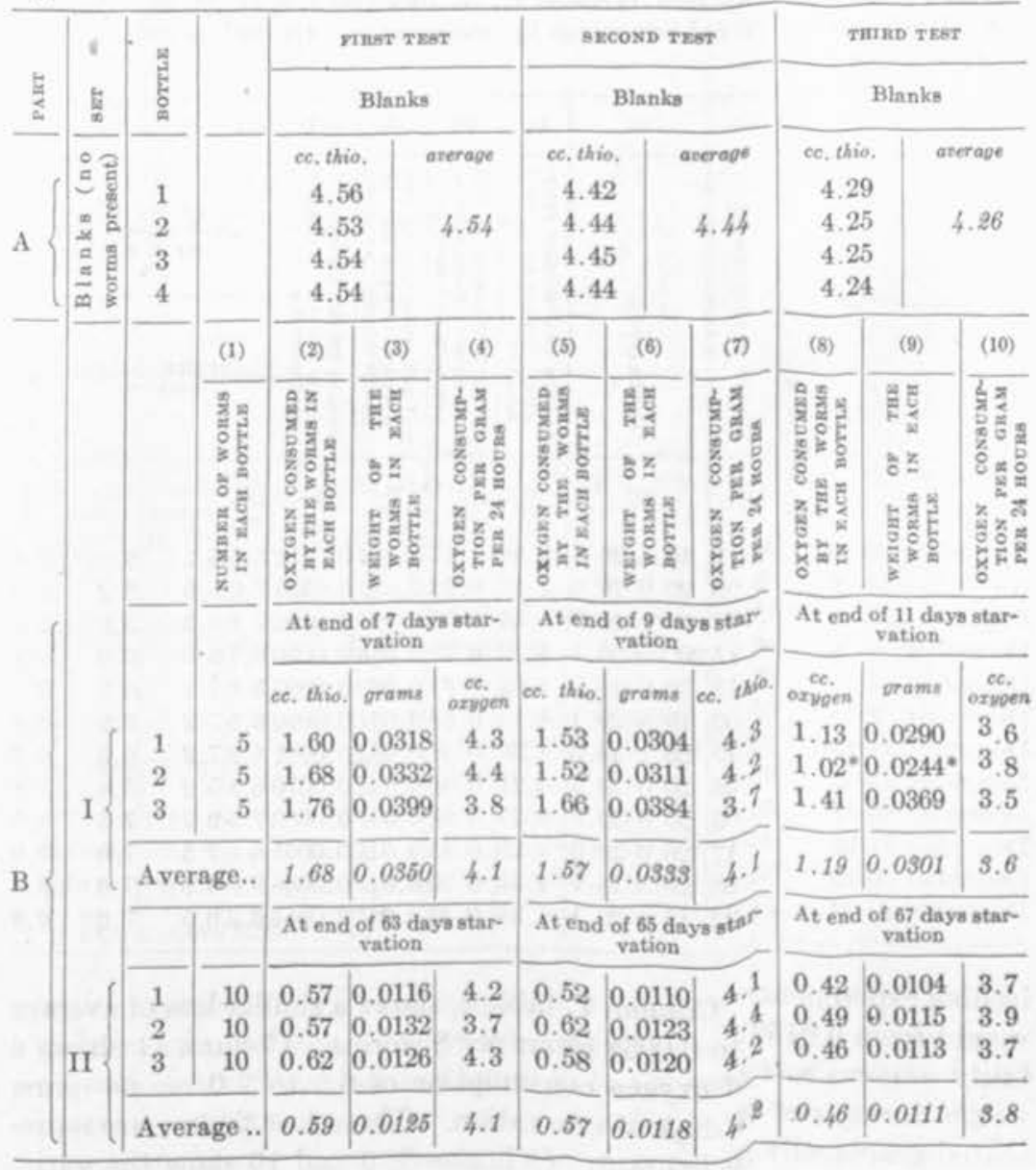

* 4 worms. 
time 12 tests of the oxygen consumption were made, each of about 46 hours' duration. Column 6 shows a steady decline in the average amount of oxygen consumed by the 8 worms in each bottle from 0.105 to $0.037 \mathrm{cc}$. per 24 hours. In figure 4 the oxygen consumption by the worms during the 34 days of observation, is shown as the control for a

TABLE 4

Showing rate of oxygen consumption by Planaria maculata during starvation. Worms starving for several weeks preceding first test and during the experiment; 8 worms in each bottle. One cubic centimeter thiosulphate equals $0.1766 \mathrm{cc}$. oxygen at N.T.P. Worms weighed November 20,27, December 1,4,11,18,25. Average weight for each test period determined by interpolation. Control for table \& See
figures 4 and 5

\begin{tabular}{|c|c|c|c|c|c|c|c|c|c|c|}
\hline (1) & (2) & (3) & (4) & (5) & (6) & (7) & (8) & (9) & (10) & \\
\hline DATE OP TEQT & 율 & & 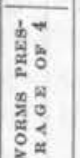 & 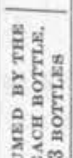 & 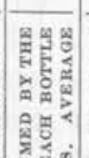 & 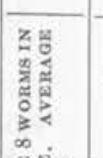 & \multicolumn{4}{|c|}{$\begin{array}{c}\text { OXYGEN CONSUMED PER } \\
\text { GRAM BODY WEIGHT } \\
\text { PER } 24 \text { HOURB } \\
\end{array}$} \\
\hline & $\begin{array}{l}\text { हैं } \\
\text { के } \\
\text { हुँ } \\
\frac{2}{3}\end{array}$ & 逍 & 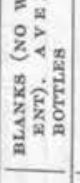 & 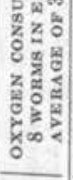 & 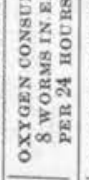 & 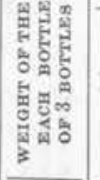 & \multicolumn{3}{|c|}{$\begin{array}{c}\text { Individual determi- } \\
\text { nations }\end{array}$} & \\
\hline & hours & ${ }^{\circ} \mathrm{C}$. & $\begin{array}{l}\text { ce. } \\
\text { thio. }\end{array}$ & i. & yoen & arams & $\begin{array}{c}c c . \\
\text { oxy- } \\
\text { oen }\end{array} \mid$ o. & $\begin{array}{c}c c . \\
\text { oxyoen }\end{array}$ & $\begin{array}{c}c c . \\
\text { oxygen }\end{array}$ & $\begin{array}{l}\text { syen } \\
\text { oen }\end{array}$ \\
\hline ovember $20-22$. & 46.17 & $19.8-20.3$ & 4.58 & 1.11 & 0.105 & 0.0152 & 5.56 . & 3.1 & $9.0(?)^{6}$ & \\
\hline $\begin{array}{l}\text { November } 24-2 \\
\text { December } 1-3\end{array}$ & 48.00 & $20.0-20.6$ & 4.47 & 0.93 & 0.085 & 0.0134 & 7.05 . & 5.6 & 6.2 & \\
\hline $\begin{array}{ll}\text { December } 1-3 . \\
\text { December } & 4-6\end{array}$ & 45.92 & $20.0-20.3$ & 4.55 & 0.79 & 0.075 & 0.0108 ? & 7.18. & 3.3 & 5.9 & \\
\hline $\begin{array}{ll}\text { December } & 4-6 \\
\text { December } & 6-8\end{array}$ & 46.15 & $20.0 \pm 00.1$ & 4.29 & 0.72 & 0.068 & 96 & 6.78. & 3.6 & 6.0 & \\
\hline $\begin{array}{ll}\text { December } & 6-8 \\
\text { December } & 8-10\end{array}$ & 46.13 & $20.0-20.2$ & 4.02 & 0.63 & 0. & $3:$ & 5.67 . & 7.1 & 6.5 & \\
\hline $\begin{array}{l}\text { December } 8-10 \\
\text { December } 11-13\end{array}$ & 46.00 & $19.8-20.1$ & 4.10 & 0.64 & 0. & & 6.57. & 7.2 & 6.9 & \\
\hline $\begin{array}{l}\text { December 11-13. } \\
\text { December } 13-15\end{array}$ & 46.17 & $20.1-20.3$ & 4.28 & 0.57 & 0. & & 6.37 & 7.2 & 6.5 & \\
\hline $\begin{array}{l}\text { December 13-15. } \\
\text { December } 15-17 .\end{array}$ & 46.25 & $20.0-20.2$ & 4.21 & 0.46 & 0. & 0. & 6.15 & 5.9 & 5.4 & \\
\hline December $18-2$ & $\left|\begin{array}{l}46.05 \\
46.17\end{array}\right|$ & $20.0-20.3$ & 4.25 & 0.58 & 0.055 & 0.0069 & 7.59 & $.2(?)$ & 7.5 & 8. \\
\hline December $20-2$ & $\mid \begin{array}{l}46.17 \\
46.05\end{array}$ & $20.0-20.3$ & 4.25 & 0.45 & 0.0430 & 0.0061 & 6.67. & & 7.0 & \\
\hline December $22-24$. & $\mid \begin{array}{l}46.05 \\
51.23\end{array}$ & $\begin{array}{l}20.3-18.7 \\
19.9-20.1\end{array}$ & $\begin{array}{l}4.31 \\
4.34\end{array}$ & $\begin{array}{l}0.50 \\
0.43\end{array}$ & 0.048 & $\begin{array}{l}0.0058 \\
0.0054\end{array}$ & & $.5(?)$ & $\begin{array}{l}7.6 \\
7.6\end{array}$ & 6. \\
\hline
\end{tabular}

feeding experiment. Column 7 , table 4 , shows a similar loss of average weight from 0.0152 to 0.0054 gram per 8 worms. Column 11 shows a fairly uniform rate of oxygen consumption of 6.5 to 7.0 cc. per gram weight during the 34 days of starvation. These last figures are represented graphically in figure 5. Columns 8,9 and 10 show the varia- 
tion in determinations of the individual bottles which indicates the limits of error in the experiment.

Table 5 gives similar observations upon starving Planaria maculata during a period of 27 days. The worms were starved 15 days previous

\section{TABLE 5}

Showing rate of oxygen consumption by Planaria maculata during starpation. Worms 10 to $13 \mathrm{~mm}$. in length on January 8; starving for 15 days previous to the first test and during the experiment; 8 worms in each bottle. Weighed January 12, 14, 15, February 5 and 13. One cubic centimeter thiosulphate equals $0.1698 \mathrm{cc}$. oxygen at N.T.P. See figure 9. For further data on control, see taple 12

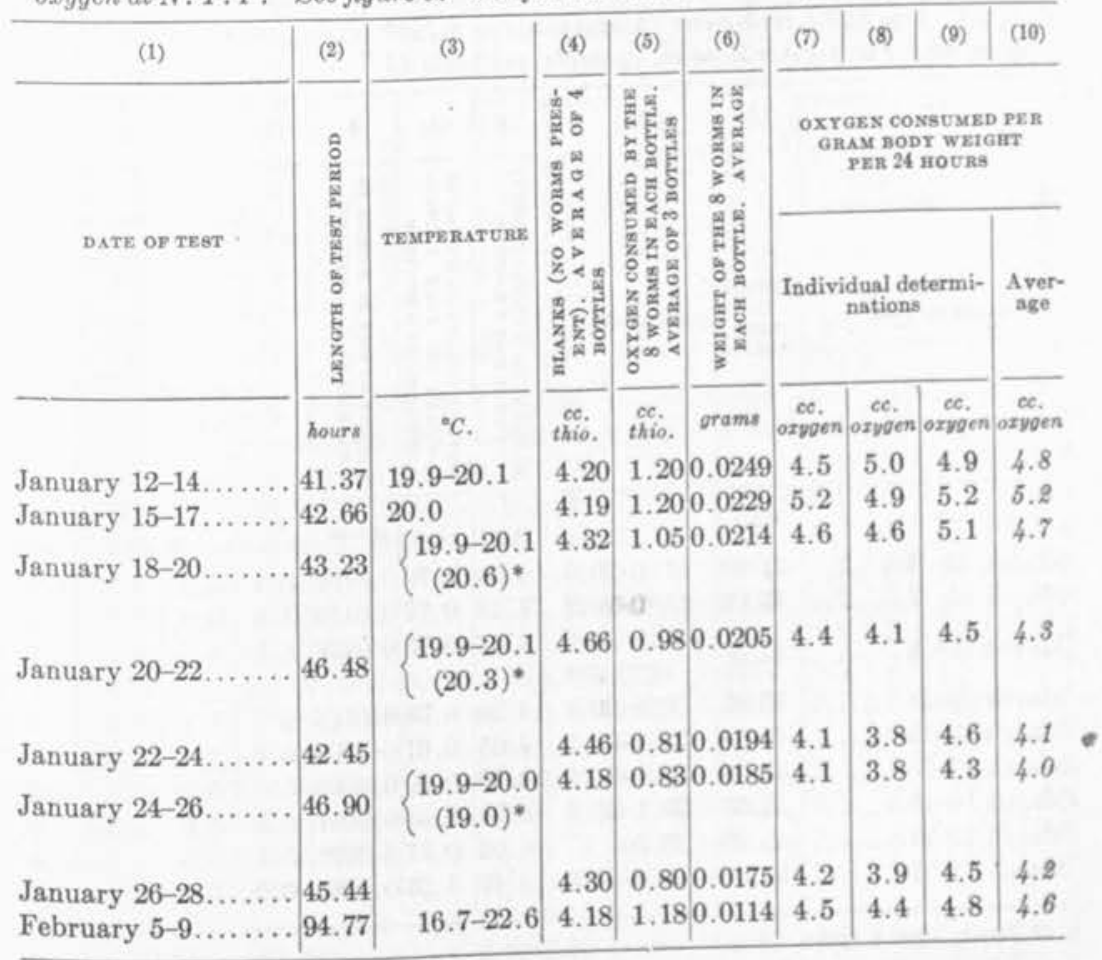

\footnotetext{
* For a short time.
}

to the experiment. The average rate of oxygen consumption per gram body weight, column 10, was less uniform in this case. The data of column 10 are represented in figure 9 , as the control for an experiment in which worms were cut in two and allowed to regenerate. It may be seen that the curves representing the rates of oxygen consumption by 
anterior pieces and posterior pieces parallel the irregularities in the curve of the normal worms, indicating some common factor or factors, probably other than the stage of starvation, affecting all worms simultaneously. Table 6 and figure 10 record results of respiration tests on $\mathrm{Pla}$ naria maculata during 24 days of starvation. The worms were starving for 4 days preceding the experiment. These again were control

TABLE 6

Showing rate of oxygen consumption by Planaria maculata during starvation. Worms 7 to $10 \mathrm{~mm}$. long February 25 ; starving for 5 days preceding the first test and during the experiment; 10 worms in each bottle. Weighed March $2,5,11,12$, 18, 30. One cubic centimeter thiosulphate $=0.1698 \mathrm{cc}$. oxygen at N.T.P. See figure 10. For further data on controls, see table 13

\begin{tabular}{|c|c|c|c|c|c|c|c|c|c|}
\hline (1) & (2) & (3) & (4) & (5) & 6 & (7) & (8) & (9) & (10) \\
\hline \multirow[b]{2}{*}{ DATE OY TEST } & \multirow{2}{*}{$\begin{array}{c}\text { LENGTI } \\
\text { OF } \\
\text { TERT } \\
\text { PKRIOD }\end{array}$} & \multirow[b]{2}{*}{ TEAPERATUAE } & \multirow{2}{*}{ 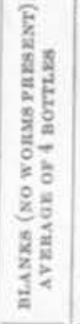 } & \multirow{2}{*}{ 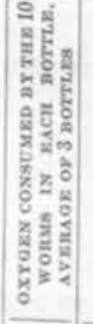 } & \multirow{2}{*}{ 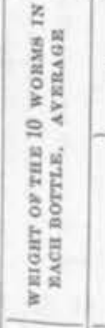 } & \multicolumn{4}{|c|}{$\begin{array}{l}\text { OXYOEN CONSCMED } \\
\text { PER GRAM HODY WEIGHT } \\
\text { PER } 24 \text { HOU NES }\end{array}$} \\
\hline & & & & & & \multicolumn{3}{|c|}{$\begin{array}{l}\text { Individual } \\
\text { determinations }\end{array}$} & $\begin{array}{c}\text { Aver- } \\
\text { age }\end{array}$ \\
\hline & hours & ${ }^{\circ} \mathrm{C}$. & co. & chio. & orams & $\begin{array}{c}c c \\
\text { oxygen }\end{array}$ & $\mid \begin{array}{c}c c . \\
\text { oxyoen. }\end{array}$ & $\left|\begin{array}{c}c c \\
\text { oxyoen }\end{array}\right|$ & oxyoen \\
\hline Mareh 2-4.. & 41.40 & $20.0-20.5$ & 4.59 & 0.790 & 0.0160 & 5.3 & 5.0 & 4.8 & 5.0 \\
\hline March $5-7$. & 45.00 & $20.0-20.2$ & 4.48 & 0.770 & 0.0149 & 4.8 & 4.8 & 4.8 & 4.8 \\
\hline Mareh $7-9$. & 47.30 & $\left\{\begin{array}{r}20.0-20.2 \\
(20.5)^{*}\end{array}\right.$ & 4.54 & 0.730 & 0.0136 & 5.1 & 4.5 & 4.9 & 4.8 \\
\hline March 9-11.. & 45.65 & $20.0-20.4$ & 4.56 & 0.740 & 0.0123 & 5.8 & 5.1 & 5.5 & 5.5 \\
\hline Mareh 12-14.. & 46.38 & $20.1-20.5$ & 4.65 & 0.610 & 0.0106 & 5.2 & 5.1 & 5.4 & 5.2 \\
\hline Mareh $14-16, \ldots$. & 46.16 & $20.0-20.5$ & 4.70 & 0.590 & 0.0096 & 5.8 & 5.5 & 5.4 & 5.6 \\
\hline March $16-18 \ldots .$. & 45.00 & $20.1-20.6$ & 4.68 & 0.550 & 0.0087 & 6.5 & 5.9 & 5.4 & 5.9 \\
\hline March 19-21.. & 42.90 & $20.0^{-}$ & 4.62 & 0.370 & 0.0076 & 5.2 & 5.0 & 4.1 & 4.8 \\
\hline March $21-29 \ldots$ & .. 191.09 & $20.0-20.5$ & 4.47 & 1.530 & 0.0062 & 6.0 & 5.3 & 5.1 & 5.4 \\
\hline
\end{tabular}

data for an experiment in regeneration and again the experimental worms showed individual fluctuations paralleling those of the control.

The experiment recorded in table 7 was the last and most complete series of continuous observations upon starvation. These worms, Planaria agilis, were starved for 7 days before the beginning of the experiment. Three determinations a week were made for six weeks 
TABLE 7

Showing uniform rate of oxygen consumption by Planaria agilis during starvation. Worms 16 to $17 \mathrm{~mm}$. long July $5 ; 5$ worms in each bottle; starving for 7 days preceding the first test and during the experiment. July 6 to $19,1 \mathrm{cc}$. thiosulphate = 0.1768 cc. oxygen at N.T.P. July 20 to August $16, t c c$, thiosulphate $=0.1751$ cc. oxygen at N.T.P. Worms weighed weekly, namely July $5,19,19,26$, August $2,9,16,22,31$ and September 6. See figures 2, 3, 6, 7 and 11. For further data on controls, see table 9

\begin{tabular}{|c|c|c|c|c|c|c|c|c|c|c|}
\hline (1) & (2) & (3) & (4) & (5) & (6) & (7) & (8) & (9) & (10) & (11) \\
\hline \multirow{3}{*}{ DATE OF TEST } & \multirow{3}{*}{ 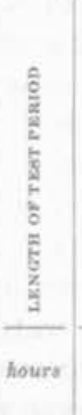 } & \multirow[b]{2}{*}{ 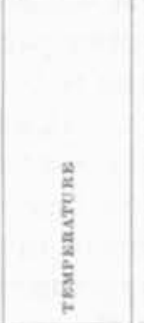 } & \multirow{2}{*}{ 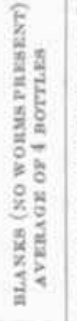 } & \multirow{2}{*}{ 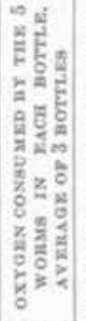 } & \multirow{2}{*}{ 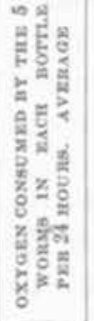 } & \multirow{2}{*}{ 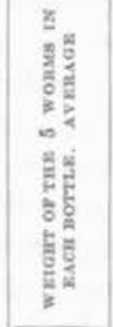 } & \multicolumn{4}{|c|}{ 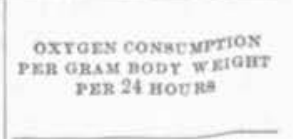 } \\
\hline & & & & & & & \multicolumn{3}{|c|}{$\begin{array}{c}\text { Individuni } \\
\text { determinations }\end{array}$} & $\begin{array}{l}8 \\
\frac{8}{4} \\
\frac{2}{4}\end{array}$ \\
\hline & & ${ }^{\circ} \mathrm{C}$ & ce. & $\begin{array}{l}\text { ce. } \\
\text { thio. }\end{array}$ & $\begin{array}{c}c c . \\
\text { oxyoen }\end{array}$ & orams & oxyoen & $\begin{array}{c}\text { ce. } \\
\text { exygen }\end{array}$ & oxpinen & $\begin{array}{l}\text { cc. } \\
\text { oxy- } \\
\text { gen }\end{array}$ \\
\hline July $6-8 \ldots \ldots$ & 45.15 & $22.0-20.0$ & 3.681 & 1.55 & 0.150 & 0.0401 & 3.7 & 3.8 & 3.8 & 3.7 \\
\hline July $8-10 \ldots$ & 43.08 & $20.0-19.6$ & 4.091 & 1.38 & 0.141 & 0.0387 & 3.5 & 3.6 & 3.8 & 3.6 \\
\hline July $10-12 \ldots$ & 45.25 & $20.4-19.9$ & 4.281 & $1.38 t$ & 0.134 & 0.0374 & 3.5 & 3.5 & 3.7 & 3.6 \\
\hline July $13-15 \ldots \ldots$ & 45.75 & $20.2-19.4$ & 3.961 & 1.26 & 0.121 & 0.0355 & 3.4 & 3.4 & 3.5 & 3.4 \\
\hline July $15-17 \ldots \ldots$ & 45.00 & $20.5-18.8$ & 3.851 & 1.20 & 0.116 & 0.0344 & 3.3 & 3.3 & 3.5 & 3.4 \\
\hline July $17-19 \ldots \ldots$ & 45.00 & $20.4-19.2$ & 3.81 & 1.146 & 0.111 & 0.0332 & 3.1 & 3.3 & 3.4 & 3.3 \\
\hline July $20-22, \ldots$ & 42.25 & $19.6-20.0$ & 3.79 & 1.01 & 0.104 & 0.0313 & 3.3 & 3.2 & 3.5 & 3.3 \\
\hline July $22-24 \ldots$ & 43.50 & $20.0-19.7$ & 3.801 & 1.02 & 0.108 & 0.0300 & 3.3 & 3.4 & 3.5 & 3.4 \\
\hline July $24-26 \ldots$. & 42.00 & $19.7-20.0$ & 3.63 & 0.92 & 0.095 & 0.0287 & 3.2 & 3.2 & 3.4 & 3.3 \\
\hline July $27-29 \ldots \ldots$ & 45.10 & $19.6-20.2$ & 3.79 & 0.93 & 0.089 & 0.0269 & 3.3 & 3.3 & 3.3 & 3.3 \\
\hline July $29-31 \ldots \ldots$ & 45.00 & $19.6-19.8$ & 3.55 & 0.87 & 0.084 & 0.0259 & 3.2 & 3.3 & 3.3 & 3.8 \\
\hline July 31 -August 2 & 43.00 & $19.8-$ & 3.96 & 0.84 & 0.085 & 0.0249 & 3.3 & 3.4 & 3.6 & 3.4 \\
\hline August $3-5 \ldots$. & 45.25 & $19.6-19.9$ & 3.92 & 0.82 & 0.079 & 0.0235 & 3.3 & 3.3 & 3.5 & 3.3 \\
\hline August $5-7 \ldots$ & 45.07 & $19.3-20.0$ & 3.79 & 0.79 & 0.076 & 0.0226 & 3.2 & 3.3 & 3.6 & 3.4 \\
\hline August $7-9 \ldots$. & 45.07 & $20.0-20.7$ & 3.98 & 0.83 & 0.080 & 0.0216 & 3.4 & 3.7 & 3.9 & 8.7 \\
\hline August $10-12 \ldots$ & 45.42 & $19.8-19.6$ & 3.73 & 0.71 & 0.067 & 0.0204 & 2.9 & 3.8 & 3.4 & 3.3 \\
\hline August $12-14 \ldots$. & 45.33 & & 3.84 & 0.68 & 0.065 & 0.0196 & 3.2 & 3.2 & 3.5 & 3.3 \\
\hline August $14-16 \ldots$. & 45.00 & $19.6-19.7$ & 4.02 & 0.66 & 0.063 & 0.0188 & 3.3 & 3.3 & 3.5 & 3.4 \\
\hline eptember $8-10$ & 45.27 & $20.0^{-}$ & 4.440 & 0. & 0.0 & 0. & 4.3 & 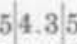 & 1 & 94.6 \\
\hline September $10-12$ & 45.00 & $20.4-20.0$ & 4.390 & $0.71^{*}$ & $0.068^{\circ}$ & $0.0151^{*}$ & 4.2 & 4 & 5.04 .8 & 84.5 \\
\hline September $12-14$ & 45.00 & $19.7-$ & 4.390 & $0.63^{\circ}$ & $0.060^{\circ}$ & $0.0144^{*}$ & 3.83. & 3.75 & 5.04 .4 & 44.8 \\
\hline
\end{tabular}

*Ten worms in eaeh bottle. 
without interruption. During this time the average consumption per 5 worms per 24 hours decreased from 0.150 to $0.063 \mathrm{cc}$. oxygen, i.e., to about 40 per cent of the original. The average weight fell, also, during this time from 0.0401 to 0.0188 gram per 5 worms. The fall in oxygen consumption followed very closely, therefore, the loss in weight. This is shown graphically in figure 3 where the average amounts of oxygen consumed are plotted along with the average weights. In general the two curves parallel each other but the curves of oxygen consumption show a greater initial decline, probably representing the remnant of the great fall in oxidations of the earliest stages of starvation due to residual food. When the oxygen consumption per gram weight is calculated, as in table 7 , column 11 , it is found to be practically constant at about 3.25 to $3.5 \mathrm{cc}$. after the first week. This is shown graphically in figure 7, where these worms served as the control for an experiment in feeding. The unusual rise on August 7 to 9, figure 7, was thought to be due to disturbing changes in the composition of the tap water. Similar irregularities have been noted in several experiments, under conditions which seem to point to the composition of the tap water as the cause. After an interruption of three weeks, the determinations of oxygen consumption were resumed. Since the worms had become very small, they were redistributed in the bottles and more individuals were added from reserve stock so as to make 10 in each bottle. These reserve worms had the same history as the others. The oxygen consumption per gram weight of body showed a marked rise over previous determinations. It averaged $4.6,4.5$ and 4.2 cc. per 24 hours in three tests. At the same time it was found that worms were beginning to die. They were very susceptible to injury in the manipulations of weighing and analysis. This interfered with continued observation of the rate of oxygen consumption and it was considered that the abnormal conditions of the worms at this time made the observed rise in oxidations of doubtful significance.

Regarding tables $4,5,6$ and 7 , it should be said that they are given in the order in which the experiments were performed. In the last experiment the procedure and manipulations were naturally better so that the results are more uniform. The last experiment was of longer duration, also, and the Planaria agilis, which were used in this case, were found generally more satisfactory for such experiments than Planaria maculata.

From all the above observations on starvation in Planaria, we conclude that the actual consumption of oxygen at constant temperature 
of $20^{\circ} \mathrm{C}$. falls continuously throughout the period of starvation, at first more rapidly, and later more slowly. The body weight also decreases continuously during starvation, figure 3 . On the other hand, the oxygen consumption per gram body weight (rate of oxidations) falls during a short period of the first few days of starvation, due probably to residual food, and then becomes uniform for a long period thereafter. During this long period of uniform rate of oxidations the worms may undergo reduction to one-half or less of their original weight. This

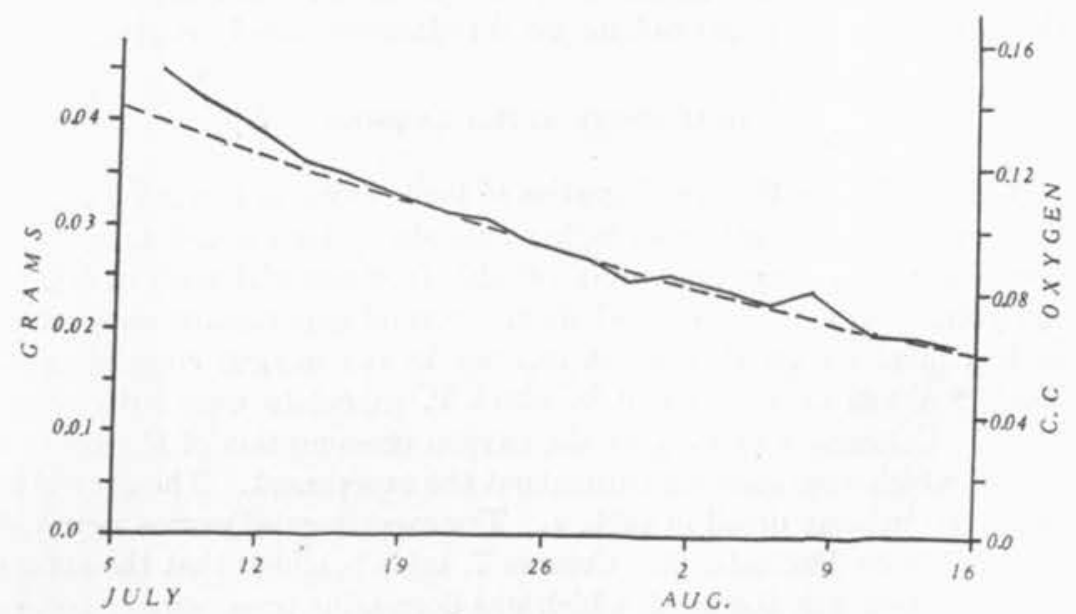

Fig. 3. Curves show decrease in oxygen consumption by Planaria agilis compared with decrease in weight during 6 weeks of starvation. Abscissas, time in weeks indicated by dates. Ordinates at the left, weight of 5 worms in grams. Ordinates at the right, oxygen consumption by 5 worms per 24 hours in cc. oxygen. Broken line represents average weight of three sets of worms weighed once a week. Solid line represents average oxygen consumption by the same three sets of worms, three tests made each week. See table 7 and figure 2 .

distinction between the early period of a few days of starvation, during which food reserves from the last feedings are effective in increasing oxygen consumption, and the later period of several weeks, during which the rate of oxidations is uniform, is very important. In the first place, the fact that the rate of oxidations is uniform during a long period of starvation (6 weeks) will serve as an important basis for the study of respiratory metabolism in these forms. In the second place, the fact that food reserves alter the respiratory metabolism for several days at the beginning of starvation makes this period unsuited for such studies. 
According to the experiments above and those in the following section on oxidations after feeding, this preliminary period during which food reserves alter the respiratory metabolism may last for a number of days in P. maculata and P. agilis. In any case before the "basal" or "standard metabolism" has been reached, the rate of oxidations is not a proper basis for comparisons.

The respiratory metabolism during extreme starvation, when the body has been reduced to a minute fraction of the original weight by starvation alone unaccompanied by fission, has not been studied, and the statements above are not intended to include such later stages.

\section{OXIDATIONS AFTER FEEDING}

It is well known that the ingestion of food results in increased oxidations and heat production in higher animals. Planaria can take in at one meal a very large amount of suitable food material, such as boiled egg yolk, clotted blood or beef liver. Several experiments show that such a meal results in a great increase in the oxygen consumption. Table 8 shows an experiment in which P. maculata were fed clotted blood. Columns 4 and 5 give the oxygen consumption of the control worms which were starving throughout the experiment. The control is described in more detail in table 4 . The experimental worms were fed blood clots on December 3. Column 7, table 8, shows that the actual amount of oxygen absorbed, which was decreasing progressively before feeding, doubled in the first test following the meal, then declined rapidly, and later more slowly. Figure 4 shows these relations. Column 8 , table 8 , shows that the worms ingested about 60 per cent of their own weight at this meal. When the rate of oxygen consumption per gram body weight was calculated as in column 12, it was found to rise suddenly from 6.7 to $9.6 \mathrm{cc}$. oxygen per gram weight and then to fall rapidly to its former level and to remain fairly constant as shown in figure 5. In this calculation the food in the digestive tract is included in the total body weight, thus making the rate of oxygen consumption appear less than its true value. If the weight of food is subtracted from the total body weight for the first test period following the meal, the rate of oxygen absorption per gram of empty body weight becomes 16.5 cc., as shown in table 8, column 12. Upon this basis of calculation, then, the ingestion of food resulted in an immediate increase in the rate of oxygen consumption of over 140 per cent. 
TABLE 8

Showing great increase in oxygen consumption by Planaria maculata after feeding clotted blood. Worms not fed for several weeks preceding the first test; 8 worms in each bottle. Experimental worms fed blood clots on December 3 . Control worms not fed. Weighed November 20, 27, December 1, 8, 4, 11, 18 and 25 . One cubic centimeter thiosulphate $=0.1766$ cc. oxygen at N.T.P. See figures 4 and 5 . For further data on controls, see table 4.

\begin{tabular}{|c|c|c|c|c|c|c|c|c|c|c|c|}
\hline (1) & (2) & (3) & (4) & (5) & (6) & (7) & (8) & (9) & (10) & (11) & (12) \\
\hline$\underline{\underline{3}}$ & & & \multicolumn{2}{|c|}{\begin{tabular}{|c|} 
CONTROL WORMG \\
9TARVING THROOEGH \\
WHOLE EXPERTMENT
\end{tabular}} & \multicolumn{7}{|c|}{ EXPERIMENT, WORMS FED BLOOD CLOTS DECEMBBER 3} \\
\hline \multirow[t]{2}{*}{ DATE OF TEET } & \multirow{2}{*}{ 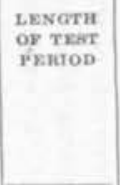 } & \multirow{2}{*}{$\begin{array}{l}\text { TEMPER- } \\
\text { ATURE }\end{array}$} & \multirow{2}{*}{$\begin{array}{c}\text { Oxygen } \\
\text { eonsumed } \\
\text { by the } 8 \\
\text { worms in } \\
\text { each bot- } \\
\text { tle per } 24 \\
\text { hours. } \\
\text { Average }\end{array}$} & \multirow{2}{*}{$\begin{array}{l}\text { Oxygen } \\
\text { consump- } \\
\text { tion per } \\
\text { gram } \\
\text { weight per } \\
24 \text { hours. } \\
\text { Average }\end{array}$} & \multirow{2}{*}{$\begin{array}{c}\text { Oxygen } \\
\text { consurned } \\
\text { by the } 8 \\
\text { worms in } \\
\text { each } \\
\text { bottle. } \\
\text { Average }\end{array}$} & \multirow{2}{*}{$\mid \begin{array}{c}\text { Oxygen } \\
\text { consumed } \\
\text { by the } 8 \\
\text { worms in } \\
\text { each bot- } \\
\text { tle per } 24 \\
\text { hours. } \\
\text { Average }\end{array}$} & \multirow{2}{*}{\begin{tabular}{|c|} 
Weight of \\
the 8 worms \\
in each bot- \\
tle. Average
\end{tabular}} & \multicolumn{4}{|c|}{$\begin{array}{l}\text { Oxygen consumption per gram body } \\
\text { weight per } 24 \text { hours }\end{array}$} \\
\hline & & & & & & & & Individu & dual determir & inations & Average \\
\hline & hours & ${ }^{\circ} \mathrm{C}$. & cc.oxygen & ec. oxyoen & ce. thio. & ce, oxygen & orams & ce. oxygen & |cc. oxyoen | & |cc. axyoen & cc. oxygen \\
\hline November $20-22$. & 46.17 & $19.8-20.3$ & 0.105 & 6.9 & 1.00 & 0.095 & 0.0155 & 6.1 & 6.3 & 5.9 & 6.1 \\
\hline November 24-26. & 48.00 & $20.0-20.6$ & 0.085 & 6.3 & 0.99 & 0.090 & 0.0135 & 6.5 & 7.8 & 5.9 & 6.7 \\
\hline \multirow[t]{3}{*}{ December $1-3 \ldots \ldots .}$. & \multirow[t]{3}{*}{45.92} & \multirow{3}{*}{$20.0-20.3$} & \multirow[t]{3}{*}{0.075} & \multirow[t]{3}{*}{7.0} & \multirow[t]{3}{*}{0.80} & 0.076 & 0.0113 & 6.8 & 7.0 & 6.4 & 6.7 \\
\hline & & & & & & \multicolumn{6}{|c|}{ Experimental worms fed blood elots December 3} \\
\hline & & & & & & & $0.0101)^{*}$ & $(15.7)^{*} \mid$ & $(15.7)^{*} \mid$ & $(17.7)^{*}$ & $(16.5)^{*}$ \\
\hline December 4-6.. & 46.15 & $20.0 \pm 0.1$ & 0.068 & 6.9 & 1.67 & 0.159 & 0.0165 & 9.3 & 9.6 & 9.8 & 9.6 \\
\hline December $6-8 \ldots$ & 46.13 & $20.0-20.5$ & 0.060 & 6.4 & 1.41 & 0.134 & 0.0153 & 9.0 & 9.3 & 8.1 & 8.7 \\
\hline December $8-10, \ldots$ & 46.00 & $19.8-20.1$ & 0.061 & 6.8 & 1.10 & 0.105 & 0.0141 & 7,6 & 7.9 & 7.0 & 7.4 \\
\hline December $11-13 \ldots$ & 46.17 & $20.1-20.3$ & 0.054 & 6.7 & 0.91 & 0.086 & 0.0126 & 6.9 & 7.4 & 6.4 & 6.8 \\
\hline December $13-15 \ldots$ & 46.25 & $20.0-20.2$ & 0.044 & 5.8 & 0.78 & 0.074 & 0.0118 & 6.1 & 6.4 & 6.3 & 6.2 \\
\hline December $15-17 \ldots$ & 46.05 & $20.0-20.3$ & 0.055 & 8.0 & 0.75 & 0.071 & 0.0110 & 6.9 & 6.9 & 5.9 & 6.5 \\
\hline December $18-20 \ldots$ & 46.17 & $20.0-20.3$ & 0.043 & 7.0 & 0.66 & 0.063 & 0.0099 & 6.4 & 7.4 & 5.6 & 6.3 \\
\hline December $20-22 \ldots$ & 46.05 & $20.3-18.7$ & 0.048 & 8.2 & 0.67 & 0.064 & 0.0093 & 6.8 & 7.8 & 6.2 & 6.8 \\
\hline December $22-24 \ldots \ldots$ & 51.23 & $|19.9-20.1|$ & 0.037 & 6.8 & 0.57 & 0.048 & 0.0085 & 5.8 & 6.1 & 5.4 & 5.7 \\
\hline
\end{tabular}

-Weight of ingested food subtracted from total body weight. 
Table 9 gives similar data for an experiment in which $\mathrm{P}$. agilis were fed beef liver. Data for the control worms, which were starving throughout the experiment, are given in columns 4 and 5 , and more fully in table 7 . After feeding upon liver, July 20 , the amount of oxygen absorbed by the experimental worms increased from 0.096 to $0.167 \mathrm{cc}$. per 5 worms per 24 hours, column 7 , table 9 . The body weight in-

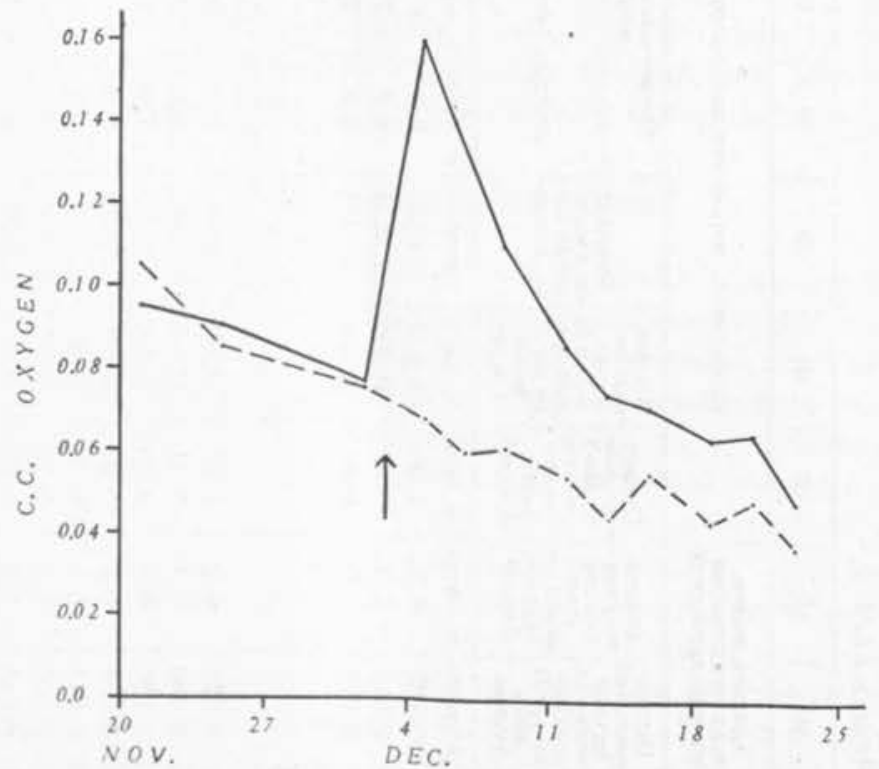

Fig. 4. Curves show decrease in oxygen consumption by starving Planaria maculata, and increase in oxygen consumption after feeding. Abseissas, time in weeks indicated by dates. Ordinates, ce. oxygen consumed by 8 worms in 24 hours. Broken line represents average of three sets of worms, starving throughout the experiment. Solid line represents average of three sets of worms, fed once on December 3. The arrow indicates when the experimental worms were fed. See table 8.

creased from 0.0276 to 0.0353 gram per 5 worms and the rate of oxygen consumption per gram, of total body weight, including the ingested food, increased from 3.5 to $4.7 \mathrm{cc}$., column 12 . Deducting the weight of food, the rate of oxygen consumption per gram of empty body weight becomes $6.4 \mathrm{cc}$. for the first test after feeding, an increase of over 80 per cent. These relations are shown graphically in figures 6 and 7 . Inspection of these curves shows that the oxidations rise suddenly with 
the taking in of food and decline rapidly during the next week or ten days to a constant level. In figure 6 , the curve of the absolute amount of oxygen consumed by the experimental worms ran parallel to the control for two weeks preceding the meal. After feeding, it rose sharply, then declined rapidly during the next 10 to 12 days, and then continued parallel with the control, but at a relatively higher position. This might indicate one of two things, either that the meal had resulted in a certain amount of growth so that the animals which were formerly smaller than the controls became slightly larger, or that the meal re-

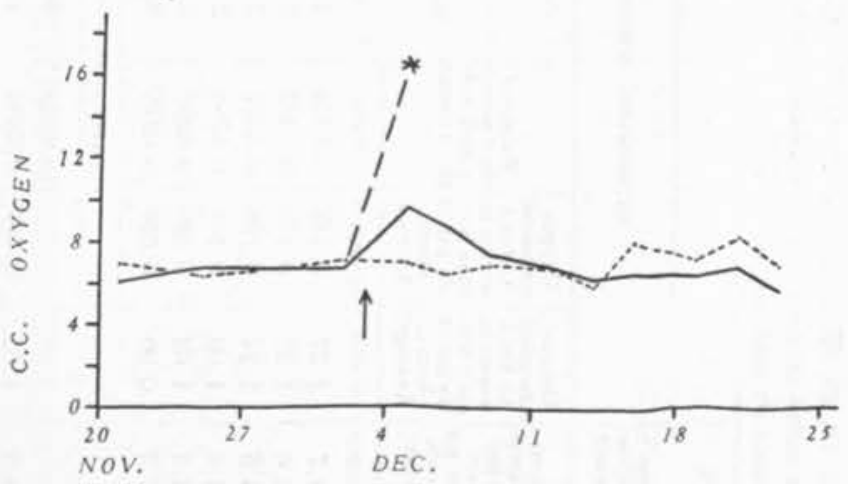

Fig. 5. Curves show practically constant rate of oxygen consumption by Planaria maculata during starvation and increase in rate of oxygen consumption after feeding. Abseissas represent time in weeks indicated by dates. Ordinates represent rate of oxygen consumption in ec. of oxygen per gram total body weight per 24 hours. Broken line represents the average of three sets of worms starving throughout the experiment. Solid line represents the average of three sets of worms fed once on December 3 (time of feeding indicated by the arrow). * represents the rate of oxygen consumption by fed worms in $c c$. oxygen per gram empty body weight (weight of body if no food had been ingested) per 24 hours. See table 8 and figure 4 .

sulted in a permanent increase in the speed of oxidations. Figure 7 and tables 9 and 7 indicate that the former interpretation is correct. A comparison of the average weights given in table 9 , column 8 , and table 7 , column 7 , shows that the experimental worms did weigh less than the control worms during the two weeks before the feeding, but that after feeding they did not become reduced ag $\imath^{\text {in }}$ to the weight of the controls. Moreover, figure 7 shows that after August 1 the rate

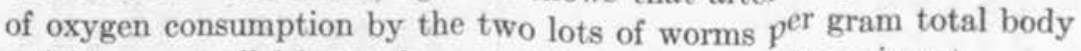
weight ran parallel for 15 days, or till the end of the experiment. 
Shoving marked increase in the oxygen consumption by Planaria agilis after feeding beefliver. Worms 15 to $16 \mathrm{~mm}$. long July 5 ; without food for 7 days preceding the first lest; 5 worms in each bottle. Experimental worms fed beef liver July 20 . Control worms not fed. Weighed weekly, namely July 5, 8, 12,19, 20, 26, August 2, 9 and 16. One cubic centimeter thiosulphate $=0.1768 \mathrm{cc}$. oxygen at N.T.P. from July 6 to 19 . One cubic centimeter thiosulphate $=0.1751 \mathrm{cc}$. oxygen at N.T.P. from July 20 to August 16 . See figures 6 and 7 . For further data on controls, see table 7 .

\begin{tabular}{|c|c|c|c|c|c|c|c|c|c|c|c|}
\hline (1) & (2) & (3) & (4) & (5) & (6) & (7) & (8) & (9) & (10) & (11) & (12) \\
\hline \multirow{3}{*}{ DATE OY TEST } & \multirow{3}{*}{$\begin{array}{l}\text { LENCTH } \\
\text { OYTEST } \\
\text { PERIOD }\end{array}$} & \multirow{3}{*}{$\begin{array}{l}\text { TEMPER- } \\
\text { ATUBE }\end{array}$} & \multicolumn{2}{|c|}{$\begin{array}{c}\text { CONTHOL WOAMs } \\
\text { STARVVNG THROUGH } \\
\text { WHOLE EXPERTMENT }\end{array}$} & \multicolumn{3}{|c|}{ EXPERTMENT. } & \multicolumn{3}{|c|}{ WORMS VED BEEY LIVER JULY 20} & \\
\hline & & & $\begin{array}{c}\text { Oxygen } \\
\text { consumed } \\
\text { by the } 5 \\
\text { worms in }\end{array}$ & $\left|\begin{array}{c}\text { Oxygen } \\
\text { eonsump } \\
\text { tion per }\end{array}\right|$ & $\mid \begin{array}{c}\text { Oxygen } \\
\text { consumed } \\
\text { by the } 5 \\
\text { worms in }\end{array}$ & $\mid \begin{array}{c}\text { Oxygen } \\
\text { consumed } \\
\text { by the s } \\
\text { worms in }\end{array}$ & $\begin{array}{c}\text { Weight of } \\
\text { the } 5 \text { worma }\end{array}$ & \multicolumn{4}{|c|}{$\begin{array}{l}\text { Oxygen consumption per gram body } \\
\text { weight per } 24 \text { hours }\end{array}$} \\
\hline & & & $\begin{array}{l}\text { each bot- } \\
\text { tle per } 24 \\
\text { hours. } \\
\text { A verage }\end{array}$ & $\begin{array}{c}\text { weight per } \\
\text { 24 hours. } \\
\text { Average }\end{array}$ & $\begin{array}{l}\text { each bot- } \\
\text { tlo per } 24 \\
\text { hours. } \\
\text { Average. }\end{array}$ & $\begin{array}{l}\text { each bot- } \\
\text { tle per } 24 \\
\text { bours. } \\
\text { Average }\end{array}$ & $\begin{array}{l}\text { in each bot- } \\
\text { tle. Average }\end{array}$ & \multicolumn{3}{|c|}{ Individual determinations } & Average \\
\hline 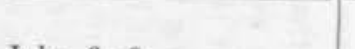 & hours & ${ }^{\circ} \mathrm{C}$. & ec. oxpoen & cc. oxyoen & ce. thio. & ce. oxygen & grams & cc, oxygen & ec. oxpoen & ec. oxyoen & cc. oxyoen \\
\hline July $6-8 \ldots \ldots \ldots \ldots$ & 45.15 & $22.0-20.0$ & 0.150 & 3.7 & 1.37 & 0.133 & 0.0346 & 3.9 & 3.9 & 3.7 & 3.8 \\
\hline July $8-10 \ldots$. & 43.08 & $20.0-19.6$ & 0.141 & 3.6 & 1.22 & 0.124 & 0.0332 & 3.7 & 3.9 & 3.7 & 3.7 \\
\hline July $10-12 \ldots \ldots \ldots \ldots$ & 45.25 & $20.4-19.9$ & 0.134 & 3.6 & 1.24 & 0.120 & 0.0317 & 3.9 & 3.8 & 3.7 & 3.8 \\
\hline July $13-15, \ldots \ldots \ldots \ldots$ & 45.75 & $20.2-19.4$ & 0.121 & 3.4 & 1.09 & 0.105 & 0.0298 & 3.6 & 3.4 & 3.4 & 3.5 \\
\hline July $15-17 \ldots \ldots \ldots \ldots$ & 45.00 & $20.5-18.8$ & 0.116 & 3.4 & 1.03 & 0.099 & 0.0887 & 3.4 & 3.5 & 3.5 & 3.5 \\
\hline \multirow[t]{2}{*}{ July $17-19 \ldots \ldots \ldots \ldots \ldots$} & 45.00 & $20.4-19.2$ & 0.111 & 3.3 & 0.99 & 0.096 & 0.0276 & 3.5 & 3.4 & 3.5 & 3.5 \\
\hline & & & & & & \multicolumn{6}{|c|}{ Experimentul worms fed beef liver July 20} \\
\hline & & & & & & & $(0.0259)^{*} \mid$ & $(6.4)^{*}$ & $(6.1)^{*}$ & $(6.7)^{*}$ & $(6.4)^{*}$ \\
\hline $\begin{array}{l}\text { July } 20-22, \ldots \ldots \\
\text { July } 22-24\end{array}$ & 42.25 & $19.6-20.0$ & 0.104 & 3.3 & 1.62 & 0.167 & 0.0353 & 4.8 & 4.5 & 4.9 & 4.7 \\
\hline July $22-24 \ldots \ldots \ldots$ & 43.50 & $20.0-19.7$ & 0.102 & 3.4 & 1.37 & 0.137 & 0.0298 & 4.7 & 4.2 & 4.9 & 4.6 \\
\hline July $24-26 \ldots \ldots \ldots$ & 42.00 & $19.7-20.0$ & 0.095 & 3.3 & 1.15 & 0.118 & 0.0289 & 4.2 & 4.0 & 4.1 & 4.1 \\
\hline July $27-29 \ldots \ldots \ldots \ldots$ & 45.10 & $19.6-20.2$ & 0.089 & 3.3 & 1.06 & 0.102 & 0.0273 & 3.8 & 3.7 & 3.8 & 8.7 \\
\hline
\end{tabular}




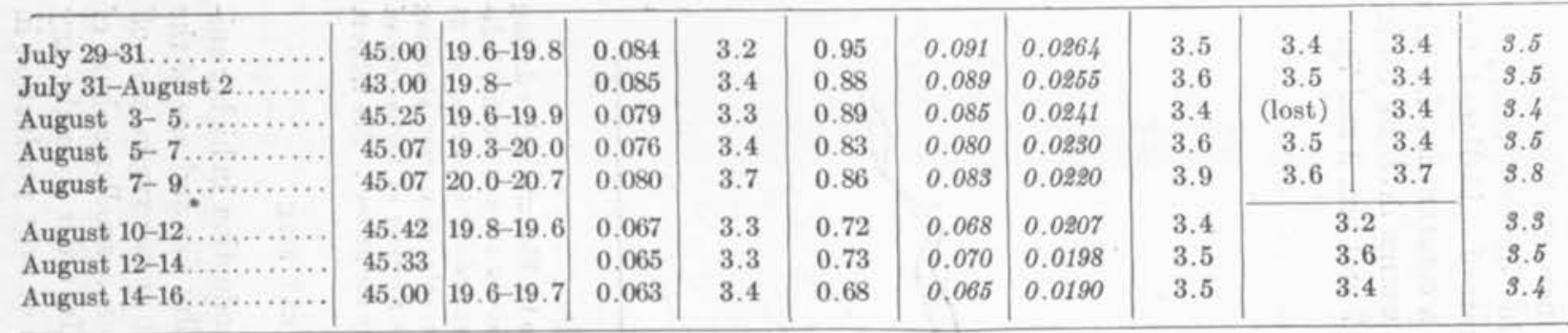

- Weight of ingested food substracted from body weight. 
It is evident, therefore, that a single feeding increases the oxidations in Planaria by 80 to 140 per cent and that this increase disappears during the first 10 to 12 days of starvation, the rate of oxidations falling sharply at first and then more slowly to reach a constant level. This result explains why the oxidations in well-fed worms decrease during the first stages of starvation (see expers. 2 and 7 and figs. 3 and 7 ).

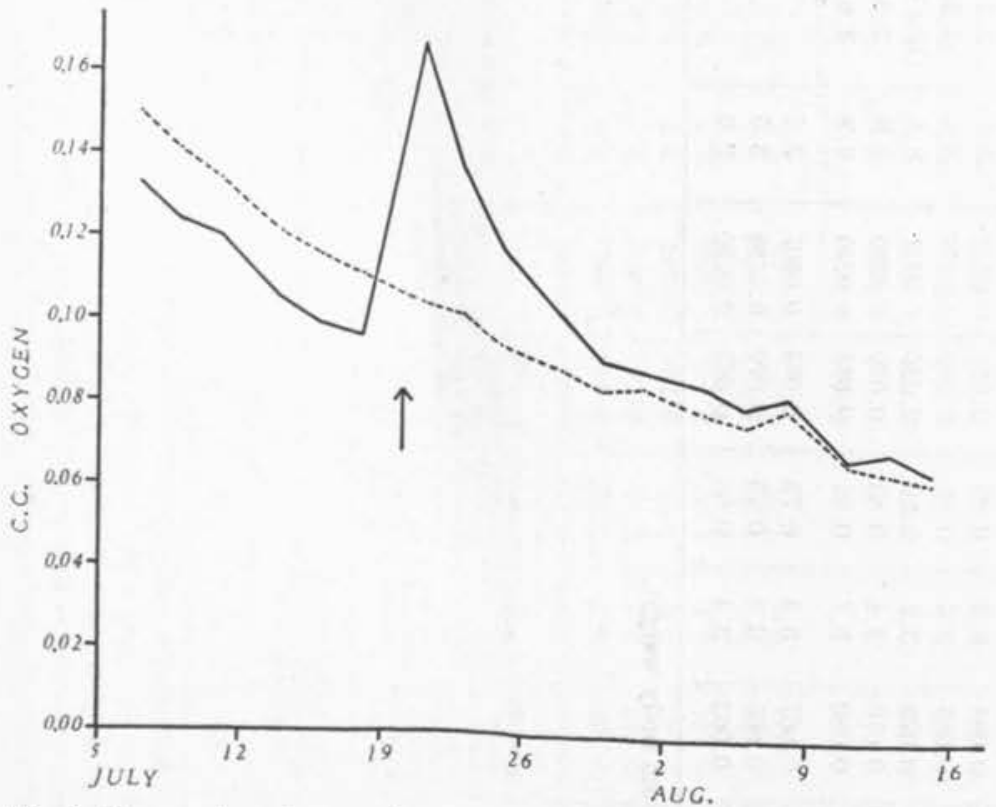

Fig. 6. Curves show decrease in oxygen consumption by Planaria agilis during starvation and increase after feeding. Abscissas represent time in weeks, indieated by dates. Ordinates represent ec, oxygen consumed by 5 worms per 24 hours. Broken line represents the average of three sets of worms starving throughout the experiment. Solid line represents the average of three sets of worms fed once on July 20 (time of feeding indieated by the arrow). See table 9 .

\section{OXIDATIONS IN WORMS OF DIFFERENT SIZE}

The rate of respiratory metabolism or heat production in higher animals is commonly said to decrease with increasing size and age of the body. It is obvious that a larger animal will use more oxygen, give off more carbon dioxide and liberate more heat than a smaller animal of the same species under the same conditions. In order to make any comparison of the rates of respiratory exchange or heat production in 
the two animals, it is necessary to calculate the respiratory metabolism with reference to some common basis such as a unit of weight or surface area. It is understood that such comparisons should be made under standard conditions of $a$, fasting; $b$, uniform temperature; and $c$, muscular rest. But it should be distinctly kept in mind that when animals of different size and age are compared in this way a difference in the rates of respiratory metabolism may or may not mean that comparable

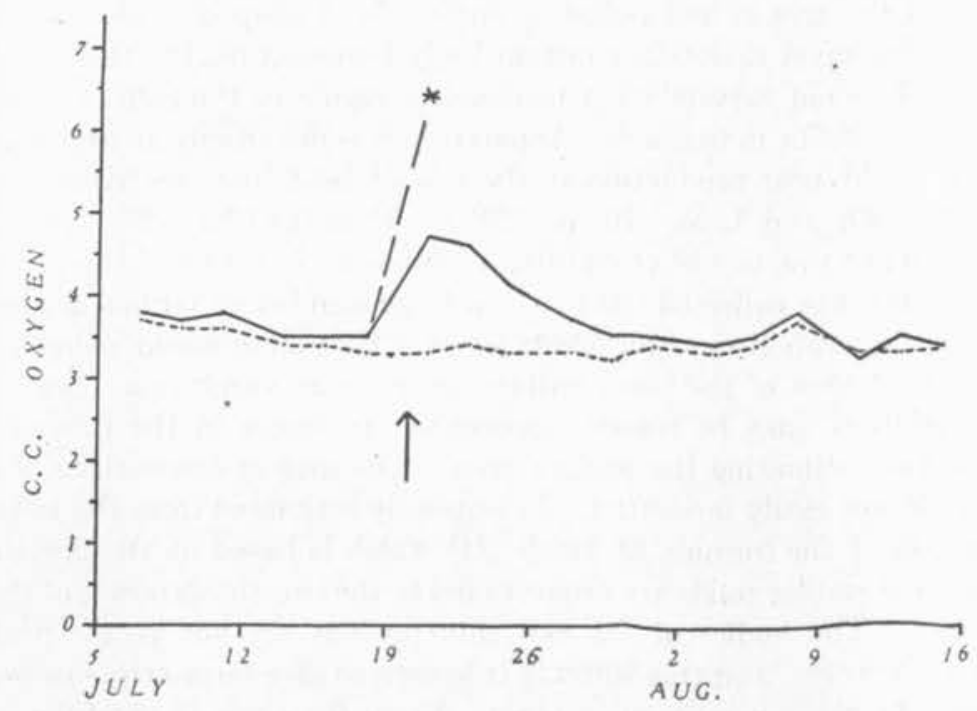

Fig. 7. Curves show constant rate of oxygen consumption by Planaria agilis during starvation and increase in rate of oxygen consumption after feeding. Abscissas represent time in weeks, indicated by dates. Ordinates represent rate of oxygen consumption in cc. oxygen per gram total body weight per 24 hours. Broken line represents the average of three sets of worms starving throughout the experiment. The solid line represents the average of three sets of worms fed once on July 20 (time of feeding indicated by the arrow). * represents the rate of oxygen consumption by the fed worms in cc. oxygen per gram empty body weight (weight of body if no food had been ingested) per 24 hours. See table 9 and figure 6 .

cells in the two animals have inherently different rates of oxidation. Different opinions are held regarding the cellular rates of oxidation in these cases (see Benedict, 22). The observation is merely that the total amounts of heat produced are not proportional to the weights or surface areas of the animals.

It is well known that among warm-blood animals the smaller animal produces more heat in proportion to its weight than the larger individual. 
Various authors since Rubner (21) have presented evidence that the respiratory metabolism of warm-blooded animals, at least, is proportional to the area of the surface of the body. The respiratory metabolism is often calculated per unit of body surface with the idea of eliminating size differences when other factors are being compared. Why the heat production should be proportional to the area of the skin is not entirely clear. In a general way, the proportionality between the rate of heat production and the area of the radiating surface is of adaptive value to animals which must maintain constant body temperature, but this consideration does not explain what mechanism regulates the rate of energy production in the individual. Apparently it is not simply an accommodation of the heat production to the rate of heat loss (see Krogh (13, pp. 133-140) and Lusk (10, p. 120)). Benedict (22), (23) has objected to the practice of computing metabolism in terms of the unit of surface and has collected data from a large number of normal controls in human metabolism experiments to show that metabolism, calculated per unit of area of the body surface, gives large variations. Some of the variation, may be traced, apparently, to errors in the prevailing method of estimating the surface area. The area of the surface of an animal is not easily measured. It is usually estimated from the weight by means of the formula of Meeh (24) which is based on the law that surfaces of similar solids are proportional to the two-thirds power of their volumes. The bodies of fat and thin persons are not geometrically similar, however, and this formula is known to give large errors in computing the skin areas in such cases. Upon the basis of careful measurements of the areas of the skin of individuals of very different proportions, Du Bois and Du Bois (25), (26), have derived a "linear" and a "height-weight" formula which give the surface area with a maximum error of only 5 per cent in contrast with the average error of 16 per cent and a maximum error of 36 per cent with the Meeh formula. The metabolism seems to be more nearly proportional to the skin area as computed with the new formula than with the older one (27). Among adult mammals, then, the individual of smaller size produces more heat in proportion to its weight than the larger individual, and whatever may be the reason, the amount of the difference seems to be in accordance with the "surface law." This is true of the persons of the same age.

When individuals of different ages are compared, the difference in the rate of heat production per unit of weight does not seem to follow the surface law so closely. The rate of heat production per square meter of surface is higher in youth and lower in old age than in middle life (28), 
(29), (27) and (10, p. 128). On the other hand the metabolism of infants per square meter is less than that of older children. That of babies in the first month of life is lowest $(12$, p. 117); (30), (31), (32), (29, charts 1 to 3 ). But Bohr's (33) measurements of the respiratory exchanges of pregnant guinea pigs with circulation through the umbilical cord suspended, indicate a rate of oxidations in the embryo per unit of weight not far different from that of the parent. Bohr and Hasselbalch (34) found that the carbon dioxide production by the developing chick embryo from the ninth to the eighteenth days was closely proportional to the weight of the embryo. These observations upon infants and embryos serve to emphasize the fact that the interpretation of differences in rate of respiratory metabolism in warm-blooded animals in relation to size and age, whether calculated per unit of surface or of weight, involves questions of the constitution and functional conditions of the body. While the metabolism studies on warm-blooded animals are commonly cited to show that the rate of oxidations is higher in animals of smaller size and in younger animals, as a matter of fact the warm blooded animals are very unsuited to the critical study of these questions.

Turning to the cold-blooded animals, observations on the rate of respiratory metabolism in relation to size and age are very inadequate. It may be noted at the outset that there is no reason for supposing that metabolism in these animals, of widely different structural organization, should follow the "surface law." It has been shown definitely by Morgulis (36) that this relationship does not exist in the flounder. $\mathrm{He}$ finds, rather, that as size of the body increases, the oxygen consumption per unit of body surface increases, and that per unit of body weight decreases, while after removal of the fins the oxygen consumption is proportional to the mass. Buytendijk (quoted by Montuori $(35$, p. 216) ) and Montuori $(35$, p. 216) both report that Scyllium of smaller size consume more oxygen per kilogram hour than those of larger size.

Observations on the rate of respiratory metabolism in invertebrates in relation to size and age are conflicting but this may be due to unsatisfactory experimental methods. Buytendijk (as quoted by Montuori (35, p. 216)) measured the oxygen consumption by Scorpaena, Octopus and Echinus in relation to body size, and Montuori (35) attempted a survey of these relations in 80 different kinds of marine animals belonging to the coelenterates, echinoderms, worms, crustaceans and fish. In the determinations on some species, the oxygen consump- 
tion per unit of weight was greater in the animals of smaller size than in those of larger size. In other series the reverse relationship was recorded, and in still other series the results were highly variable. These results may mean that standard conditions were not maintained in all cases, that the individuals compared were not strictly comparable or that in some cases the forms chosen were unsuited in behavior and respiratory habits to the solution of the question. Each species would require more critical individual study to determine the reasons for the irregularities. The conclusion of Montuori that "the consumption of oxygen, calculated per unit of weight, is, in general, absolutely independent of the dimensions of the animal," hardly seems justified from such highly variable determinations. The subject requires much more careful quantitative work under more definitely controlled conditions than has hitherto been done, before any conclusions of general application can be drawn. Some forms of animals, beeause of ineonstant behavior, are quite unsuited as experimental material.

Careful measurements of the rate of respiratory metabolism per unit of weight in lower cold-blooded animals have indicated, however, that there is a decrease in rate of oxidations as the size of the body increases. Bounhiol (37) found this relationship in the oxygen consumption of annelids of different size, and Miss Wolf, in this laboratory, has found it in the leech, erayfish, branchipus, May-fly nymph and Stonefly nymph, under very conclusive experimental conditions. The number of determinations, made by the writer, of the rate of oxygen consumption by Planaria in various kinds of experiments, makes it certain that consistent results can be obtained for this form with the methods used. Various incidental observations in the course of these experiments point to the fact that smaller worms absorb more oxygen in proportion to their weight than larger worms, and the following systematic experiments show it very clearly.

Table 10 gives comparative measurements of the oxygen consumption by $\mathrm{P}$. agilis of five different sizes. Planaria differ considerably in body proportions, the region posterior to the pharynx being much longer in some individuals than in others. To make worms as nearly uniform as possible, all except the smallest, set I, were cut at the plane of normal fission, a short distance posterior to the mouth. This was done 21 days before the determinations of oxygen consumption were made. All worms were without food for 22 days previous to the experiment. At the time of the respiration test, the worms of set I averaged $6.08 \mathrm{~mm}$. in length, worms of set II, $8.4 \mathrm{~mm}$., those of set III,11.8, 
TABLE 10

Showing decrease in the rate of oxygen consumption by Planaria agilis with increase in size of the body. Worms starving for 22 days preceding the experiment and during the experiment. Tails removed at the fission plane 21 days before the experiment of all sets except set 1 , the smallest worms. Test period of 24 hours' duration. Temperature $19.6^{\circ} \mathrm{C} . \pm 0.01$. Capacity of bottles $130 \mathrm{cc}$. Correction for $4 \mathrm{cc}$. of water displayed by rods and reagents, multiply by 1.032. One cubic centimeter thiosulphate $=0.1738 \mathrm{cc}$. oxygen at N.T.P. Worms weighed 6 hours after the test. See figure 8

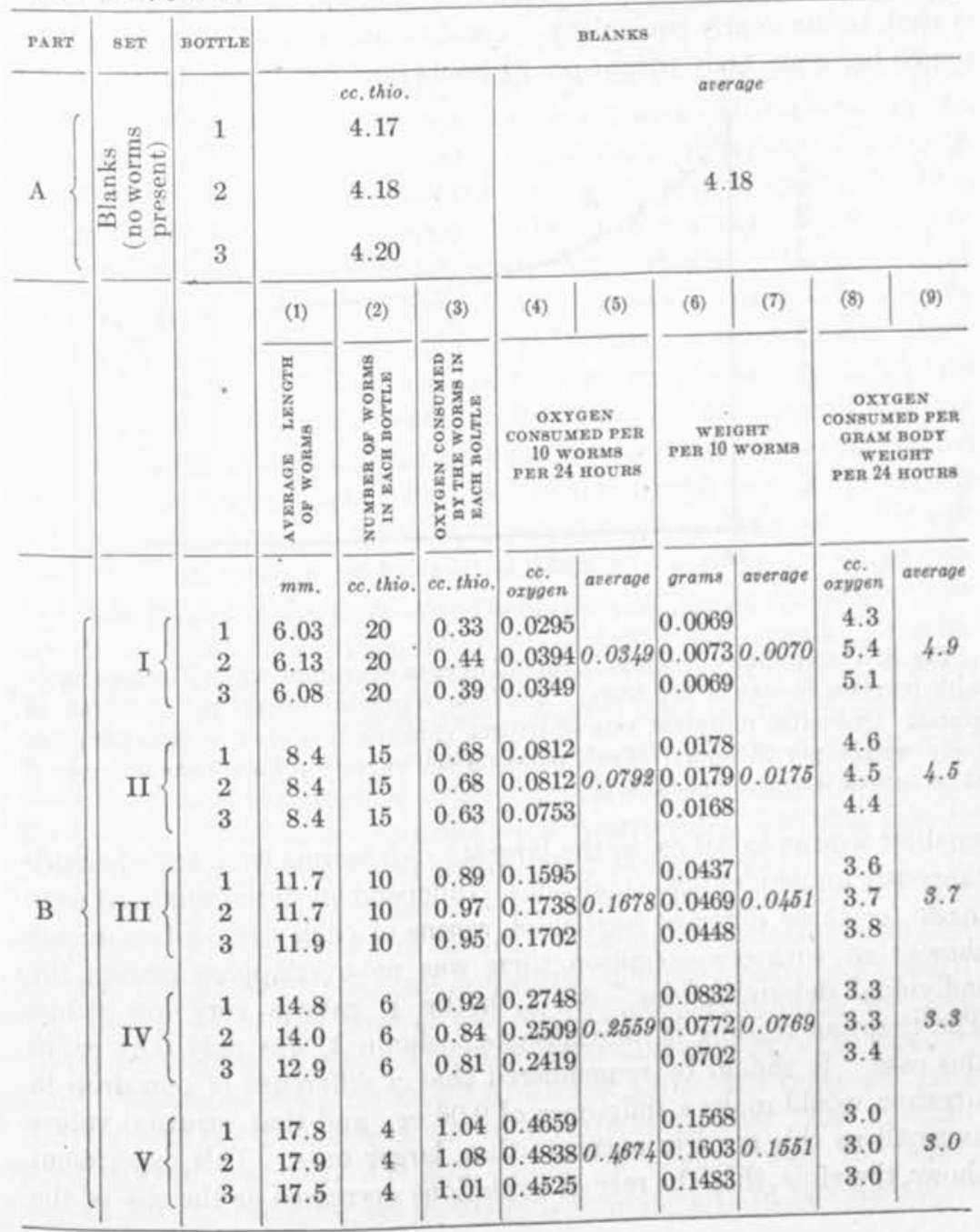


those of a set IV, $13.9 \mathrm{~mm}$. and those of set V, $17.7 \mathrm{~mm}$., as shown in column 1. Length, however, is no satisfactory measure of size even though precautions are taken, as described above, to make the worms as nearly comparable as possible in body proportions. The weights, as given in columns 6 and 7 , ranged from 0.0070 to 0.1551 gram per 10 worms. The largest weighed twenty-two times as much as the smallest. Because of this great difference in size, the number of individuals in each bottle was varied so as to make the amounts of oxygen absorbed in each bottle nearly equivalent. The average amount of oxygen consumed per gram body weight per 24 hours decreased from $4.9 \mathrm{cc}$. in the

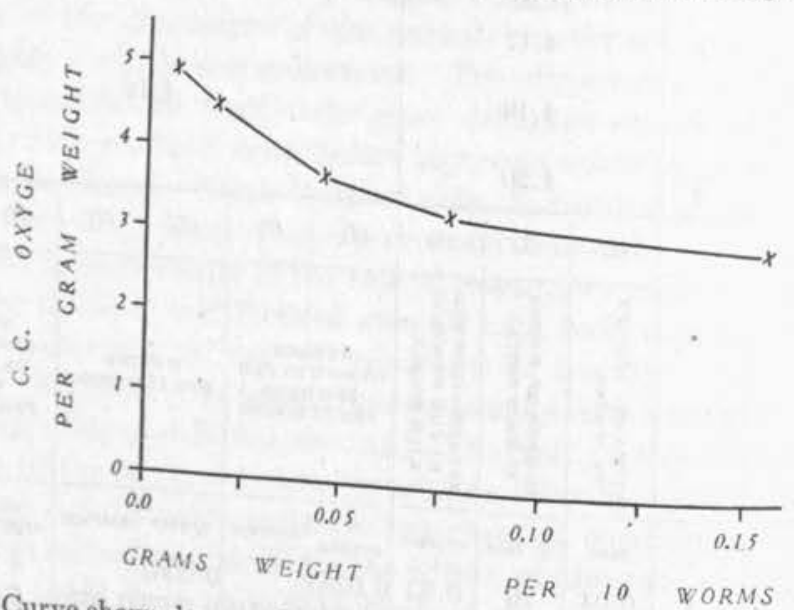

Fig. 8. Curve shows decrease in rate of oxygen consumption by Planaria agilis grams. Ordinates represent body. Abscissas represent weight per 10 worms in body weight per 24 hours. Each oxygen consumption in cc. oxygen per gram three sets of worms. See table 10 . point on the curve represents the average of

smallest worms to $3.0 \mathrm{ce}$. in the largest. All worms were tested simulmade for three different conditions. Independent determinations were shows that, with one exception, of worms of each size, and column 8 individual determinations. Set there was no overlapping among the The titration reading of thiot I, bottle 1 , gave a very low value. this case. It should be remosulphate, column 3 , was only $0.33 \mathrm{cc}$. in titration would make a differemered that a difference of one drop in as small as this are less shows, therefore, that the rate than larger ones. This experiment 
worms inereased. These results are shown in figure 8 where the amount of oxygen consumed per gram body weight per 24 hours at $20^{\circ} \mathrm{C}$. is plotted against body weight per 10 worms. This curve shows at a glance that the rate of oxidations decreases with increasing size, and that the decrease in oxidations is not directly proportional to the increase in weight. Among smaller worms, these differences are greater than among larger worms. Most of the difference was between worms less than 0.08 gram weight per 10 individuals. Worms of twice that size showed little further decrease in their oxidations.

It might be thought that the differences in the rates of oxidations among Planaria of different sizes, recorded in table 10, might be due to differences in activity. Was there a graduated difference in activity among the worms of different sizes during the respiration test? This question was tested by removing the heads of worms of different sizes so as to eliminate practically all locomotion. Worms of three different sizes were used, table 11. Those of each size were divided into two sets of three bottles each. A control test was made in which all worms were uncut and normal. Columns 5 and 6 show that, in each case, the two sets of worms of the same size had the same rate of oxygen consumption, and that the differences between the different sizes confirm the previous experiment, table 10. Before the second test, table 11, the heads were removed from the worms in one set of each size. In this test the normal worms, column 10 , duplicated the rates of oxygen consumption given in the previous control test, while the headless worms in each case used less oxygen, 85 to 90 per cent of the normal. In somparing the headless worms of the three sizes, however, the size differences remain. The headless small worms used $3.9 \mathrm{cc}$. of oxygen per gram weight per 24 hours, the medium-sized worms, $3.3 \mathrm{cc}$, and the large worms, $2.8 \mathrm{cc}$. We conclude, therefore, that the rate of oxidations in Planaria decreases with increasing total body weight, and that this decrease is not accounted for by difference in locomotion.

The worms of sets II, III and V of table 10 were used as sets II a, III a and V a, respectively, of table 11. Since the worms were weighed for each test, these experiments constitute, in reality, three independent determinations of the normal rate of oxygen consumption by these worms, in relation to size. The three determinations gave the same results. The smaller worms used $4.5,4.5$ and $4.6 \mathrm{cc}$. of oxygen per gram body weight per 24 hours in the three determinations. The mediumsized worms used $3.7,3.6$ and 3.7 ec. of oxygen, and the larger worms $3.0,3.1$ and $3.1 \mathrm{cc}$. of oxygen, respectively, in the successive determinations. 
Showing that the difference in rate of oxygen consumption by Planaria agilis of different size is not due to differences in locomotion. Worms starving for 27 days preceding the experiment and during the experiment. Tails removed at the fission plane 26 days before the experiment. Worms of sets $I I, I I I$ and V are of the same sizes as sets II, III and V respectively of table 10 . Duration of first test period 24.08 hours, of second test period 24 hours. Worms weighed the day before each test. Just before the beginning of the second test the heads were cut from the worms of sets $I b, I I b$, and IIIb. Worms of sets Ia, IIa and IIIa were not cut. Temperature $19,8 \mathrm{C} . \pm 0.1$. One cubic centimeter thisosulphate $=0.1738$ cc. oxygen at $N . T . P$.

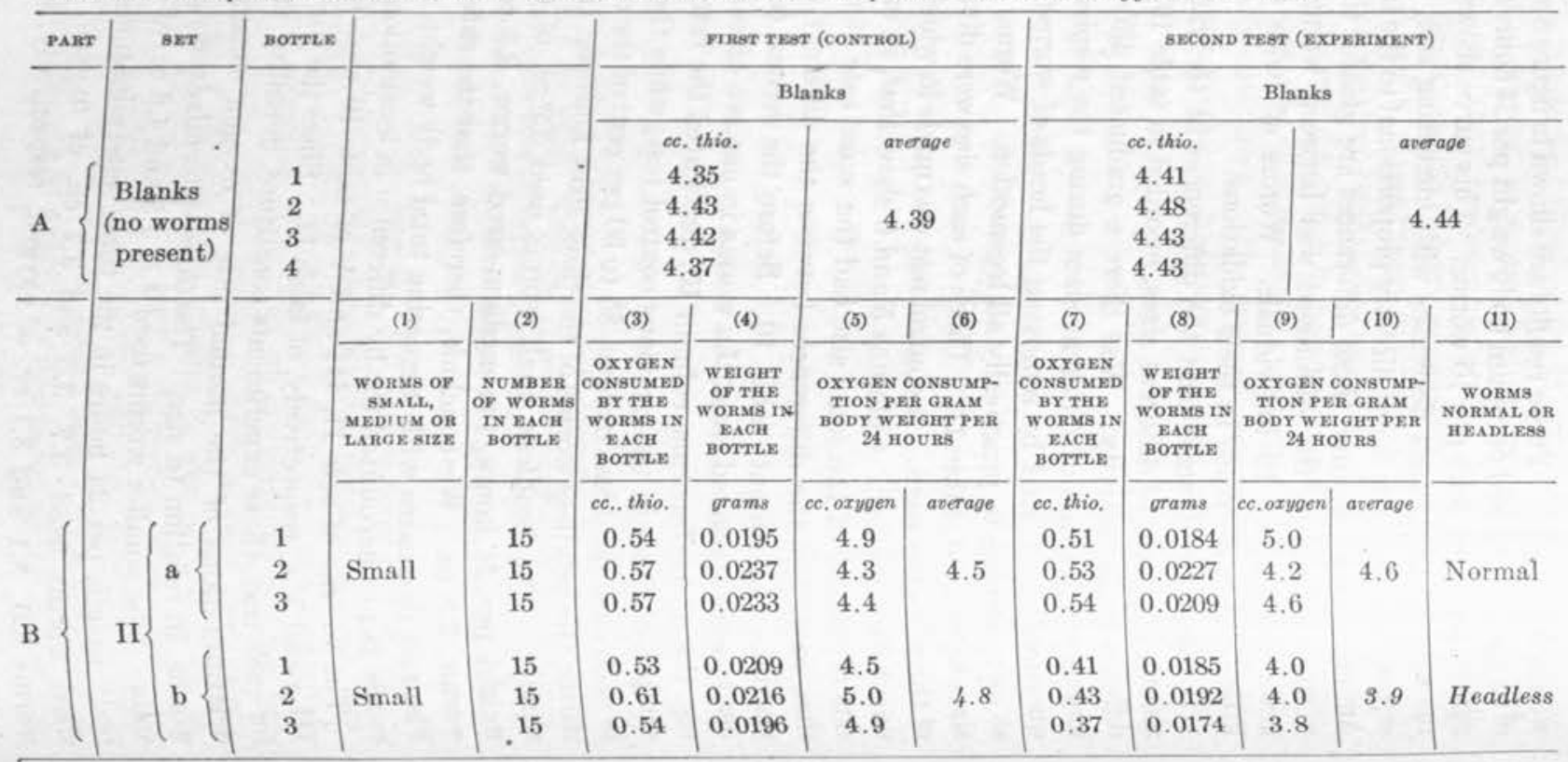




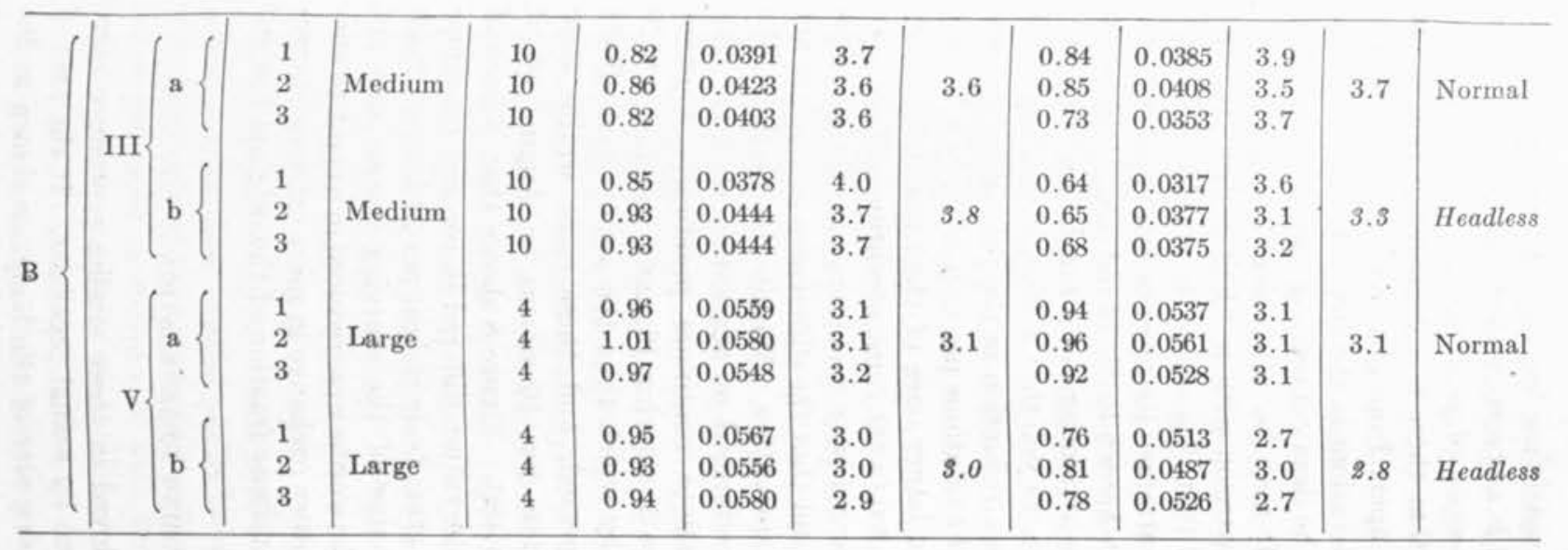


While it is clear that larger Planaria use less oxygen in proportion to their weight than smaller ones, it is not certain that this difference is to be associated with age or senescence of protoplasm. In the case of man, it is commonly supposed that there is a decrease in the rate of oxidations, associated with age, apart from changes in the oxidations which may be associated with alterations in the size of the body. Such a distinction is not apparent in the data concerning the rate of respiratory metabolism in Planaria. It may be convenient to call a "fullgrown" Planarian "old" in comparison with a "half-grown" individual, but it should be remembered that Planaria of the species dealt with in this discussion, after they have attained the more or less variable maximum size for the species, are not known to die of old age. Old age in man is not synonymous with the attainment of a maximum ("adult") body size. We have no evidence, as yet, that a Planarian of constant size becomes senescent or suffers a reduction in the rate of oxidations.

The statement that the rate of oxidations per unit of body weight is higher in small Planaria than in larger ones of the same species, assumes that the worms are compared in the same condition of nutrition, namely that they have been starved long enough to pass the accelerative effects of previous feedings, and that the differences in size are not due to differences in length of starvation. Within the limits of the experiments which have been performed on starvation we have concluded that the rate of oxidations continues practically constant after the early stages. In figure 3 , starving Planaria weighed 0.0720 gram per 10 worms on July 12 , by which time the accelerative effects of previous feeding had disappeared, and these same worms were reduced in weight to 0.0360 gram per 10 worms on August 16 at the end of the last respiration test. Figure 8 shows that worms of these two weights and of equal starvation differed in oxygen consumption by about $0.5 \mathrm{cc}$. oxygen per gram body weight per 24 hours. Such a change in the respiratory exchange of the starving worms was not found (see fig. 7). In this case the worms were reduced in weight to onehalf of the original. The respiratory exchange in more extreme starvation, with reduction in size to a minute fraction of the original has not been studied.

\section{OXIDATIONS DURING REGENERATION}

The species of Planaria employed in these studies reproduce more commonly by agamic fission than by sexual processes. If the rate of oxidations decreases with increasing size of the body, as shown in the 
preceding section, then it follows that it should increase with regeneration of small pieces of large worms into complete small worms. Natural fission results in two pieces of very unequal size and character. The anterior piece is much larger and retains the old head and body as far back as a level just posterior to the mouth. After regeneration it is essentially the original parent with a shorter tail but with little change in other proportions. On the other hand, the posterior piece is much smaller and undergoes profound reorganization into an animal with head and body of smaller proportions. Experiments show that the posterior piece undergoes considerable increase in rate of oxidations during regeneration while the anterior piece retains the original rate of oxidations of the parent practically unchanged.

Table 12 records the results of a preliminary experiment in which $\mathrm{P}$. maculata were cut at the normal fission plane and allowed to regenerate, the oxygen consumption of the anterior pieces, the posterior pieces and uncut control worms being followed for 24 days after the operation. Column 4 gives the oxygen consumption by the normal controls (see also table 5). In column 11 the average rate of oxygen consumption by the anterior pieces is seen to be almost equal to that of the normal controls throughout the period of regeneration. The rate of oxygen consumption by the posterior pieces, however, is considerably higher in each determination than that by the controls or that by the anterior pieces. These results are shown also in figure 9 .

In a second preliminary experiment, worms were cut just posterior to the auricles, and allowed to regenerate new heads. Under these conditions they were not much reduced in size during the regeneration of the new head. These worms were more comparable, therefore, to the anterior pieces of the preceding experiment than to the posterior pieces. Table 13 shows that the worms regenerating their heads maintained a rate of oxidation practically equal to that of control normal worms for the period of observation, 17 days. These results are shown also in figure 10 .

Table 14 and figure 11 give a more complete series of determinations of the oxygen consumption by $\mathrm{P}$. agilis during two weeks preceding and four weeks following experimental fission. The rate of oxygen consumption per gram body weight per 24 hours of normal worms ran very uniform throughout the experiment, column 4. These normal worms have been discussed in connection with table 7. The experimental worms duplicated very closely the rate of oxygen consumption by the controls during two weeks preceding the operation, table 14, column 11. After eutting the experimental worms in two at the normal fission plane, the 
Showing increase in the rate of oxygen consumption by Planaria maculata with regeneration. Worms 10 to $13 \mathrm{~mm}$. in length January 8; starving for 15 days previous to the first test and during the experiment; 8 worms in each bottle. January 15 experimental worms cut in two a short distance posterior to the mouth. Control worms not cut. Weighed January 18 , 14, 15 , February 5 and 13 . One cubic centimeter thiosulphate equals $0.1698 \mathrm{cc}$, oxygen at $N$. T. P. See figure 9 . For further data on controls, see table 5

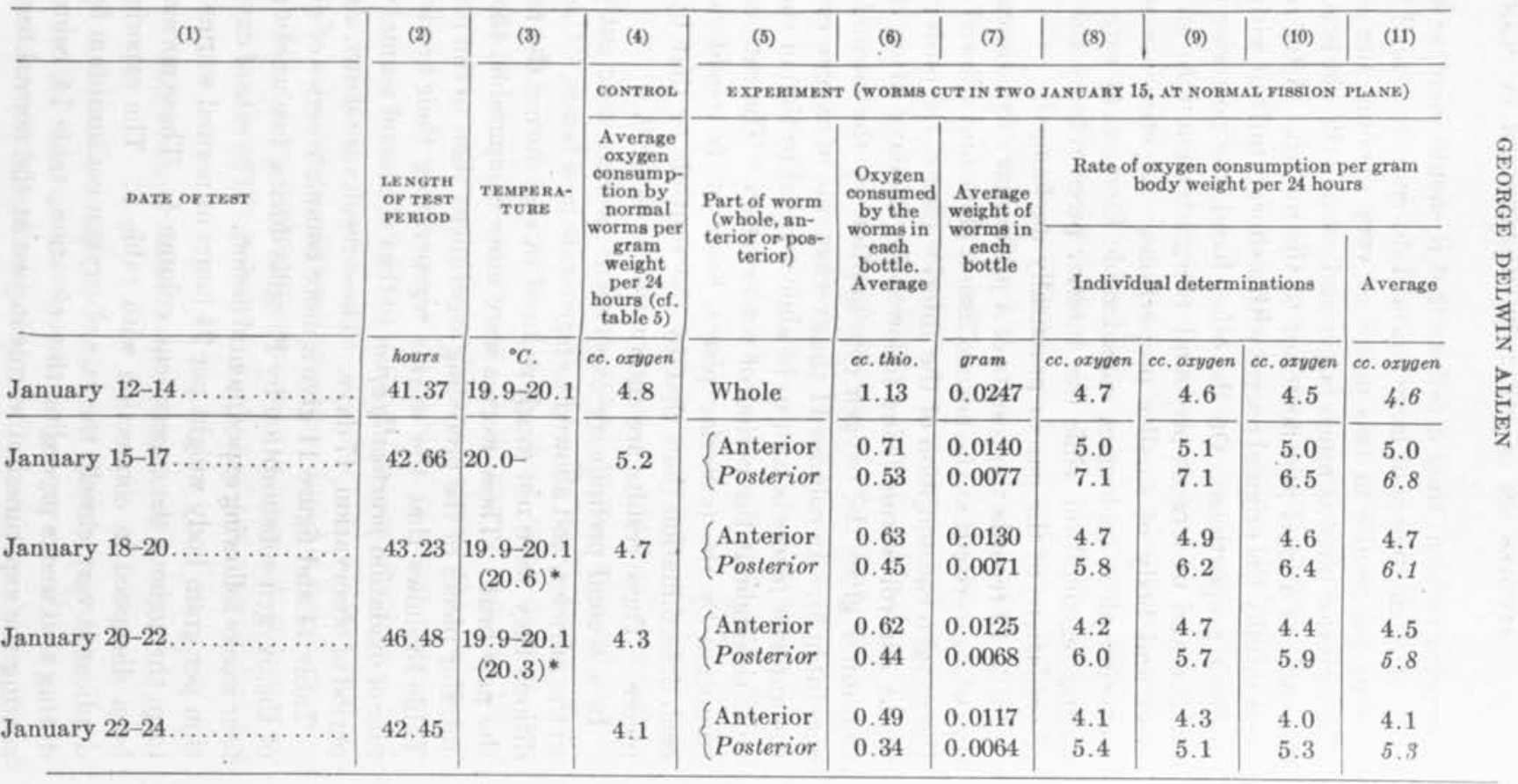




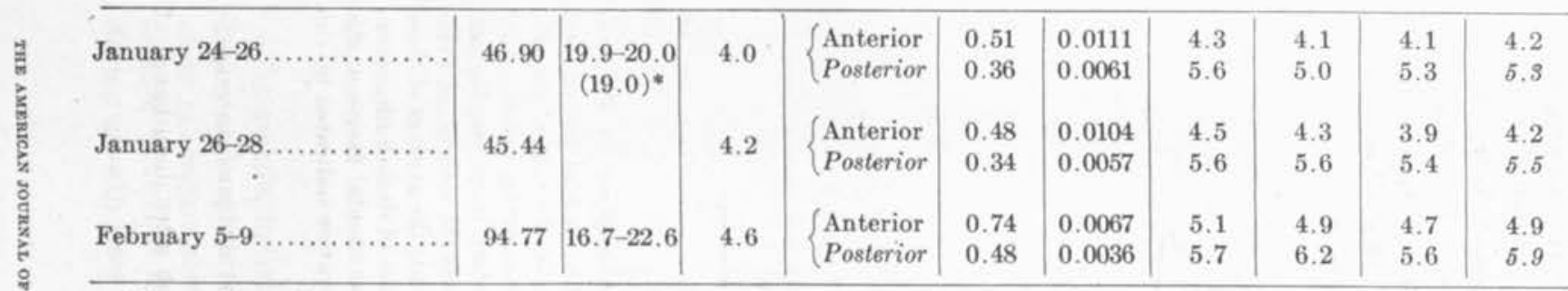


anterior pieces continued for four weeks to absorb the same amounts of oxygen per gram body weight as the controls, columns 11 and 4 . The rate of oxygen absorption by the posterior pieces, however, rose gradually above the controls during regeneration. These posterior pieces reorganized during this period to form complete worms of smaller size than the controls or than the anterior'pieces. The following notes indicate the progress of regeneration of the tail pieces.

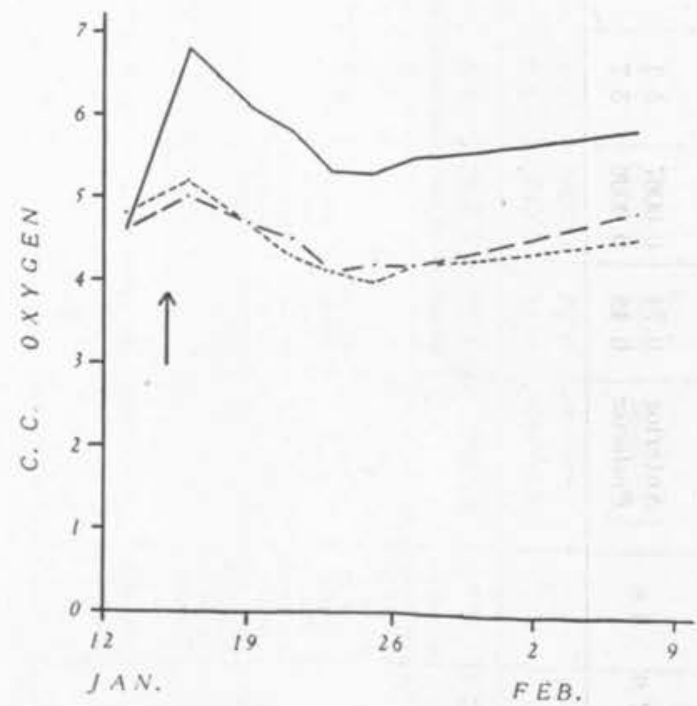

Fig. 9. Curves show increase in the rate of oxygen consumption by Planaria maculata during regeneration of posterior pieces from experimental fission, and no increase, within the limits of error of the experiment, in the rate of oxygen consumption in anterior pieces. Abscissas represent time in weeks, indicated by dates. Ordinates represent the rate of oxygen consumption in ec. oxygen per gram body weight per 24 hours. The broken line represents the control, an average of three sets of normal worms. The solid line represents the average of three sets of posterior pieces from experimental fission. The line of dashes represents the average of three sets of the anterior pieces from experimental fission of the same worms: Worms cut on January 15 (time of the operation indicated by the * arrow). See table 12 .

July 20. Cut experimental worms across body a short distance posterior to the mouth. dish.

July 24. New head, wedge-shaped. Some locomotion after disturbance of

July 26. Auricles and eyes. Worms elongating. 
July 29. Auricles well developed but not full length. Heads appear white to the naked eye. Pigment appearing on head. Inactive till prodded. Locomotion rapid.

August 2. Still white-headed.

August 5. Pigmentation of head still incomplete. Worms more elongated.

TABLE 13

Showing no increase, within the limits of error of the experiment, in the rate of oxygen consumption by Planaria maculata during regeneration of the head. Worms 7 to $10 \mathrm{~mm}$. long February 25 ; starving for 5 days preceding the first test and during the experiment; 10 worms in each bottle. Heads cut off from the experimental worms just posterior to the auricles March 12. Control worms not cut. Worms weighed March $2,5,11,12,18$ and 30 . One cubic centimeter thiosulphate $=0.1698$ cc. oxygen at N.T.P. See figure 10. For further data on the controls, see table 6

\begin{tabular}{|c|c|c|c|c|c|c|c|c|c|c|}
\hline & (1) & (2) & (3) & (4) & (5) & (6) & (7) & (8) & (9) & (10) \\
\hline \multirow{3}{*}{\multicolumn{2}{|c|}{ DATE OY TEST }} & \multirow{3}{*}{$\begin{array}{c}\text { LENGTH } \\
\text { OF } \\
\text { TEST } \\
\text { PEBIOD }\end{array}$} & \multirow{3}{*}{$\begin{array}{c}\text { TEMPERA- } \\
\text { TURE }\end{array}$} & CONTROL & \multicolumn{6}{|c|}{ EXPERIMENT } \\
\hline & & & & 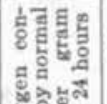 & 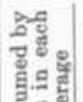 & 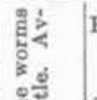 & \multicolumn{4}{|c|}{$\begin{array}{c}\text { Rate of oxygen consumption } \\
\text { per gram body weight } \\
\text { per } 24 \text { hours }\end{array}$} \\
\hline & & & & 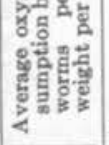 & 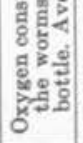 & 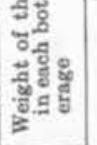 & \multicolumn{3}{|c|}{$\begin{array}{c}\text { Individual } \\
\text { determinations }\end{array}$} & $\begin{array}{c}\text { Aver- } \\
\text { age. }\end{array}$ \\
\hline & & hours: & ${ }^{\circ} \mathrm{C}$. & $\underset{\text { oxyoen }}{c .}$ & $\begin{array}{c}\text { ec. } \\
\text { thio. }\end{array}$ & orams & $\begin{array}{c}\text { ce. } \\
\text { oxyoen }\end{array}$ & $\left|\begin{array}{c}c c . \\
\text { oxygen }\end{array}\right|$ & $\begin{array}{c}c o, \\
\text { oxyoen }\end{array}$ & $\underset{\text { oxyoen }}{\infty}$ \\
\hline March & $2-4 \ldots \ldots \cdots$ & 41.40 & $20.0-20.5$ & 5.0 & 0.77 & 0.0163 & 5.0 & 5.1 & 4.4 & 4.8 \\
\hline March & $5-7 \ldots \ldots \ldots$ & 45.00 & $20.0-20.2$ & 4.8 & 0.80 & 0.0149 & 4.9 & 5.2 & 4.8 & 5.0 \\
\hline March & $7-9 \ldots \ldots \ldots$ & 47.30 & $20.0-20.5$ & 4.8 & 0.74 & 0.0138 & 4.7 & 5.1 & 4.5 & 4.8 \\
\hline \multirow[t]{2}{*}{ March } & $9-11 \ldots \ldots \ldots$ & \multirow[t]{2}{*}{45.65} & \multirow[t]{2}{*}{$20.0-20.4$} & \multirow[t]{2}{*}{5.5} & \multirow[t]{2}{*}{0.720} & \multirow[t]{2}{*}{0.0126} & 5.1 & 5.3 & 5.4 & 5.3 \\
\hline & & & & & & & \multicolumn{4}{|c|}{$\begin{array}{l}\text { Heads removed from } \\
\text { experimental worms on } \\
\text { March } 12\end{array}$} \\
\hline March & $12-14 \ldots$. & 46.38 & $20.1-20.5$ & 5.2 & 0.51 & 0.0092 & 4.9 & 5.4 & 4.9 & 5.0 \\
\hline March & $14-16 \ldots$ & 46.16 & $20.0-20.5$ & 5.6 & 0.52 & 0.0084 & 5.7 & 5.8 & 5.5 & 5.6 \\
\hline March & $16-18 \ldots$ & 45.00 & $20.1-20.6$ & 5.9 & 0.46 & 0.0077 & 5.4 & 6.1 & 5.5 & 5.6 \\
\hline March & $19-21 \ldots$ & 42.90 & $20.0-$ & 4.8 & 0.34 & 0.0067 & 5.2 & 4.9 & 4.5 & 5.0 \\
\hline March : & $21-29 \ldots$ & 191.09 & $\mid 20.0-20.5$ & 5.4 & 1.39 & 0.0056 & 5.7 & 5.9 & 5.0 & 5.5 \\
\hline
\end{tabular}

The smaller individuals in a population of Planaria usually result from fission and regeneration. This experiment shows that during the processes of regeneration the higher rate of oxidation characteristic of smaller worms is attained. If the respiration of these small worms during growth were followed, undoubtedly a progressive decline in rate 
Shoving increase in the rate of oxygen consumption by Planaria agilis with regeneration in the posterior zoöid after artificial fission, and no increase in the rate of oxygen consumption, within the limits of error of the experiment, with regeneration in the anterior zoôid. Worms 17 to $18 \mathrm{~mm}$. long July 5 , starving for 7 days previous to the experiment and during the experiment; 5 worms in each bottle before the operation and 10 in each bottle after the operation. Experimental worms cut in two at a level a short distance posterior to the mouth on July 20. Control worms not cut. Worms weighed once each week, namely July 5, 13, 19, 20, 26, A ugust 8, 9 and 16. One cubic centimeter thiosulphate equals 0.1768 cc. oxygen at N.T.P. from July 6 to July 19. One cubic centimeter thiosulphate equals 0.1751 cc. oxygen at N. T. P. from July 20 to August 16 . See figure 11 . For
further data on controls, se6 table 7

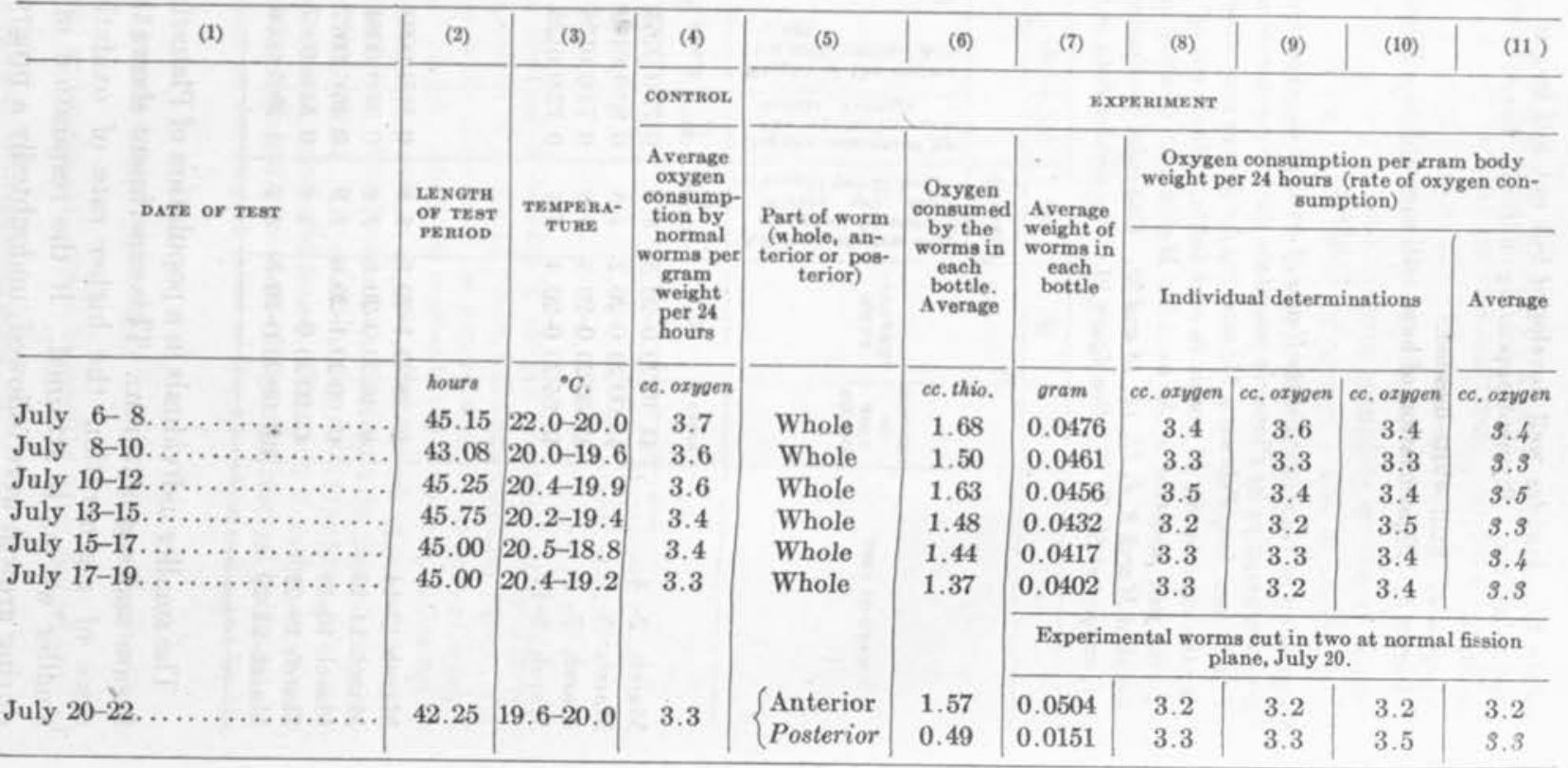


July 22-24.

July 24-26.

July $27-29$.

July 29-31

July 31-August 2 .

August 3-5.

August 5-7.

August 7-9

August 10-12.

August 12-14.

August 14-16.

\begin{tabular}{|c|c|c|c|c|c|c|c|c|c|}
\hline & & & $\{$ Anterior & 1.54 & 0.0486 & 3.1 & 3.2 & 3.2 & 3.2 \\
\hline 43.50 & $20.0-19.7$ & 3,4 & Posterior & 0.54 & 0.0142 & 3.6 & 3.7 & 4.2 & 3,8 \\
\hline \multirow[t]{2}{*}{42.00} & \multirow[t]{2}{*}{$19.7-20.0$} & \multirow{2}{*}{3.3} & $\{$ Anterior & 1.43 & 0.0468 & 3.1 & 3.1 & 3.3 & 3.1 \\
\hline & & & Posterior & 0.49 & 0.0135 & 3.6 & 3.7 & 3.8 & 3.7 \\
\hline \multirow{2}{*}{45.10} & \multirow[t]{2}{*}{$19.6-20.2$} & \multirow[t]{2}{*}{3.3} & $\left\{\begin{array}{l}\text { Anterior } \\
\text { D }\end{array}\right.$ & 1.48 & 0.0442 & 3.1 & 3.2 & 3.3 & 3.2 \\
\hline & & & Posterior & 0.49 & 0.0122 & 3.8 & 3.7 & 3.9 & 3.8 \\
\hline \multirow[t]{2}{*}{45.00} & \multirow[t]{2}{*}{$19,6-19,8$} & \multirow[t]{2}{*}{3.2} & $\left\{\begin{array}{l}\text { Anterior } \\
0\end{array}\right.$ & 1.40 & 0.0426 & 3.1 & 3.1 & 3.2 & 3.2 \\
\hline & & & Posterior & 0.49 . & 0.0118 & 3.9 & 3.8 & 4.2 & 4.0 \\
\hline \multirow[t]{2}{*}{43.00} & \multirow[t]{2}{*}{19.8} & \multirow[t]{2}{*}{3.4} & $\left\{\begin{array}{l}\text { Anterior } \\
\text {. }\end{array}\right.$ & 1.32 & 0.0410 & 3.2 & 3,2 & 3.4 & 3.3 \\
\hline & & & Postarior & 0.46 & 0.0113 & 4.1 & 4.1 & 4.1 & 4.1 \\
\hline \multirow{2}{*}{45.25} & \multirow{2}{*}{$19.6-19.9$} & \multirow{2}{*}{3.3} & Anterior & 1.33 & 0.0385 & 3.3 & 3,3 & 3.3 & 3.3 \\
\hline & & & Posterior & 0.48 & 0.0106 & 4.3 & 4.1 & 4.6 & 4.3 \\
\hline \multirow[t]{2}{*}{45.07} & \multirow{2}{*}{$19.3-20.0$} & \multirow{2}{*}{3.4} & Anterior & 1.29 & 0.0367 & 3.4 & 3.3 & 3.5 & 3.4 \\
\hline & & & Posterior & 0.46 & 0,0101 & 4.3 & 3.9 & 4.8 & 4.4 \\
\hline \multirow[t]{2}{*}{45.07} & \multirow{2}{*}{$20.0-20.7$} & \multirow{2}{*}{3.7} & Anterior & 1.33 & 0.0350 & 3.5 & 3.5 & 3.8 & 3.6 \\
\hline & & & Posterior & 0.49 & 0.0097 & 4.8 & 4.7 & 5.2 & 4.9 \\
\hline \multirow[t]{2}{*}{45.42} & \multirow[t]{2}{*}{$19.8-19.6$} & \multirow[t]{2}{*}{3.3} & Anterior & 1.17 & 0.0329 & 3.3 & 3.4 & 3.5 & 3.4 \\
\hline & & & Posterior & 0.41 & 0.0090 & 4.4 & 4.2 & 4.4 & $4 \cdot 4$ \\
\hline \multirow[t]{2}{*}{45.33} & & \multirow[t]{2}{*}{3.3} & $\left\{\begin{array}{l}\text { Anterior } \\
\text {. }\end{array}\right.$ & 1.15 & 0.0317 & 3.3 & 3,6 & 3.6 & 3.5 \\
\hline & & & Posterior & 0.38 & 0.0086 & 4.4 & 3.7 & 4.6 & 4.2 \\
\hline \multirow[t]{2}{*}{45.00} & \multirow[t]{2}{*}{$19.6-19.7$} & \multirow[t]{2}{*}{3.4} & $\left\{\begin{array}{l}\text { Anterior } \\
\text { Petenion }\end{array}\right.$ & 1.08 & 0.0304 & 3.3 & 3.4 & 3.6 & 3.4 \\
\hline & & & Posterior & 0.37 & 0.0082 & 4.3 & 4.1 & 4.6 & 4.3 \\
\hline
\end{tabular}


of oxygen consumption would be found as the animals became larger. It is not very convenient to follow the oxidations in the same worms during growth, but it seems unnecessary to do so. Worms of different sizes selected from a laboratory stock of the same history, except as regards reproduction, and tested simultaneously under identical conditions, give more certain results. Such experiments are described in the preceding section.

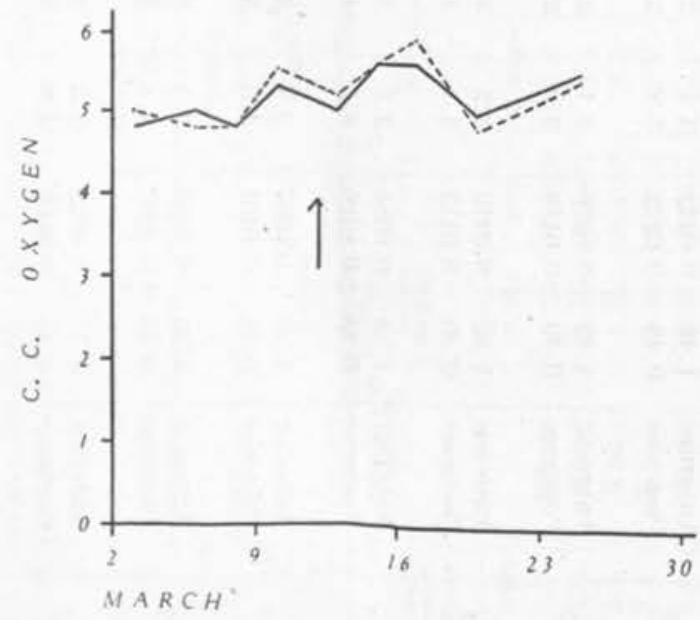

Fig. 10. Curves show no increase, within the limits of error of the experiment, in the rate of oxygen consumption by Planaria maculata during regeneration of the head. Abscissas represent time in weeks, indicated by dates. Ordinates represent rate of oxygen consumption in ec. oxygen per gram total body weight per 24 hours. The broken line represents the control, an average of three sets of normal worms. The solid line represents the average of three sets of worms whose heads were cut off just posterior to the auricles on March 12 (time of the operation indicated by the arrow). See table 13.

It should be clearly understood that these experiments upon regeneration of Planaria are not advanced as evidence that the regeneration process, as such, or, more generally, that growth or morphogenesis, necessitates a higher rate of oxidation. In figure 11 the rate of oxygen consumption in the tails rose progressively during regeneration and did not show a fall with completion of the process. The higher rate at the end of the process is attributed to the new organization of the worm, i.e., to the result of the process, not to the process itself. At least the experimental data do not constitute a secure foundation for concluding otherwise. 


\section{SUSCEPTIBILITY AS A MEASURE OF OXIDATIONS}

The susceptibility of Planaria and other animals to the toxic action of alcohol, potassium cyanide and other substances, in other words, the length of time the animals live in solutions of these substances, has been used extensively by Child, Hyman and others as a measure of the "rate of metabolism." This practice has been based upon inadequate knowledge either of the nature of the action of these toxic agents

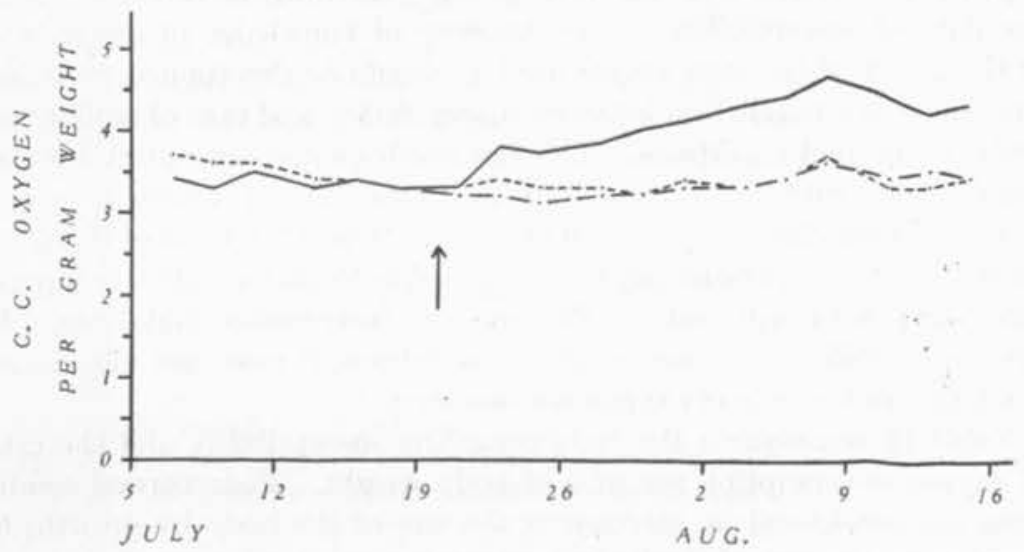

Fig. 11. Curves show increase in the rate of oxygen consumption by Planaria agilis during regeneration of posterior pieces from experimental fission, and no increase, within the limits of error of the experiment, in the rate of oxygen consumption in the anterior pieces. Abseissas represent time in weeks, indicated by dates. Ordinates represent rate of oxygen consumption in cc. oxygen per gram total body weight per 24 hours. The broken line represents the control, the average of three sets of normal worms. The solid line represents the average of three sets of experimental worms before the eutting operation on July 20 , and of the posterior pieces after that date. The line of dashes represents the average of the three sets of anterior pieces from the operation. The time of the operation is indicated by the arrow. See table 14.

or of the parallelism between the susceptibility of animals and their "rate of metabolism." The substances first used for this purpose were anesthetics and potassium cyanide, sometimes classed as an anesthetic. It was supposed that these substances inhibit the oxidations, and they were spoken of as "depressing agents" (1, p. 571); (2, p. 150); $(3$, pp. $419,420,444) ;(4$, p. 65$) ;(8$, p. 104$)$. The effect of none of these substances upon the oxidations in Planaria or other animals upon which 
they were used was determined. The writer (13) has shown that potassium cyanide, the agent most used for the susceptibility studies, does inhibit oxygen consumption in Planaria, but it does not follow from this fact that the worms with higher rate of oxidation must be more susceptible to the cyanide, nor that those that are more susceptible to cyanide must have a higher rate of oxidations. Furthermore, many other substances of very different chemical nature and probably of very different physiological action have been used for determining susceptibility. Before drawing conclusions regarding metabolism from the data of susceptibility, in the absence of knowledge of the nature of the action of the toxic agents used, it should be determined, at least, that there is a parallelism between susceptibility and rate of oxidations under all normal conditions. This has not been done excepting for the comparisons with the carbon dioxide production by Planaria in the Tashiro "biometer" previously mentioned. Upon the basis of the data presented in the present paper, it is possible to make certain comparisons between susceptibility of Planaria and their rate of oxidations. If the susceptibility is a measure of the oxidations, it must not vary independently of the rate of oxygen consumption.

Table 15 summarizes the facts regarding susceptibility and the rate of oxygen consumption per unit of body weight. Four normal conditions are considered; $a$, increase in the size of the body by growth; $b$, decrease in the size of the body by agamic reproduction; $c$, starvation; and $d$, feeding. Starvation is naturally divided into the early and the later stages, making five items in the table. In the so-called "indirect susceptibility method," less susceptibility, or, conversely, greater resistance, is supposed to indicate a higher "rate of metabolism," while in the "direct method" greater susceptibility is supposed to indicate a higher rate of metabolism or rate of oxidations. The letters in the table refer to the following quotations and references to the literature on susceptibility:

A. (1) pages 544 to 547 . Figures 1 and 2.

(4) page 83 and figure 4.

B. (1) pages 555 to 564 .

C. "In this connection it should be noted, again, that when well-nourished worms are kept without food, the resistance increases somewhat during the first three or four weeks, as the reserves disappear and after that decreases rapidly" $(1$, p. 549$)$.

"If the resistance of the worms to anesthetics is in any degree a criterion of age, as it seems to be, then it is evident that while starvation alone does not 
TABIE 15

Showing that susceptibility of Planaria to the toxic action of alcohol or potassium cyanide varies independently of the rate of oxygen consumption. Changes in susceptibility determined by Child. For references, see text pages 464 to 466 under letters $A, B, C$, etc., as given in table. Changes in rate of oxygen consumption determined by the writer

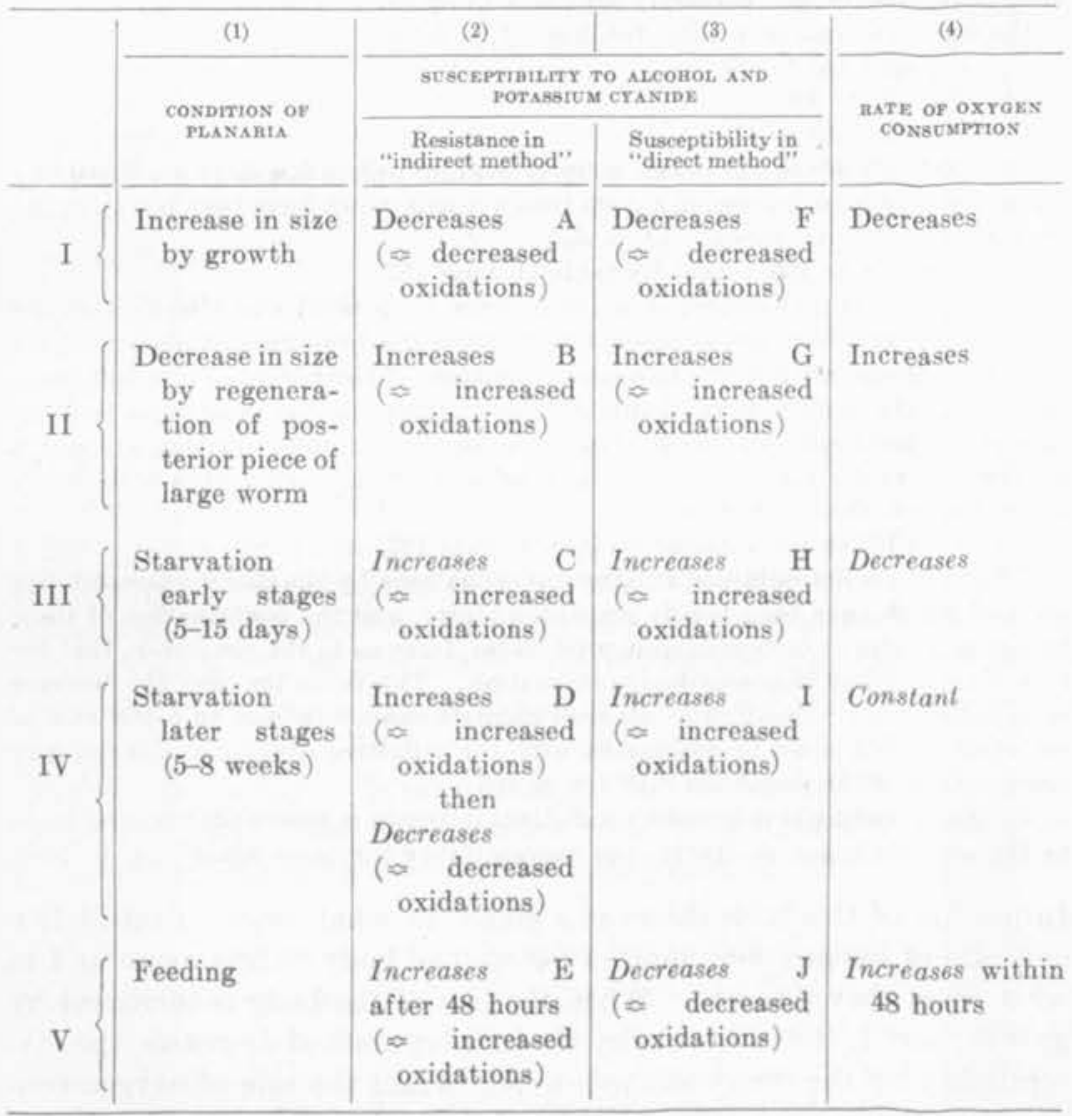

rejuvenate these animals, except to a slight extent in the early stages, ${ }^{\mathrm{a}}$ yet feeding after a long period of starvation does accomplish this very effectively" $(1, \mathrm{p} .555)$.

"During the first two or three weeks of starvation before any marked reduction occurs, the rate of metabolism increases but decreases after reduction begins (indirect method, meaning that resistance increases during first two or three weeks) (3, p. 437).

3 Italics mine. 
D. "I have performed numerous experiments with worms in various stages of starvation and always with the same result, viz., the reduced worms show even less resistance than before reduction" $(1$, p. 547$)$.

E. (1) page 555 , quoted above under C.

"The effect of feeding after starvation does not appear as increased resistance to any marked extent until at least 48 hours after feeding. Probably this period of time represents that necessary for the attainment of a certain stage and rate of the metabolic reactions after feeding" (1, p. 549).

F. (3) pages 423 to 427 .

(4) pages 93 to 100.

G. (4) pages 105 to 110 .

H. "Animals which have been without food for only a few days are distinctly more susceptible to depressing agents than animals which have been fed up to the beginning of the experiment" ( $3, \mathrm{p} .434)$.

(4) pages 156 to 160 , especially table 11 , page 157 .

I. "In all several hundred individuals have been testd and always with the same result, viz., increase in susceptibility from the beginning of starvation on until the animals are reduced to a minute fraction of their original size and death occurs. If the method is valid this increase in susceptibility must mean that the rate of the metabolic processes increases as starvation and reduction proceed, a conclusion exactly the opposite of that reached from my earlier work with the indirect method alone" (3, p. 427 ).

(4) pages 156 to 160 , especially table 11 , page 157 .

"But the results obtained in later investigations by the direct susceptibility method which have been briefly presented above, and the confirmation of these by the estimates of carbon dioxide production, force us to the conclusion that the rate of metabolism increases during starvation. This being the case, the decrease in capacity for acclimation in starved animals cannot be due to a low rate of metabolism, but must be associated with the nutritive condition in some way independent of the metabolic rate" $(4$, p. 165$)$.

J. "Each feeding is followed by a distinct decrease in susceptibility, and later, as the animals begin to starve, the susceptibility inereases again" (4, p. 169).

Inspection of this table shows at a glance in what eases susceptibility and rate of oxygen consumption per unit of body weight agree and in what cases they disagree. When the size of the body is increased by growth, part I, the resistance by the indirect method decreases, the susceptibility by the direct method decreases and the rate of oxygen consumption decreases. When the size of the body is decreased by experimental fission and regeneration, part II, these three items all increase. These facts are consistent with the theory of a relationship between susceptibility and rate of metabolism. But when the conditions of starvation and feeding are considered, the picture changes. During the first stages of starvaton the rate of oxygen consumption falls sharply, column 4 , but the susceptibility by the direct method increases instead of decreases. This striking decrease in the oxidations occurs chiefly 
during the first few days. Since the indirect method requires a number of days for making determinations, it is perhaps not well adapted for eatching the conditions during this brief period. Statements were made, however, that the resistance by this method increased somewhat during the first three or four weeks without food, as contrasted with the decrease afterwards. During the later stages of starvation, i.e., after the first 10 days, approximately, the rate of oxygen consumption runs practically constant, while the susceptibility in the direct method continues to increase steadily. In the indirect method, the increase in resistance which begins in the early stages is reported to continue during a total of three or four weeks, after which it is followed by $\mathrm{r}$ decrease in resistance. It should be clearly understood that this table and diseussion refer only to the first seven to nine weeks of starvation, and do not include later stages of more extreme starvation. What changes may occur in the respiratory metabolism, later on, do not concern the point under discussion, which is that the susceptibility of Planaria to potassium cyanide and alcohol, and the rate of respiratory metabolism per unit of total body weight vary independently of each other. Such independent variations are clearly shown within the periods which are considered in this discussion. The fall in rate of oxidations during the early stages of starvation is large and is not reflected in any decrease in susceptibility. On the other hand, the increase in susceptibility during the period of starvation included in these experiments is large (4, p. 157, table 11) and is not paralleled by an increase in rate of oxygen consumption. It may be noted, furthermore, that the discrepancies revealed in the table are too great to be altered materially by minor differences in the respiratory metabolism of different species of Planaria.

Feeding causes an enormaus increase in the rate of oxygen consumption, but it is reported (4, p. 169) that "each feeding is followed by a distinct decrease in susceptibility, and later, as the animals begin to starve, the susceptibility increases again" (direct susceptibility method). In the indirect method, feeding results in an increased resistance as well as in an increased oxygen consumption but it may be noted that "the effect of feeding after starvation does not appear as increased resistance to any marked extent until at least 48 hours after feeding." The maximum effect of feeding in increasing the rate of oxygen consumption is within this 48-hour period. These comparisons show, therefore, that susceptibility in Planaria varies independently of rate of respiratory metabolism. 
B. L. Lund (38) and E. J. Lund (11), (39) have shown a similar lack of agreement between susceptibility and rate of oxidations in Paramecium. Starving Paramecia are more susceptible to potassium cyanide than those that are well fed, but the starving Paramecia consume less oxygen and give off less earbon dioxide. Child ( 7, p. 217$)$ has criticized Lund because "he has apparently failed to recognize an essential point, viz., that susceptibility as measured by progress of death and disintegration concerns primarily the ectoplasm or the body-surface and bodywall. Statements to this effect have been made repeatedly in the work on susceptibility." These statements, however, give no indication that the "rate of metabolism" under discussion "concerns primarily the ectoplasm or the body-surface and the body-wall." On the contrary, statements have been made repeatedly in the work on susceptibility to aria in the Tashiro "bons of the carbon dioxide production by Planthe susceptibility method (eter" have confirmed results obtained by (8, p. 104)). The follow (e.g., (3, pp. 422,343$)$; $(4$, pp. $73,161,202)$;

The rate of production of earbon dioxide in the starved, reduced animals is rate is much higher per unit of boung, growing animal of the same size, and this results obtained by the direet body weight than that in large, old animals. The the estimations of the earbon susceptibility method are thus fully confirmed by

in the "biometer") (4, p. 161). tion by Planaria confirmed by measurements of the oxygen consumpgen consumption and by the writer, nor by measurements of the oxyby Lund.

\section{CONCLUSIONS}

In conclusion it should be noted that the purpose of these studies is to contribute to the critical analysis of the rôle of rate of respiratory metabolism in the animal organism. It may be conceived to be the ing the "rate of metion of bold and sugestive theories such as those of Child regardfactors involved in the questio serve as a basis for analysis of all the should be examined with question. All facts should be welcome and proper relation to the general probertiality to place them in their aspects appear and new need for disem. As the analysis proceeds, new factors involved. The term "for discrimination between the various ferent senses. Attention has been of metabolism" may be used in difrespiratory metabolism. Ex been confined in this paper to the rate of ent things. What should seem to term is capable of meaning differ- 
comparisons of the relative rates of respiratory metabolism in animals of different size and age are data that give us the rate of respiratory metabolism per unit of weight or volume of living protoplasm in the body of the animal. No other basis is really satisfactory. Material should be selected and methods devised which supply these conditions as nearly as possible. Warm-blooded animals are very unsatisfactory material for such work, and this fact should be considered before drawing conclusions of general application from the data of mammalian calorimetry. If the method of susceptibility to the toxic action of such substances as potassium cyanide, when applied to the lower invertebrates, could provide a means of approaching the ideal conditions in measuring the "rate of metabolism" or rate of oxidations, it would be of very great value in the analysis of these problems. This method has been compared in the present paper with measurements of the rate of oxygen consumption in proportion to the weight of the body, and it has been found that the susceptibility does not give a reliable index of the rate of oxidations as thus defined. Since we have no data regarding the rate of oxidations upon the basis of any other definition, we must conclude that, in the present state of our knowledge regarding the action of these substances, only direct methods are reliable for determining the rate of respiratory metabolism.

\section{SUMMARY}

1. The oxygen consumption by P. maculata and P. agilis decreases progressively during starvation at constant temperature, more rapidly at first and somewhat more slowly later. The body weight also decreases during starvation, and the worms become smaller in body dimensions.

2. The rate of oxygen consumption per unit of body weight in starving $\mathrm{P}$. maculata and $\mathrm{P}$. agilis decreases rapidly during the first few days, due to the decreasing accelerative effect of food residuum left from the previous feeding. The length of this period may vary with the temperature and the amounts and kinds of food previously ingested, but in the experiments reported it lasted as long as 10 to 14 days, although the accelerative effects were small after the first 7 days.

3. At the end of this period of the accelerative effects of food reserve from previous meals, the rate of oxidations reaches a constant level which is maintained for several weeks in P. agilis (5 to 8 weeks in the experiments reported). During this period of constant rate of oxidations, the starvation results in a decrease in the body weight of at least one-half of the original. 
4. The ingestion of food by starving $P$. maculata and $P$. agilis results in a great increase in the oxygen consumption ( 80 to 140 per cent in the experiments reported). After this initial rapid rise, which reaches its maximum within the first 48 hours or less, the rate of oxidations per unit of body weight falls more slowly during 7 to 14 days to reach a constant level. When this constant level is reached after a single feeding, the rate of oxygen consumption per unit of body weight is the same, within the limits of error of the experiment, as it would have been if the animal had not been fed. However, after the rate of oxidations has returned to this constant level the animal weighs more and consumes more oxygen in absolute units than would have been the case if the animal had not been given a meal (see figs. 4 and 6 ).

5. The later period of starvation, after the accelerative effects of food reserves have disappeared, is the proper basis of reference in studying respiratory metabolism in Planaria.

6. Larger Planaria have a lower rate of oxidations per unit of total body weight than smaller worms of the same species when the latter do not owe their small size to starvation. The experiments reported do not permit making any general statement to cover all cases of differences in size due to starvation alone since the more extreme stages of starvation are not included in this study (see paragraph 3 above).

7. After fission of a large worm, the tail piece, which becomes reorganized into a small-sized worm, gains a higher rate of oxygen consumption per unit of body weight. With regeneration in the anterior piece, which does not involve important alterations in the body, the rate of oxygen consumption remains constant within the limits of accuracy of the method. It is not assumed that the increase in rate of oxidations in the posterior piece is due to the use of measurable amounts of energy in the processes of regeneration or morphogenesis as such.

8. The susceptibility of Planaria to the toxic action of potassium cyanide and alcohol, as reported by Child, varies independently of the rate of oxidations per unit of body weight, and is, therefore, not a reliable measure of the oxidations as thus defined. If the rate of oxidations or the "rate of metabolism" is defined differently, then it remains to be shown that susceptibility is a reliable measure of either.

\section{APPENDIX}

Since the above was written, three papers have appeared which deal with the respiratory metabolism in Planaria $(40),(41)$ and $(42)$. Hyman (41) has attempted to strengthen the theory that susceptibility is a 
measure of rate of oxidations by showing that potassium cyanide inhibits the oxidations in Planaria dorotocephala; her results confirm those of the writer reported in the first paper of this series (13). The two studies supplement each other since the experiments of Hyman covered short periods of time while those of the writer covered longer periods. Hyman argues that "since cyanides decrease the rate of oxygen consumption, it follows that cells or organisms or parts of organisms which have the highest rate of respiratory exchange will be more susceptible to cyanide and will, therefore, die in lethal concentrations of cyanide faster than parts or organisms respiring less actively" (41, p. 353). The writer does not wish to discuss this argument further than to call attention to the facts observed in Paramecium and Planaria, namely, that fed animals have a higher rate of respiratory exchange but live longer in lethal concentrations of cyanides than starving animals.

Child (40) has compared the rates of carbon dioxide production by equal weights of Planaria dorotocephala of different sizes and in different stages of starvation, as determined by the phenolsulphonephthalein indicator method. The data do not permit a calculation of the actual quantities of carbon dioxide produced, but show that the worms in one tube caused a higher or lower hydrogen ion concentration than those in another tube. Child concludes from his experiments with this indicator method that the rate of carbon dioxide production is greater in small than in large worms, that it "decreases rapidly during the first stages of starvation and continues to decrease more slowly during several weeks, but that in advanced stages of starvation it increases" (40, p. 256). The advanced stages in which it is reported that the rate of oxidations increases are apparently later than the stages included in the experiments of the present writer, although it is hardly possible to compare the rates of starvation in two different species of Planaria under different conditions of observation. The data regarding differences in rate of oxidations in animals of different size and during the earliest stages of starvation are in agreement with those of the present paper.

These conclusions, it may be noted, are very different from either of the two former conclusions of Child which were based on susceptibility data. Child himself calls attention to these discrepancies and offers an explanation to preserve the theory that susceptibility is a measure of rate of oxidations. He recalls observations previously neglected, to the effect that during early starvation of Planaria, the susceptibility of the intestinal tract is different from that of the body wall, the former decreasing while the latter increases. The interpretation suggested is that 
the ectoderm and body wall, which maintain their functional activity and subsist in part upon their own substance from the beginning, show a gradual increase in rate of oxidation during starvation, while the rate of oxidation in the alimentary tract undergoes rapid and marked decrease in the absence of food and probably still further decrease more slowly, as the reserves are used. Alimentary tract oxidation in well-fed animals is so large a part of the total oxidation that the decrease in activity of the alimentary tract in the absence of food brings about a decrease in total $\mathrm{CO}_{2}$ production, in spite of the probable increase in $\mathrm{CO}_{2}$ production in ectoderm and body well $(40$, p. 254$)$.

In the absence of any experimental evidence that the oxidations in the body wall change with starvation and feeding, as Child suggests, rather than in accordance with the oxidations of the animal as a whole, the observed facts must be considered damaging to the theory that susceptibility is a measure of rate of oxidations. If the possibility that the oxidations in the body wall may change in a direction exactly opposite to the rate of oxidations of the whole animal is pressed, it must be borne in mind that the evidence which is cited in support of the theory, also, consists of measurements of the respiratory exchange of whole animals. Estimations of the total carbon dioxide production by Planaria in the Tashiro "biometer" have served as proof of the value of the susceptibility method. They were cited for this purpose in the last paper by Child (42, p. 381) although in the preceding paper it was reported that the biometer gave different results (as regards different conditions of nutrition) than the indicator method, so that "work with the biometer was discontinued because I came to believe that the method was not suitable for the material" (40, p. 250 ). However, whether reliance is placed upon the "biometer," the indicator method or the writer's Winkler method, the data obtained by these methods have given only the rate of respiratory metabolism of whole animals.

The distinction between the rate of oxidations in the animal as a whole and that in particular organs carries the question ultimately to the individual cells. Here we have the information that starving Paramecia are more susceptible to cyanide but have a lower rate of oxidations than fed Paramecia. The explanation suggested by Child is that during starvation in Paramecium, the ectoplasmic oxidations increase while the endoplasmic oxidations, which make up the major part of the whole, decrease. Is susceptibility in other animals such as Planaria to be attributed finally to conditions in the surface of the cell rather than to the oxidations of the cell as a whole? What does survival time tell us with certainty about oxidations? 


\section{BIBLIOGRAPHY}

(1) Cmin: Arch. f. Entwicklungsmech., 1911, xxxi, 537.

(2) CHILD: Arch. f. Entwicklungsmech., 1913, xxxvii, 108.

(3) CHrр: Arch. f. Entwicklungsmech., 1914, xxxviii, 418.

(4) ChiLD: Senescence and rejuvenescence, Chicago, 1915.

(5) CHILD: Individuality in organisms, Chicago, 1915.

(6) Cнгир: Biol. Bull., 1918, xxxiv, 49.

(7) Child and Hyman: Biol. Bull., 1919, xxxvi, 183.

(8) Hyman: Journ. Exper. Zoöl., 1916, xx, 99.

(9) HrMan: Journ. Exper. Zoöl., 1917, xxiv, 55.

(10) LUsk: Science of nutrition, 3rd ed., 1917.

(11) LUND: This Journal, 1918, xlvii, 167.

(12) Квонн: Respiratory exchange of animals and man, London and New York, 1915 .

(13) Allen: This Journal, 1919, xlviii, 93.

(14) Johansson, Landergren, Sonden and Tigerstadt: Skand. Areh. f. Physiol., 1897, vii, 29.

(15) Benedict: Carnegie Institution Pub. 77, 1907.

(16) Lemman, Mueller, Munk, Senator and Zuntz: Areh. f. path. Anat. u. Physiol., 1893, exxxi, Suppl. 1.

(17) Benedict: Carnegie Institution Pub. 203, 1915.

(18) Zontz: Biochem. Zeitschr., 1913, lv, 341.

(19) Hrul: Journ. Physiol., 1911, xliii, 379.

(20) Brunow: Zeitschr. f. Allg. Physiol., 1911, xii, 215.

(21) RUBNer: Zeitschr. f. Biol., 1883, xix, 535.

(22) Benedict: Journ. Biol. Chem., 1915, xx, 263.

(23) Benedict, Emmes, Roth and Smith: Journ. Biol. Chem., 1914, xviii, 139.

(24) Meen: Zeitschr. f. Biol., 1879, xv, 425.

(25) Du Bors AND De Bors: Arch. Int. Med., 1915, xv, 868.

(26) De Bors and Du Bors: Arch. Int. Med., 1916, xvii, 863.

(27) Gephart and De Bors: Arch. Int. Med., 1916, xvii, 902.

(28) Magnds-Levy and Falk: Arch. f. Physiol., 1899, Suppl. 314.

(29) Do Bors: Arch. Int. Med., 1916, xvii, 887.

(30) Benedict and TALBOT: Carnegie Institution Pub. 201, 1914.

(31) Benedict and Talbot: Carnegie Institution Pub. 233, 1915.

(32) Muruin and Hoobler: Amer. Journ. Diseases of Children, 1915, ix, 81.

(33) BoHr: Skand. Arch. f. Physiol., 1900, x, 413.

(34) Bohr and Hasselbalch: Skand. Arch. f. Physiol., 1900, x, 149.

(35) Montuonr: Arch. Ital. de Biol., 1913, lix, 213.

(36) Morgutis: This Journal, 1915, xxxvi, 207.

(37) Bounhiol: Ann. des Sci. Naturelles, 1902, xvi, 1.

(38) Lund: Biol. Bull., 1918, xxxv, 211.

(39) LuND: This Journal, 1918, xlvii, 318.

(40) ChrLр: This Journal, 1919, xlviii, 231.

(41) Hyman: This Journal, 1919, xlviii, 340.

(42) CHud: This Journal, 1919, xlviii, 372. 